UNIVERSIDADE DE SÃO PAULO

FACULDADE DE ECONOMIA, ADMINISTRAÇÃO E CONTABILIDADE DE RIBEIRÃO PRETO

DEPARTAMENTO DE ADMINISTRAÇÃO

PROGRAMA DE PÓS-GRADUAÇÃO EM ADMINISTRAÇÃO DE ORGANIZAÇÕES

ALEXANDRE RODRIGUES CAJUELA

Capacidade de absorção em startups sob a perspectiva do gerenciamento de processos de negócio

ORIENTADORA: PROFA. DRA. SIMONE VASCONCELOS RIBEIRO GALINA

RIBEIRÃO PRETO 
Prof. Dr. Vahan Agopyan

Reitor da Universidade de São Paulo

Prof. Dr. Dante Pinheiro Martinelli

Diretor da Faculdade de Economia, Administração e Contabilidade de Ribeirão Preto

Prof. Dr. Marcio Mattos Borges de Oliveira

Chefe do Departamento de Administração 
ALEXANDRE RODRIGUES CAJUELA

\title{
Capacidade de absorção em startups sob a perspectiva do
} gerenciamento de processos de negócio

\author{
Versão Corrigida.
}

A original encontra-se disponível no Serviço de Pós-Graduação da FEA-RP/USP.

Dissertação apresentada do Programa de PósGraduação em Administração de Organizações da Faculdade de Economia, Administração e Contabilidade de Ribeirão Preto da Universidade de São Paulo, para obtenção do título de Mestre em Ciências.

ORIENTADORA: PROFA. DRA. SIMONE VASCONCELOS RIBEIRO GALINA 
Autorizo a reprodução e divulgação total ou parcial deste trabalho, por qualquer meio convencional ou eletrônico, para fins de estudo e pesquisa, desde que citada a fonte.

FICHA CATALOGRÁFICA

Cajuela, Alexandre Rodrigues

Capacidade de absorção em startups sob a perspectiva do gerenciamento de processos de negócio. Ribeirão Preto, 2018.

130 p. : il. ; $30 \mathrm{~cm}$

Dissertação de Mestrado, apresentada à Faculdade de Economia, Administração e Contabilidade de Ribeirão Preto/USP. Área de concentração: Administração de Organizações.

Orientadora: Galina, Simone Vasconcelos Ribeiro.

1. Capacidade de absorção. 2. Gerenciamento de processos de negócio. 3. Relacionamentos interorganizacionais. 4. Vantagem competitiva. 


\section{FOLHA DE APROVAÇÃO}

\section{Nome: CAJUELA, ALEXANDRE RODRIGUES}

Título: Capacidade de absorção em startups sob a perspectiva do gerenciamento de processos de negócio

Dissertação apresentada ao Programa de PósGraduação em Administração de Organizações da Faculdade de Economia, Administração e Contabilidade de Ribeirão Preto da Universidade de São Paulo para obtenção do título de Mestre em Ciências.

Área de concentração: Administração de Organizações.

Aprovado em:

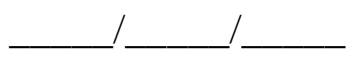

Banca Examinadora

$\operatorname{Prof}(a) . \operatorname{Dr}(\mathrm{a})$ Instituição:

Julgamento: Assinatura:

Prof(a). Dr(a). Instituição:

Julgamento: Assinatura:

Prof(a). Dr(a). Instituição:

Julgamento: Assinatura: 
"If you have an apple and I have an apple and we exchange apples then you and I will still each have one apple. But if you have an idea and I have an idea and we exchange these ideas, then each of us will have two ideas."

George Bernard Shaw (1856-1950) 


\section{AGRADECIMENTOS}

Nesta jornada que começou em 2015, como aluno especial na disciplina Internacionalização de Empresas e Inovação, conheci minha futura orientadora a professora Simone Galina, a quem agradeço imensamente a confiança depositada, paciência e dedicação em conduzir o trabalho de orientação acadêmica.

Mas para que essa jornada começasse, tive o incentivo, o apoio e a ajuda de muitas pessoas: meus diretores Fernando Pereira e Dra. Brígida Prudêncio, pela compreensão e generosidade em adequar meus horários de trabalho para iniciar os estudos; minhas eternas amigas e excolegas de trabalho, Cilene Lima e Tânia Zambon que sempre com bom humor, ajudaram nas escalas de trabalho; meus coordenadores, que sempre ajudaram na adequação dos horários de aulas; a diretora Valdete Magalhães que deu apoio para a continuidade dos estudos, bem como o diretor administrativo Fábio dos Santos; o Sr. João Carlos sempre com muita paciência e presteza, ajudou a superar a dificuldade da distância; meus amigos e colegas de trabalho, pela paciência e compreensão. Muito obrigado a todos!

Lembro-me de todos os professores do PPGAO que contribuíram para a construção desta dissertação, cada um com sua particularidade e servindo como fonte de inspiração: Adriana Cristina Ferreira Caldana, Gilberto Aparecido Prataviera, Janaina de Moura Engracia Giraldi, Luciano Thomé e Castro, Marcos Fava Neves e Silvia Inês Dallavalle de Pádua. A professora Adriana Maria Procópio de Araujo do PPGCC que aceitou nos receber e compartilhar suas experiências, nos estimulando e nos fazendo repensar a forma de atuar como docente. Tenho muito orgulho de ter sido aluno de professores tão dedicados, competentes e generosos... Muito obrigado!

Meus amigos do grupo de Pesquisa em Inovação e Internacionalização de Empresas da FEARP (ININT), que sempre ajudaram a tornar o trabalho de pesquisa melhor e menos solitário: Luisa Vendruscolo, Maxwell de Oliveira, Ana Claudia Bansi, Marlon Fernandes Alves e Jessâmine Salvini. Obrigado por suas opiniões, ideias e companhia!

Meu agradecimento aos servidores administrativos da Pós-Graduação da FEA-RP e Biblioteca Central, sempre muito educados, prestativos e eficientes. Agradeço também as servidoras da Casa de Hóspedes, que sempre acolhem os hóspedes com muito carinho e atenção, sem dizer que é um dos lugares mais bonitos e sossegados do campus de Ribeirão Preto.

Muito obrigado aos empreendedores das startups respondentes da pesquisa e principalmente, aos que me receberam em suas empresas, mesmo não me conhecendo. Foi pela generosidade e confiança dessas pessoas que este trabalho de pesquisa pôde ser realizado.

Um agradecimento especial aos meus pais Júlio e Catarina, que me incentivaram e me apoiaram em uma decisão bem difícil, para continuar os estudos com maior dedicação. Agradeço também meu irmão Henrique pela ajuda e presteza, sem esquecer das minhas sobrinhas Bruna, Maria Eduarda e Manuela.

Agradeço a Deus, ao meu anjo guardião e aos bons espíritos que sempre me acompanharam nessa jornada, me concedendo coragem, paciência, resignação e proteção. 


\section{RESUMO}

CAJUELA, A. R. Capacidade de absorção em startups sob a perspectiva do gerenciamento de processos de negócio. 2018. 132 f. Dissertação (Mestrado) - Faculdade de Economia, Administração e Contabilidade de Ribeirão Preto, Universidade de São Paulo, Ribeirão Preto, 2018 .

Capacidade de absorção é um tipo de capacidade dinâmica da firma, presente na literatura de gestão estratégica e que demonstra a aprendizagem organizacional, a partilha de conhecimentos, a inovação e o desempenho da empresa. Estudos anteriores indicam que é importante se concentrar nas rotinas e processos que as organizações usam para adquirir, assimilar, transformar e explorar o conhecimento, dentro do conceito de capacidade de absorção. Entretanto, é ainda um tema recente e pouco estudado na academia e, por isso, alguns autores chamam a atenção para a falta de estudos dos processos relacionados a efetiva implementação e realização da capacidade de absorção nas empresas. Nesse contexto, o objetivo deste trabalho é fornecer uma compreensão de como a capacidade de absorção ocorre nas startups, que mantém relacionamentos interorganizacionais com grandes empresas, para obtenção de vantagem competitiva, sob a perspectiva do gerenciamento de processos de negócio. Para atender aos objetivos propostos, foi utilizado o estudo de caso como método de pesquisa, permitindo identificar os gatilhos que iniciam e terminam os processos de absorção de conhecimento nas startups, bem como as atividades estruturadas e sistematizadas que operacionalizam o conceito. Foi construído um diagrama de atividades que representa o modelo de processos para o desenvolvimento da capacidade de absorção, indicando que os processos de negócio estão relacionados aos fluxos de informações que são processados pelas startups nos programas de aceleração corporativa. As vantagens competitivas decorrentes da capacidade de absorção concretizam-se nas startups por meio da flexibilidade estratégica, inovação do tipo organizacional e no desempenho organizacional, avaliado na perspectiva de seus processos internos. O estudo contribui para o avanço no estado da arte ao descrever os processos de negócio relacionados à operacionalização do conceito de capacidade de absorção em startups, por meio dos relacionamentos interorganizacionais com as grandes empresas.

Palavras-chave: Capacidade de absorção. Gerenciamento de processos de negócio. Relacionamentos interorganizacionais. Vantagem competitiva. 


\begin{abstract}
CAJUELA, A. R. Absorptive capacity in startups from the perspective of Business Process Management. 2018. 132 f. Dissertation (Master Thesis) - School of Economics, Business Administration and Accounting at Ribeirão Preto, University of São Paulo, Ribeirão Preto, 2018.

Absorptive capacity is a type of dynamic capabilities of the firm, present in the strategic management literature, that demonstrates the organizational learning, the knowledge sharing, the innovation and the performance of the company. Previous studies indicate that it is important to focus on the routines and processes that organizations use to acquire, assimilate, transform and exploit knowledge within the concept of absorptive capacity. However, it is still a recent and little-studied topic at the academy and therefore some authors draw attention to the lack of studies of the processes related to the effective implementation and realization of the absorptive capacity in the companies. In this context, the aim of this work is to provide an understanding of how absorptive capacity occurs in startups, which maintains interorganizational relationships with large companies, to gain competitive advantage, from the perspective of Business Process Management. To meet the proposed objectives, the research method was the case study, that is allowing the identification of triggers that initiate and end the processes of absorptive of knowledge in the startups, as well as structured and systematized activities that operationalize the concept. An activity diagram was made that represents the process model for the development of absorptive capacity, indicating that the business processes are related to the information flows that are processed by the startups in the corporate accelerator programs. The competitive advantages arising from the absorptive capacity are achieved in the startups through strategic flexibility, organizational-type innovation and organizational performance, evaluated from the perspective of their internal processes. The study contributes to the advancement in the state of the art by describing the business processes related to the operationalization of the concept of absorptive capacity in startups, through the interorganizational relationships with the large companies.
\end{abstract}

Keywords: Absorptive capacity. Business process management. Interorganizational relationships. Competitive advantage. 


\section{LISTA DE QUADROS}

Quadro 1 - Conceituações da capacidade de absorção .........................................................24

Quadro 2 - Tipos de inovação segundo o Manual de Oslo ....................................................29

Quadro 3 - Perspectivas de avaliação do desempenho organizacional no BSC ..................... 31

Quadro 4 - Conceitos básicos relacionados a processos de negócio ....................................... 34

Quadro 5 - Influência do ciclo de BPM no desenvolvimento da capacidade de absorção ....... 40

Quadro 6 - Resumo dos métodos de pesquisa empregados no trabalho ................................. 45

Quadro 7 - Etapas para a pesquisa exploratória qualitativa definida como estudo de caso..... 47

Quadro 8 - Itens de medição para o constructo capacidade de absorção................................. 48

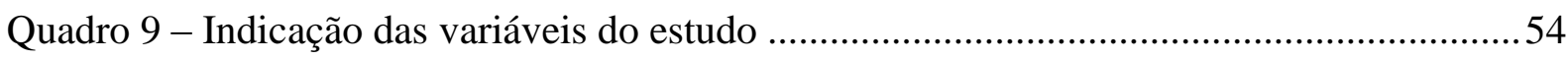

Quadro 10 - Grandes empresas e seus programas de aceleração ...........................................60

Quadro 11 - Startups pré-definidas como unidades de análise ............................................ 76

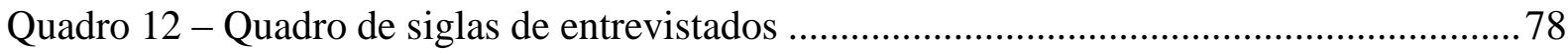

Quadro 13 - Palavras-chave utilizadas como indicadores da capacidade de absorção ............. 80

Quadro 14 - Processo de aquisição e assimilação de conhecimento .................................... 102

Quadro 15 - Processo de transformação e exploração do conhecimento................................ 103 


\section{LISTA DE FIGURAS}

Figura 1 - Um modelo de capacidade de absorção ........................................................... 25

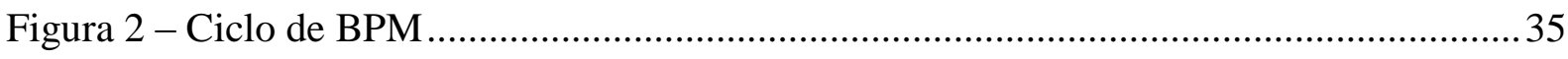

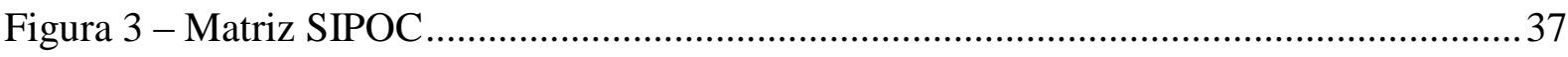

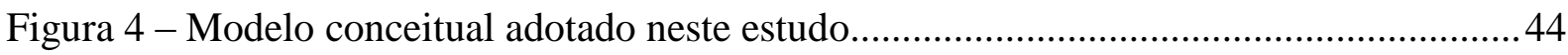

Figura 5 - Estudo triangulado de fontes de evidências ........................................................ 49

Figura 6 - Unidades de registro e de contexto na análise categorial temática ........................50

Figura 7 - Relação da proposição de estudo com objetivos e teorias aplicadas ......................52

Figura 8 - Abordagem da replicação aos estudos de casos múltiplos ......................................55

Figura 9 - Startups inseridas nos programas de aceleração (novembro 2017) ....................... 63

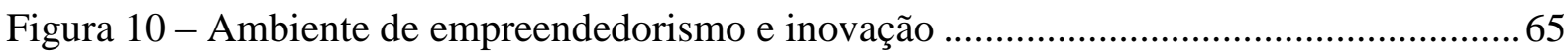

Figura 11 - Startups participantes do estudo (unidades de análise) ........................................77

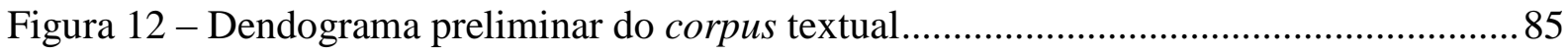

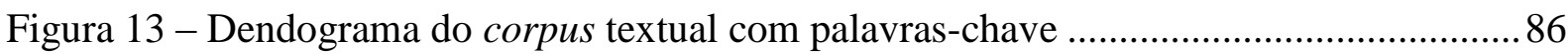

Figura 14 - Nós em cluster por similaridade de codificação ............................................... 88

Figura 15 - Reconfiguração do modelo de ambientes de empreendedorismo e inovação ..... 107

Figura 16 - Capacidade de absorção em startups sob a perspectiva do gerenciamento de processos de negócio 


\section{LISTA DE GRÁFICOS}

Gráfico 1 - Estado sede da aceleradora (dados secundários) ................................................58

Gráfico 2 - Estado sede da aceleradora (dados do levantamento) .........................................59

Gráfico 3 - Frequência relativa ponderada das dimensões da capacidade de absorção........... 73

Gráfico 4 - Índice de reconhecimento da parceria entre startups e grandes empresas ............ 75

Gráfico 5 - Envolvimento das startups em relações comerciais com a grande empresa ..........91

Gráfico 6 - Percentual de texto codificado como "relações comerciais" ..................................92

Gráfico 7 - Percentual de texto codificado como "aquisição" ................................................. 94

Gráfico 8 - Percentual de texto codificado como "assimilação"............................................96

Gráfico 9 - Percentual de texto codificado como "exploração" ............................................ 100 


\section{LISTA DE TABELAS}

Tabela 1 - Startups que mantém parceria ou relacionamento com grandes empresas............. 67

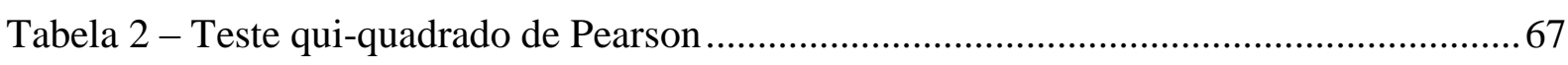

Tabela 3 - Tabulação cruzada do reconhecimento da parceria ................................................ 69

Tabela 4 - Frequência e percentual de respostas para aquisição............................................ 71

Tabela 5 - Frequência e percentual de respostas para assimilação ......................................... 71

Tabela 6 - Frequência e percentual de respostas para transformação ......................................72

Tabela 7 - Frequência e percentual de respostas para exploração ………............................... 72

Tabela 8 - Teste de normalidade da média geral das dimensões da capacidade de absorção.. 74

Tabela 9 - Estatística descritiva da média geral das dimensões da capacidade de absorção ...74

Tabela 10 - Teste de normalidade do índice de reconhecimento da parceria ......................... 75 


\section{LISTA DE ABREVIATURAS}

ABPMP - Association of Business Process Management Professionals adj. - Adjetivo

Asymp. Sig. - Asymptotic Significance

BPM - Business Process Management

BPMN - Business Process Model and Notation

BPR - Business Process Reengineering

df - degrees of freedom

Iramuteq - Interface de R pour Analyses Multidimensionnelles de Textes et de Questionnaires MVP - Minimum Viable Product

OECD - Organisation for Economic Co-operation and Development

OMG - Object Management Group

P\&D - Pesquisa e Desenvolvimento

s. - Substantivo

Sig. - Significance

SPSS - Statistical Package for the Social Sciences

Std. Deviation - Standard Deviation

TQM - Total Quality Management

V. - Verbo

vs. - versus 


\section{SUMÁRIO}

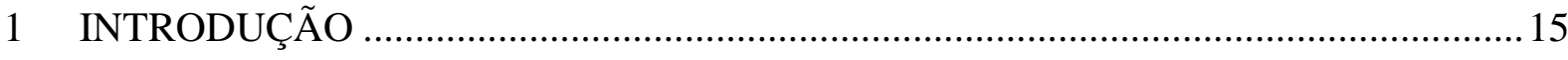

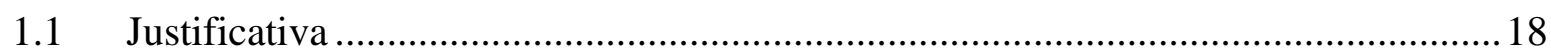

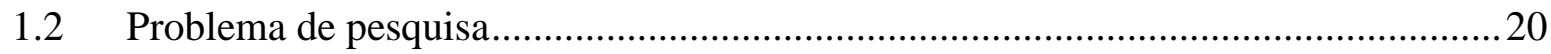

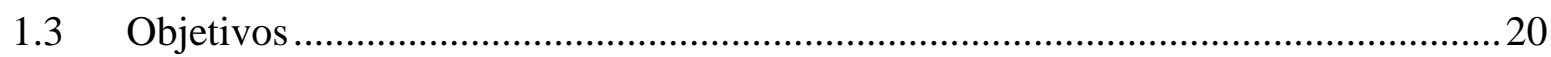

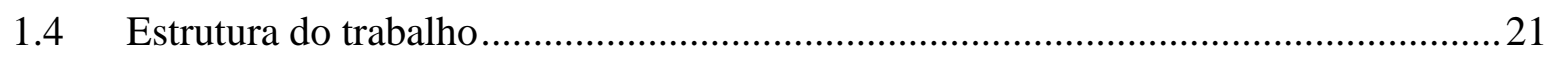

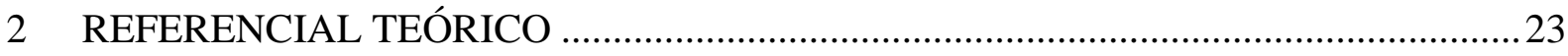

2.1 Conceituando capacidade de absorção como uma capacidade dinâmica ..................23

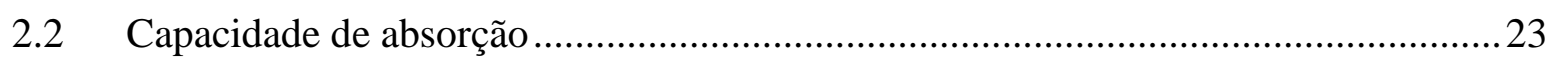

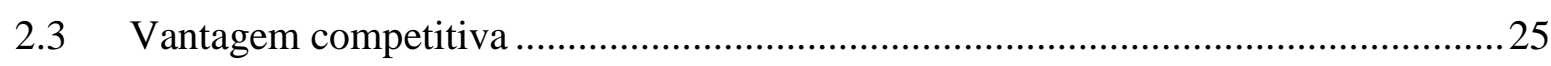

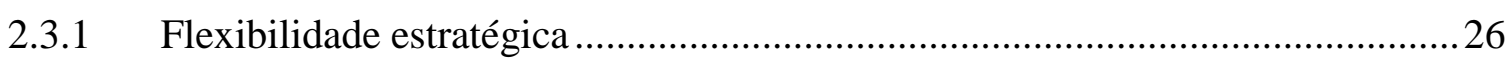

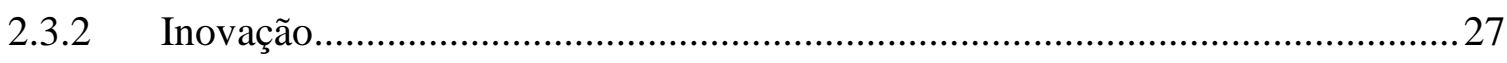

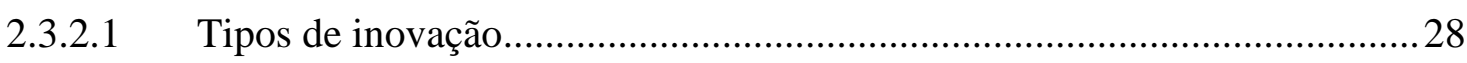

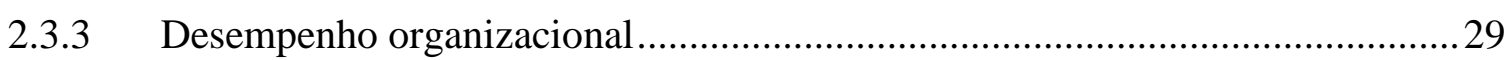

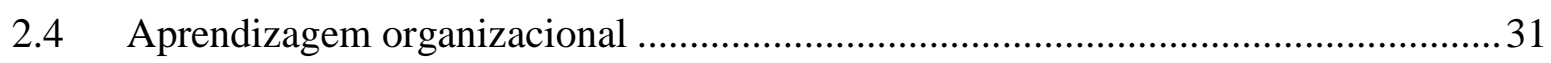

2.5 Gerenciamento de processos de negócio .............................................................. 32

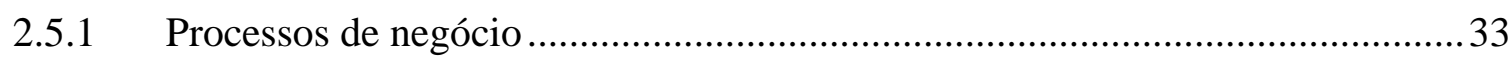

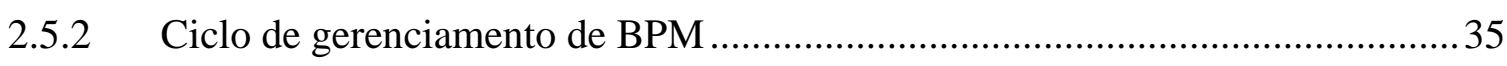

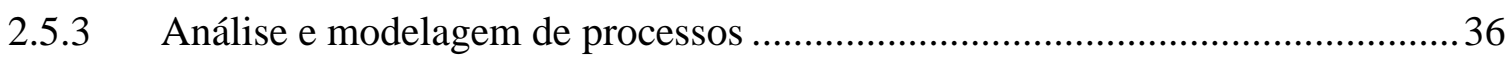

2.6 Relação entre gerenciamento de processos de negócio e capacidade de absorção ....37

2.6.1 Influências e efeitos do BPM no desenvolvimento da capacidade de absorção. 39

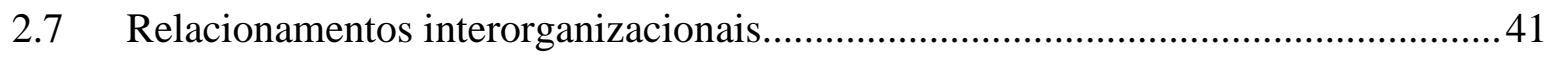

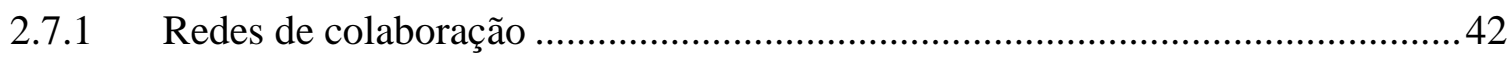

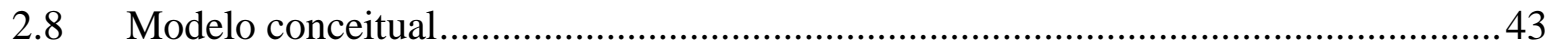

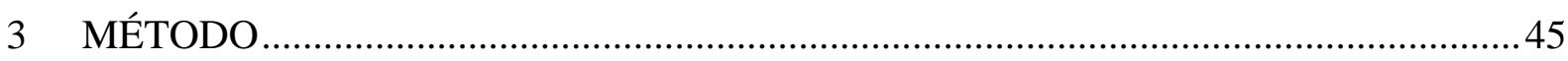

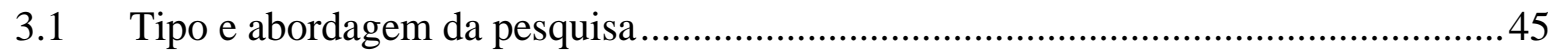

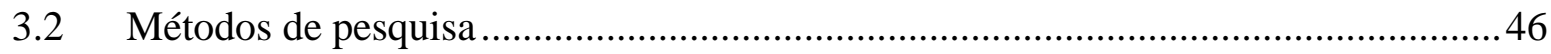

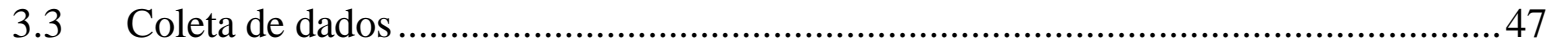

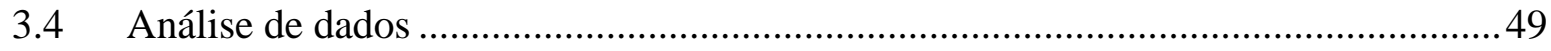

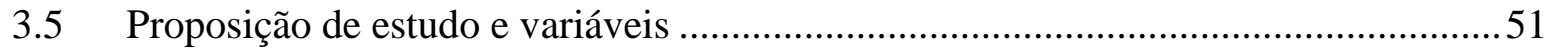

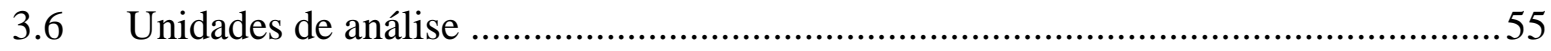

4 APRESENTAÇÃO DOS CASOS E UNIDADES DE ANÁLISE ..................................57

4.1 Relacionamentos interorganizacionais em aceleradoras: cenário para o caso...........57

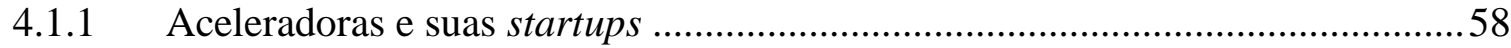

4.1.2 As empresas por trás das aceleradoras estudadas ..............................................64 
4.2 Critérios para definição das unidades de análise ....................................................66

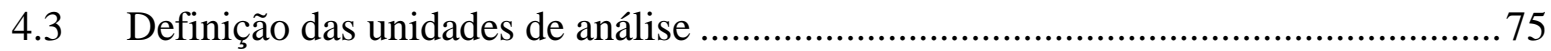

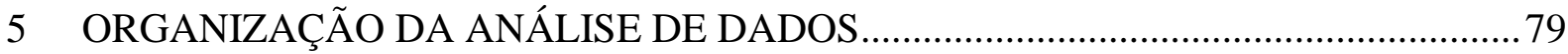

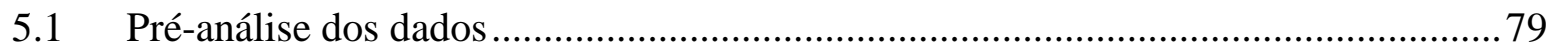

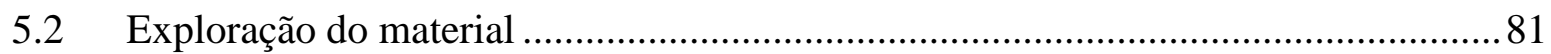

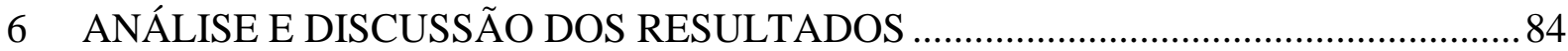

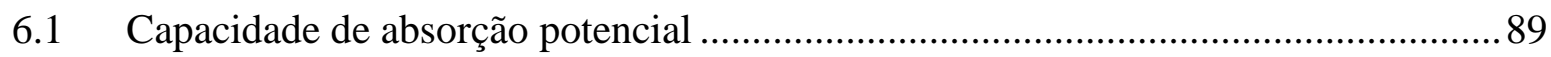

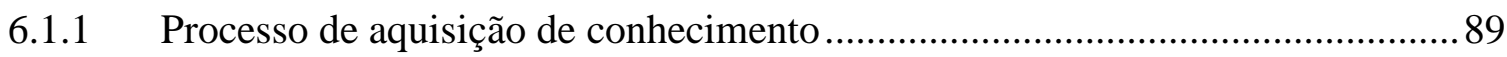

6.1.2 Processo de assimilação de conhecimento ....................................................... 94

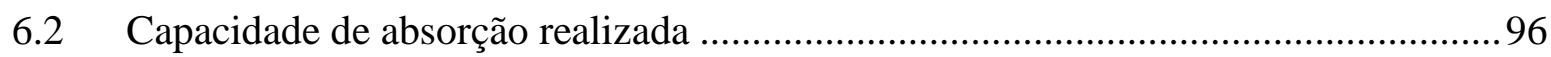

6.2.1 Processo de transformação de conhecimento ................................................... 97

6.2.2 Processo de exploração de conhecimento ..................................................... 98

6.3 Processos de negócio relacionados à capacidade de absorção das startups .............100

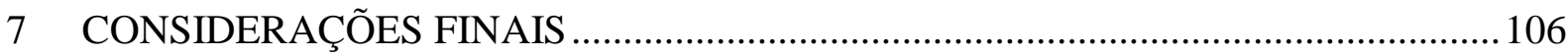

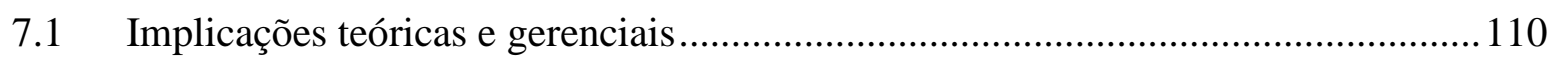

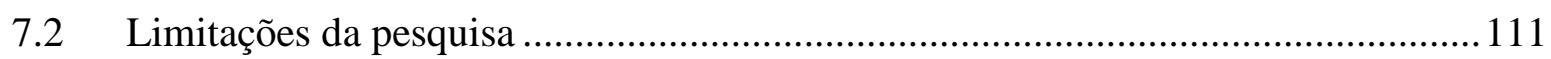

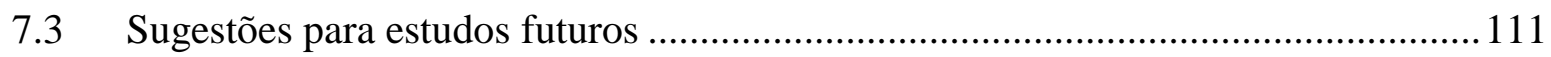

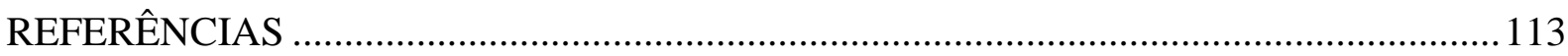

APÊNDICE A - PROTOCOLO PARA O ESTUDO DE CASO …...................................... 120

APÊNDICE B - QUESTIONÁRIO ONLINE UTILIZADO NA PESQUISA SURVEY ...... 126 


\section{INTRODUÇÃO}

O cenário atual de crescente competitividade entre empresas, complexidade, dinamicidade e incertezas do ambiente onde estão inseridas tem provocado a necessidade de adoção de modelos de gestão que cultivem noções de mudança e inovação, proporcionando às organizações formas de inserção neste ambiente turbulento e mutável, tornando-se uma questão de sobrevivência e sucesso.

As capacidades comuns de uma empresa, quando bem aprimoradas, permitem que a organização desempenhe de forma eficiente suas atividades atuais (TEECE, 2012). Winter (2003) afirma que a capacidade organizacional é um conjunto de rotinas de alto nível que, juntamente com seus fluxos de entrada de implementação, confere à organização um conjunto de opções de decisão para produzir resultados significativos, operando em um comportamento rotineiro, altamente padronizado, repetitivo ou quase repetitivo, fundado em parte no conhecimento tácito. Em contrapartida, as capacidades dinâmicas de uma empresa, definidas como um conjunto de comportamentos, habilidades e capacidades organizacionais que, quando combinadas, criam processos que as organizações devem usar para poderem se adaptar e manter vantagens competitivas (MEIRELLES; CAMARGO, 2014), cresceram em importância, uma vez que a expansão do comércio levou a uma maior especialização e respostas competitivas mais rápidas, em um sistema global que exige uma necessidade aprimorada da empresa em desenvolver e manter capacidades de combinar recursos para oferecer valor aos clientes (TEECE, 2012).

Em ambientes de negócios em rápido movimento e abertos à concorrência global, caracterizados pela dispersão nas fontes geográficas e organizacionais de inovação e fabricação, uma vantagem competitiva sustentável requer capacidades dinâmicas únicas e difíceis de serem replicadas. Essas capacidades podem ser aproveitadas para criar, ampliar, atualizar, proteger e manter a base de ativos exclusiva da empresa, sendo definida como competências de nível superior que determinam a capacidade da empresa de integrar, construir e reconfigurar recursos e competências internos e externos para abordar e, possivelmente, moldar ambientes de negócios em rápida mudança (TEECE, 2007).

Com base em conclusões empíricas, Wang e Ahmed (2007) identificaram três principais fatores que compõem o constructo de capacidade dinâmica: a) capacidade adaptativa; b) capacidade de absorção; c) capacidade inovadora. Os três fatores explicam os mecanismos das empresas de vincular a vantagem de recursos internos à vantagem competitiva baseada no mercado externo. Em destaque neste estudo, as empresas com maior capacidade de absorção demonstram maior 
capacidade de aprender com parceiros, integrando informações externas e transformando-as em conhecimento incorporado. Quanto mais uma empresa demonstra sua capacidade de absorção, mais ela exibe capacidades dinâmicas (WANG; AHMED, 2007).

Essa relevância da inter-relação organizacional para o desenvolvimento de capacidades e inovação na firma vem sendo estudada há tempos e por correntes teóricas distintas. Cohen e Levinthal (1990, p. 128), em seu artigo seminal, apresentam o conceito de capacidade de absorção como "a capacidade de uma empresa para reconhecer o valor da informação nova, externa, assimilá-la e aplicá-la para fins comerciais”. Zahra e George (2002) definem capacidade de absorção como um conjunto de rotinas organizacionais e processos pelos quais as empresas adquirem, assimilam, transformam e utilizam os conhecimentos externos para produzir uma capacidade organizacional dinâmica, onde essas quatro capacidades representam as quatro dimensões da capacidade de absorção, desempenhando papéis diferentes, mas complementares, ao explicar como podem influenciar os resultados organizacionais. Nesse contexto, a obtenção de inovação de fontes externas requer basicamente duas etapas: as empresas devem primeiro encontrar fontes externas de informações e, em seguida, trazer essas informações para dentro da empresa, como meio para adicionar ou complementar a base de conhecimento interno (WEST; BOGERS, 2014).

O conceito de capacidade de absorção apresentado por Cohen e Levinthal (1990) e Zahra e George (2002) é discutido por Lewin, Massini e Peeters (2011) que afirmam, com poucas exceções, que as rotinas organizacionais específicas e os processos que constituem a capacidade de absorção das empresas são pouco explorados pelos pesquisadores, constituindo uma área de estudo promissora. Os autores enfatizam o conceito de capacidade de absorção como um conjunto de rotinas e processos que envolvem a capacidade das empresas para iniciar a mudança a partir de dentro, bem como identificar e assimilar as ideias do ambiente externo, retornando ao conceito inicial proposto por Cohen e Levinthal (1990), no qual as organizações desenvolvem a capacidade de gerar novos conhecimentos a nível interno, permitindo a absorção do conhecimento gerado externamente. Capacidade de absorção é vista como uma competência essencial para as organizações e a forma como é efetivamente implementada nas empresas permanece relativamente mal conhecida (ARIBI; DUPOUËT, 2016). Esses autores argumentam que as poucas obras existentes apresentam a capacidade de absorção como um processo essencialmente linear e a forma como as diferentes fases deste processo são realmente realizadas continua a ser pouco estudada.

Os questionamentos dos autores supracitados conduzem o foco deste estudo ao gerenciamento de processos de negócio ou Business Process Management (BPM), no intuito de utilizar essa 
abordagem gerencial para analisar os processos de negócio relacionados a efetiva implementação e realização da capacidade de absorção. O BPM vai além das rotinas organizacionais e estruturas funcionais, representando uma nova forma de visualizar as operações de negócio. Burlton (2010) argumenta que o planejamento de atividades faz parte do processo de administração de empresas e a maioria das organizações realiza esta tarefa. Contudo, há um grande número de empresas que não sistematizam um processo para desenvolver conexões entre os resultados que desejam atingir e as capacidades necessárias para chegar aos resultados planejados (entregabilidade). Há necessidade de um conjunto profissional, disciplinado, repetível e confiável de práticas sobre processos de negócio.

BPM é uma abordagem de gerenciamento e não apenas uma ferramenta ou método isolado, facilitando a comunicação e a cooperação entre tudo o que se faz na organização. Essa abordagem serve de elo entre as estratégias e competências organizacionais e as diversas atividades diárias da empresa, incluindo a tecnologia da informação e de comunicação, o conhecimento organizacional, recursos materiais e financeiros e ferramentas administrativas, dentre outros (VALLE; OLIVEIRA, 2016).

Por outro lado, Weiblen e Chesbrough (2015) acrescentam que muitos esforços anteriores de capitalizar sobre as complementaridades entre grandes empresas e startups não tiveram suas expectativas atendidas e foram discretamente abandonados, principalmente pela diferença entre as formas empresariais e de realização do trabalho, que se tornam verdadeiros desafios para a obtenção de resultados quando ambos os lados trabalham juntos. Durante os últimos anos, no entanto, os esforços corporativos para desenvolver ambientes de inovação entre grandes empresas e startups parecem estar aumentando ${ }^{1}$ (BRINK, 2017; JANG; LEE; YOON, 2017). Em sua busca por velocidade e inovação, a indústria de tecnologia, em particular, tem procurado várias maneiras de se envolver com startups. Assim, o pensamento de Weiblen e Chesbrough (2015) vem ao encontro da realidade que vemos no Brasil nos dias de hoje: ao criar centros de estímulo a pequenos empreendedores, as grandes empresas buscam as novas ideias que as startups são capazes de gerar. Quando uma empresa cresce muito, o processo de inovação tornase mais complexo devido a muitos trâmites burocráticos e administrativos, citando somente alguns motivos. Por essas razões, algumas grandes empresas passaram a ver as startups, mais

\footnotetext{
${ }^{1}$ Grandes empresas querem se parecer mais com startups - uma combinação entre conceitos de manufatura enxuta e o jeito de trabalhar de startups está mudando a organização de equipes em grandes empresas no mundo - Exame (SCHERER, 2017); Os desafios de trazer as inovações de startups para grandes empresas - executivos do Itaú, Accenture e Saint-Gobain compartilham suas experiências e aprendizados na arte de inovar - Época Negócios (BIGARELLI, 2017); Contratos entre grandes empresas e startups crescem 194\% no Brasil - estudo do movimento 100 Open Startups analisou 408 empresas e mais de 3 mil startups entre julho de 2015 e julho de 2017 - O Estado de S. Paulo (INGIZZA, 2017).
} 
enxutas e ágeis, como opção para gerar constantemente atividades de inovação (ROCHA, 2016).

Além disso, é cada vez mais comum o envolvimento de grandes empresas com startups devido as consequências da crise econômica e política que o Brasil vem enfrentando nos últimos anos, indicando que a maneira de inovar está ganhando novos contornos, como as parcerias com startups. Um dos efeitos da crise é o contingenciamento de recursos e o orçamento público para investimento em pesquisa e desenvolvimento têm enfrentado reduções expressivas. $\mathrm{O}$ Ministério da Ciência e Tecnologia, Inovações e Comunicações (MCTIC) reduziu seu orçamento em 44\%, da mesma forma ocorreu com o Banco Nacional de Desenvolvimento Econômico e Social (BNDES), reduzido em 40\% no ano de 2016. Outro vetor de fomento à ciência e inovação, o Fundo Nacional de Desenvolvimento Científico e Tecnológico (FNDCT), do qual a Financiadora de Estudos e Projetos (Finep) é braço executivo, também sofre com o contingenciamento. Diante desse cenário, as grandes empresas estão encontrando nas parcerias externas com startups uma estratégia para mitigar riscos e pulverizar investimentos, buscando fora da empresa expertises e capacidades necessárias para alavancar suas estratégias de inovação (DATT; MEIRELLES, 2017).

Nos últimos anos observou-se, não só no Brasil, mas em diversos outros países, o surgimento de aceleradoras de empresas criadas por grandes empresas. Organizações como Google, Telefônica, Samsung e banco Itaú, para citar somente algumas, tem investido em polos de apoio a novos negócios com o objetivo principal de gerar inovação continuamente (ROCHA, 2016). Este movimento vem recebendo destaque em noticiários, revistas e jornais de grande circulação nacional, revelando uma área de estudos promissora para pesquisadores que desejam entender como o empreendedorismo está se desenvolvendo no Brasil, principalmente no que diz respeito a promoção de atividades de inovação por meio dos relacionamentos interorganizacionais.

Em relação a tais aspectos, surge, neste estudo, a oportunidade de sistematizar o conhecimento empírico e teórico, apresentando resultados que descrevem os processos de negócio relacionados à operacionalização do conceito de capacidade de absorção nas startups. Face a isto, a pesquisa adotou uma perspectiva de processos sobre a capacidade de absorção, buscando entender como a capacidade de absorção ocorre nas startups, por meio dos relacionamentos interorganizacionais com grandes empresas, com o objetivo de criação e sustentabilidade de vantagem competitiva.

\subsection{Justificativa}


Na concepção de Zahra e George (2002), é importante se concentrar nas rotinas e processos que as organizações usam para adquirir, assimilar, transformar e explorar o conhecimento, dentro do conceito de capacidade de absorção. Em contrapartida, autores como Lewin, Massini e Peeters (2011) afirmam que as rotinas organizacionais específicas e processos que constituem a capacidade de absorção das empresas são pouco explorados pelos pesquisadores, da mesma forma que Aribi e Dupouët (2016) chamam a atenção para a falta de estudos dos processos relacionados a efetiva implementação e realização da capacidade de absorção nas empresas.

Atualmente, grande parte da literatura sobre relacionamentos interorganizacionais para a inovação tem se concentrado nas atividades de grandes organizações, com poucos estudos examinando os modelos de inovação das pequenas e médias empresas ou as relações que sustentam abordagens colaborativas dentro desse setor (DOOLEY; KENNY; CRONIN, 2015). Além disso, Nambisan e Baron (2013) afirmam que pesquisas em empreendedorismo tem negligenciado ambientes de inovação como um local para o empreendedorismo e criação de startups. Porém, é evidente que os ambientes de inovação baseados em parcerias com grandes empresas tornam-se um ambiente fértil para a criação e desenvolvimento de novas firmas, dado os inúmeros benefícios associados ao acesso aos mercados já estabelecidos, branding ${ }^{2}$, vantagens de reputação, acesso a propriedade intelectual e know-how técnico (CECCAGNOLI et al., 2012), aumentando oportunidades e auxiliando as startups a superarem algumas barreiras de entrada, inexperiência e apoio para novas tecnologias, corroborando com o pensamento de Eisenmann, Parker e Van Alstyne (2009). Nesse contexto, se as grandes empresas buscam descobrir novos nichos de negócios, os empreendedores das startups, por sua vez, beneficiamse do acesso a espaços de trabalho colaborativo, mentoria, cursos e, em alguns casos, recursos financeiros para acelerar seus projetos (ROCHA, 2016).

O cenário atual descrito acima apresenta-se como pano de fundo à motivação para realização deste estudo, uma vez que as aceleradoras de empresas criadas por grandes empresas representam um nicho em crescimento no Brasil e configuram-se como um ambiente propício para troca de conhecimentos. Nas palavras de Zahra e George (2002), pesquisas anteriores indicam um consenso implícito no papel e resultados da capacidade de absorção como um conjunto de habilidades da firma para gerenciar o conhecimento. Levando em conta a convergência de objetivos, ou seja, o conhecimento organizacional, justifica-se a escolha das

\footnotetext{
${ }^{2}$ Atribuição de um nome ou marca registrada a um produto, podendo tornar-se quase um sinônimo do próprio produto. O termo está relacionado a empresas cujas marcas são fortes no mercado, possuindo um ativo de grande valor em virtude do renome de suas marcas (HINDLE, 2002).
} 
aceleradoras de empresa como ambiente de investigação e contextualização de conceitos teóricos.

Tais argumentos apontam uma importante lacuna teórica a ser explorada, relativa à ênfase na análise dos processos para operacionalização da capacidade de absorção em organizações de diferentes tamanhos, com o objetivo de gerar e sustentar vantagens competitivas. O trabalho de pesquisa irá contribuir para o avanço no estado da arte sobre processos de aprendizagem organizacional e relacionamentos interorganizacionais, proporcionando também o entendimento de métodos organizacionais relevantes para a gestão da inovação, lançando luz empírica sobre conceitos teóricos.

\subsection{Problema de pesquisa}

Com base no cenário apresentado, há uma falta de observação direta ou análise das rotinas e processos que compõem efetivamente a capacidade de absorção, além da necessidade de melhor compreensão e operacionalização dos conceitos. Percebe-se também que grande parte das pesquisas sobre inovação colaborativa foram realizadas sob a perspectiva das grandes empresas, revelando uma escassez de estudos focados em startups.

Dentro dessa problemática de investigação dos processos que compõem efetivamente a capacidade de absorção em startups, surge a pergunta motivadora deste estudo: nos relacionamentos interorganizacionais entre grandes empresas e startups, como as startups absorvem conhecimento das grandes empresas, sob a perspectiva do gerenciamento de processos de negócio, com o objetivo de criar vantagem competitiva?

\subsection{Objetivos}

A partir do problema de pesquisa, foram elaborados o objetivo geral e os objetivos específicos. O objetivo geral deste estudo é fornecer uma compreensão de como a capacidade de absorção ocorre nas startups que mantém relacionamentos interorganizacionais com grandes empresas, para obtenção de vantagem competitiva. Para atingir esse objetivo, os seguintes objetivos específicos foram estabelecidos:

a) mapear a rede de colaboração constituída pelos relacionamentos interorganizacionais entre as startups e grandes empresas; 
b) descrever como os processos de negócio são utilizados pelas startups para adquirir, assimilar, transformar e utilizar os conhecimentos adquiridos da grande empresa;

c) analisar os processos de negócio que constituem a capacidade de absorção das startups, bem como sua implementação e realização, a fim de promover vantagens competitivas.

O estudo busca levantar resultados que contribuam para o avanço no estado da arte sobre o desenvolvimento da capacidade de absorção nos relacionamentos interorganizacionais, com ênfase na aprendizagem organizacional das startups. Além do avanço do conhecimento, um dos objetivos da pesquisa em administração é resolver problemas práticos, tornando as decisões administrativas mais eficazes. A operacionalização dos conhecimentos gerados e o retorno deles para a sociedade e para as organizações pode tornar-se uma contribuição adicional de qualquer projeto de pesquisa (NEVES; CONEJERO, 2012). Ao final deste estudo, pretende-se apresentar implicações práticas e recomendações acionáveis sobre os processos que as empresas podem utilizar para desenvolver e gerenciar a capacidade de absorção (LANE; KOKA; PATHAK, 2006), descrevendo os processos de negócio relacionados à operacionalização do conceito de capacidade de absorção nas startups.

\subsection{Estrutura do trabalho}

De modo a responder o problema de pesquisa e cumprir o objetivo proposto, o presente trabalho está estruturado em sete capítulos destinados à introdução, revisão da literatura, abordagem metodológica, apresentação, organização, análise e discussão dos casos, encerrando com as considerações finais.

O primeiro capítulo introduz e contextualiza o fenômeno estudado, assim como apresenta as principais lacunas existentes na literatura, a questão de pesquisa e o objetivo do estudo.

Em seguida, no segundo capítulo, foi realizada a revisão da literatura necessária para o desenvolvimento do trabalho. O referencial teórico delimitou o escopo do estudo aos conceitos que são pertinentes ao problema de pesquisa, mediante a análise de documentos de domínio científico tais como livros e artigos científicos. Esse método de pesquisa, chamado de pesquisa bibliográfica, é um estudo de fontes científicas secundárias que tratam do fenômeno em estudo sob as contribuições de diferentes autores, contribuindo também para o avanço no estado da arte sobre o tema. 
Os aspectos metodológicos da pesquisa empírica foram discutidos no terceiro capítulo, contemplando a escolha do método adequado para obter as informações necessárias para solucionar o problema de pesquisa. Optou-se pelo método do estudo de caso, tendo em vista o tipo de questão de pesquisa e o objetivo de investigar um fenômeno contemporâneo em profundidade. De forma complementar, foi utilizado um levantamento (survey) para auxiliar na definição das unidades de análise e diversificação as fontes de evidências de dados.

O capítulo quatro apresenta os casos em estudo e o detalhamento dos critérios utilizados para a definição das unidades de análise e é complementado pelo capítulo cinco, que por sua vez detalha a organização do plano de análise de dados e a exploração do material. Já o capítulo seis desenvolve a análise dos dados coletados, buscando evidências convergentes dos casos apresentados junto ao referencial teórico.

Por fim, o sétimo capítulo contempla as considerações finais, onde são apresentadas as contribuições do estudo, implicações teóricas e gerenciais, suas limitações e sugestões para trabalhos futuros. Nesse capítulo, também se apresenta o cumprimento do objetivo e a resposta ao problema de pesquisa. 


\section{REFERENCIAL TEÓRICO}

Para atender aos objetivos propostos, estão descritos neste estudo os referenciais teóricos referentes à capacidade de absorção, destacando a obtenção de vantagem competitiva e a aprendizagem organizacional, bem como gerenciamento de processos de negócio e relacionamentos interorganizacionais, apresentando a relação entre os temas.

\subsection{Conceituando capacidade de absorção como uma capacidade dinâmica}

Para entender o conceito de capacidade de absorção, se faz necessário primeiramente compreender o que são capacidades dinâmicas. Segundo Teece (2007), o conceito de capacidades dinâmicas baseia-se nas ciências sociais e comportamentais e procura explicar a natureza e os fundamentos das capacidades necessárias para sustentar o desempenho empresarial em uma economia aberta e de rápida inovação, dispersas globalmente. O mesmo autor também define capacidades dinâmicas como a habilidade das organizações em integrar, construir e reconfigurar competências internas e externas, face a ambientes em rápida mudança. Por essa definição, competências organizacionais devem ser entendidas como processos organizacionais e gerenciais ou padrões de prática corrente e de aprendizado.

Empresas com forte capacidade dinâmica são muito empreendedoras, capazes não só de se adaptar ao ecossistema de negócios, mas também dar-lhes forma por meio de inovação e colaboração com outras empresas, entidades e instituições. O desenvolvimento, implantação e proteção de ativos intangíveis e capital intelectual são essenciais para a competitividade das empresas (TEECE, 2007).

Muitos tipos de capacidades dinâmicas foram identificados e estão relacionados ao desenvolvimento de produtos, gerenciamento de alianças e tomada de decisões estratégicas, fundamentam Zahra e George (2002). Para estabelecer um escopo empírico claro, neste estudo será examinado o processo de capacidade de absorção de uma organização como uma capacidade dinâmica, pois o foco está nos relacionamentos interorganizacionais, corroborando com as conclusões de Wang e Ahmed (2007).

\subsection{Capacidade de absorção}

Surge então a capacidade de absorção como uma capacidade dinâmica da firma, onde seus efeitos refletem a aprendizagem organizacional, a partilha de conhecimentos, a inovação e o 
desempenho da empresa (FLATTEN et al., 2011). A inovação é um processo baseado no conhecimento, onde criam-se possibilidades por meio da combinação de diferentes conjuntos de conhecimentos. Tal conhecimento pode já existir dentro da organização, baseado em algo que já foi visto ou experimentado antes, ou pode resultar de um processo de busca por tecnologias, mercados, ações da concorrência, dentre outros (TIDD; BESSANT; PAVITT, 2008). Muitas vezes, uma empresa sozinha não tem todas as capacidades de que precisa para inovar e estas capacidades complementares estão cada vez mais espalhadas em contextos internos e externos. Estas capacidades, por sua vez, não são desenvolvidas de maneira isolada, dependendo muitas vezes de processos inovadores interativos ou de simples troca (PORTO, 2013).

Este estudo segue a reconceituação oferecida por Zahra e George (2002), destacando dois subconjuntos de capacidade de absorção: potencial e realizada. Capacidade potencial compreende aquisição e assimilação de conhecimento e capacidade realizada a transformação e aproveitamento do conhecimento. O Quadro 1 explica as quatro dimensões da capacidade de absorção. Os autores ressaltam que a maioria dos estudos empíricos mostram relações significativas entre capacidade de absorção e a produção inovadora, dentre outros resultados relacionados à criação de vantagem competitiva. No entanto, a avaliação dessas relações ainda é trabalhada com constructo de capacidade de absorção como uma caixa preta, ou seja, sem que ela seja avaliada em seus variados componentes.

Quadro 1 - Conceituações da capacidade de absorção

\begin{tabular}{|c|c|c|}
\hline Capacidade de Absorção & Dimensão & Constructo \\
\hline \multirow[b]{2}{*}{ Potencial } & Aquisição & $\begin{array}{l}\text { Refere-se à habilidade da empresa em identificar } \\
\text { e obter conhecimentos a partir de fontes externas. }\end{array}$ \\
\hline & Assimilação & $\begin{array}{l}\text { Refere-se à habilidade da empresa para } \\
\text { desenvolver processos e rotinas úteis na análise, } \\
\text { interpretação e compreensão dos conhecimentos } \\
\text { adquiridos externamente. }\end{array}$ \\
\hline \multirow[t]{2}{*}{ Realizada } & Transformação & $\begin{array}{l}\text { Refere-se ao desenvolvimento e refinamento das } \\
\text { rotinas que facilitam a combinação dos } \\
\text { conhecimentos existentes (internos) com os } \\
\text { conhecimentos adquiridos externamente, a fim de } \\
\text { utilizá-los no futuro. }\end{array}$ \\
\hline & Exploração & $\begin{array}{l}\text { Refere-se à capacidade da empresa em melhorar, } \\
\text { expandir e usar as rotinas existentes, } \\
\text { competências e tecnologias para criar algo com } \\
\text { base no conhecimento transformado. }\end{array}$ \\
\hline
\end{tabular}

Fonte: Adaptado de Zahra e George (2002).

No que se refere às várias abordagens conceituais, sob o ponto de vista de Lane, Koka e Pathak (2006), inovação é o único tema convergente quanto às dimensões de utilização da capacidade 
de absorção, pois é resultado da aprendizagem organizacional. Os autores acreditam que a capacidade de absorção ajuda na velocidade, frequência e magnitude de inovação e que a inovação produz conhecimento que se torna parte da capacidade de absorção da empresa. A Figura 1 ilustra o modelo que conecta os dois subconjuntos de capacidade de absorção (potencial e realizada), assim como as fontes externas de conhecimento. O modelo indica que tanto a capacidade de absorção potencial quanto a realizada contribuem diferencialmente, porém, de forma complementar para desenvolvimento de vantagem competitiva nas organizações.

Figura 1 - Um modelo de capacidade de absorção

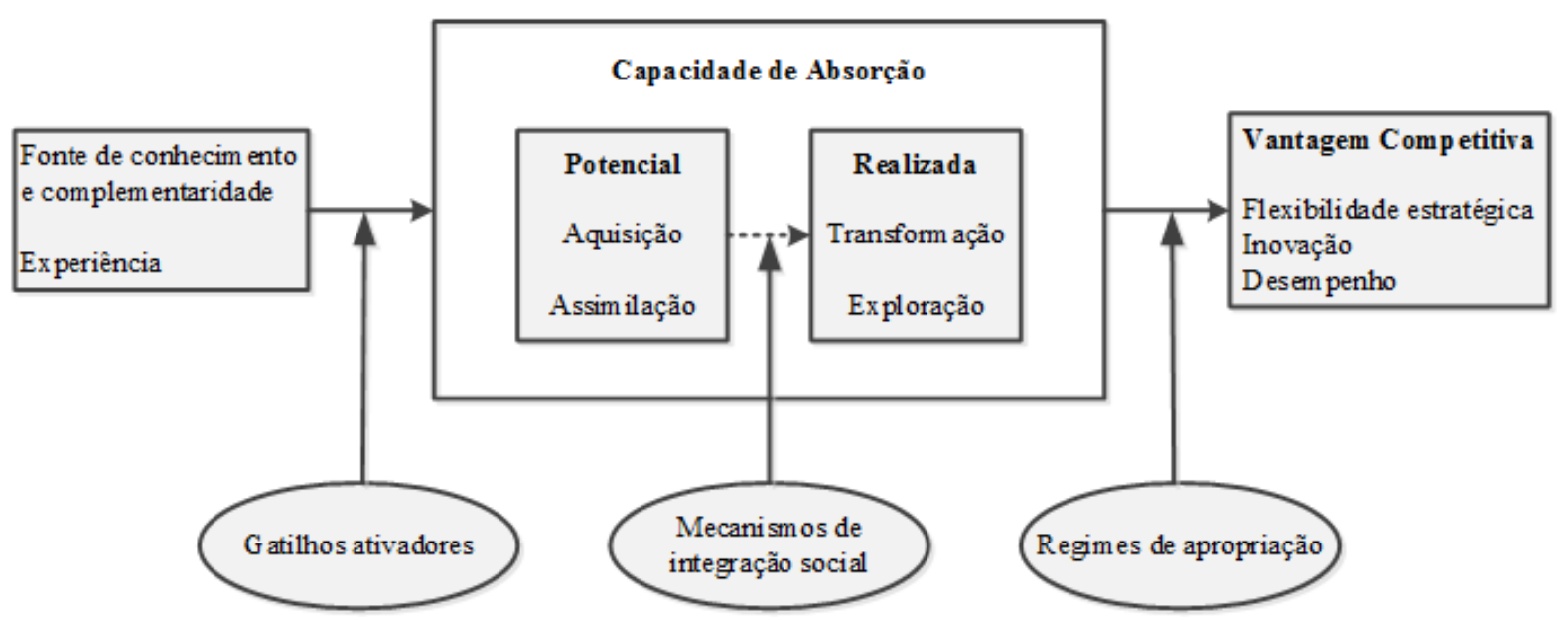

Fonte: Zahra e George (2002, p. 192).

Devido ao estreito relacionamento com o objetivo geral deste estudo, a obtenção de vantagem competitiva será analisada em detalhes na próxima seção.

\subsection{Vantagem competitiva}

Quando os recursos são valiosos, raros, inimitáveis e não substituíveis, eles podem fornecer à empresa uma vantagem competitiva (BARNEY, 1991). A capacidade de uma organização para efetivamente criar, gerenciar e explorar o conhecimento é um desses recursos críticos e, por ser um conjunto de capacidades baseadas no conhecimento, a capacidade de absorção pode ser uma fonte de vantagem competitiva para a empresa (ZAHRA; GEORGE, 2002). Os referidos autores defendem que a capacidade de absorção de uma empresa pode ser uma fonte primária de criação e sustentação de uma vantagem competitiva, abrindo a caixa preta da sustentabilidade da vantagem competitiva em mercados dinâmicos. 
Enquanto a vantagem competitiva pode advir de tamanho ou patrimônio da firma, dentre outros fatores, Tidd, Bessant e Pavitt (2008) afirmam que esse cenário está gradativamente mudando por conta daquelas organizações que conseguem mobilizar conhecimento e avanços tecnológicos em favor da criação de novidades em suas ofertas de produtos ou serviços, bem como nas formas como criam e lançam essas ofertas.

Embora existam muitas maneiras pelas quais uma empresa pode obter vantagem competitiva, Zahra e George (2002) esclarecem que a inovação e a flexibilidade estratégica são os fatores mais importantes em mercados dinâmicos e pertencem ao subconjunto de capacidade de absorção potencial. As capacidades de transformação e exploração, que a capacidade de absorção realizada compreende, são susceptíveis de influenciar o desempenho organizacional, por meio da inovação de produtos e processos.

\subsubsection{Flexibilidade estratégica}

A capacidade de absorção potencial desempenha um papel importante na renovação da base de conhecimento de uma empresa e nas habilidades necessárias para competir em um mercado em constante mudança. Empresas que são flexíveis no uso de seus recursos e capacidades são mais propensas a manter uma vantagem competitiva devido a flexibilidade na reconfiguração de suas bases de recursos e capacidades, sendo capazes de capitalizar oportunidades estratégicas emergentes (ZAHRA; GEORGE, 2002).

Da mesma forma, Zhou e Wu (2010) definem flexibilidade estratégica como a capacidade de uma empresa em realocar e reconfigurar seus recursos organizacionais, processos e estratégias para lidar com mudanças ambientais, representando um tipo de capacidade dinâmica que permite que as empresas abordem as descontinuidades no meio ambiente. Sob esse aspecto, é interessante pressupor que as organizações não são apenas agentes passivos na pressão exercida pelas forças do ambiente, mas também possuem o poder de influenciar e moldar tal ambiente, onde maior é a importância da mudança e adaptação contínuas alinhadas com a incerteza e turbulência do ambiente (PORTO, 2013).

O conceito de flexibilidade estratégica foi utilizado na tese de Dobelin (2016) como indicativo da presença de capacidades dinâmicas nas organizações e o estudo demonstrou que a flexibilidade estratégica é um componente complementar da capacidade dinâmica, apresentando uma relação significativa e positiva junto ao constructo. Sendo a capacidade de absorção uma capacidade dinâmica de criação e utilização do conhecimento, capaz de melhorar a capacidade de uma empresa em obter e sustentar vantagem competitiva, concluiu-se com o 
estudo que a flexibilidade estratégica é demonstrada quando a organização consegue modificar rapidamente sua estratégia e controlar as forças de mercado, sendo capazes de alterar facilmente os planos futuros e ajustar a organização ao ambiente, melhorando a efetividade e criando mudanças no mercado.

\subsubsection{Inovação}

Na afirmação de Tidd, Bessant e Pavitt (2008, p. 86) "a inovação é um processo de fazer de uma oportunidade uma nova ideia e de colocá-la em uso de maneira mais ampla possível". O processo de inovação vem evoluindo desde 1950 e as teorias mais atuais concentram-se em operações paralelas e integradas entre organizações, onde os vínculos entre fornecedores, principais clientes e alianças horizontais estão fortalecidos, caracterizando uma crescente interatividade para fora da empresa, no entender dos autores supracitados.

Schumpeter (1961) teve uma influência decisiva nas teorias da inovação, pois defende que o desenvolvimento econômico é conduzido pela inovação, por meio de um processo dinâmico onde novas tecnologias substituem as antigas. Há diferentes graus de novidade, desde melhorias incrementais menores até mudanças realmente radicais (TIDD; BESSANT; PAVITT, 2008), corroborando com o pensamento do primeiro autor, que classifica a inovação como radical, apresentando rupturas mais intensas e incremental, que dá continuidade ao processo de mudança. A esse respeito, Schumpeter (1961) acrescenta que existe uma constante busca pela criação de algo novo, sempre orientado para novas fontes de lucratividade, causando a destruição de velhas regras e o estabelecimento de novas, em um processo que ele define como “destruição criativa".

Neste contexto, o Manual de Oslo (OECD, 2005) apresenta diretrizes para a implementação de pesquisas sobre inovação em países em desenvolvimento, refletindo as diferentes características das economias e das sociedades desses países. Sob essas diretrizes, o manual define que (OECD, 2005, p. 158)

Os exercícios de mensuração devem, portanto, centrar-se no processo de inovação e não nos seus resultados e enfatizar como as capacitações, os esforços e os resultados são tratados. Por essa razão, é igualmente ou mais importante determinar e analisar os esforços realizados pelas empresas e organizações (as atividades de inovação) e suas capacitações (estoques e fluxos) do que os resultados (inovações). Os fatores que dificultam ou facilitam a inovação são vistos como indicadores-chave nesse contexto. 
Em relação a tais afirmações, a gestão de uma organização pode projetar processos e estruturas para suportar a inovação (PORTO, 2013) e neste caso, depara-se com a delimitação do estudo em atividades de inovação, focando no processo e não nos resultados de inovação.

A inovação é amplamente considerada como um fator chave para o desenvolvimento econômico e competitividade das empresas, regiões e nações. Algumas situações são evidentes, como a diminuição dos ciclos de vida dos produtos, tornando os esforços de inovação cruciais para a sobrevivência das organizações, em um ambiente onde as mudanças ocorrem cada vez mais rápido. Muitas organizações já estão implementando atividades colaborativas e abertas de inovação com parceiros externos e estes tipos de atividades abertas de inovação estão associadas a um número substancial de benefícios potenciais, revelando-se também desafiadoras (VAN LANCKER et al., 2016).

\subsubsection{Tipos de inovação}

A inovação é movida pela habilidade de estabelecer relações, detectar oportunidades e tirar proveito das mesmas e está estreitamente relacionada à mudança, transformando ideias e conhecimentos em produtos mais modernos e melhor prestação de serviços (TIDD; BESSANT; PAVITT, 2008). Por tratar-se de mudança, a inovação pode assumir diversas formas e os autores supracitados abordam o tema em quatro categorias abrangentes:

a) inovação de produto - mudanças em produtos e serviços que uma empresa oferece;

b) inovação de processo - mudanças na forma, métodos ou procedimentos para criação e entrega de produtos e serviços;

c) inovação de posição - reposicionamento da percepção de um produto ou processo já estabelecido em um contexto de uso específico ou na forma como são introduzidos;

d) inovação de paradigma - mudanças nos modelos mentais subjacentes que orientam o que a empresa faz.

Da mesma forma, о Manual de Oslo (OECD, 2005) explica que uma empresa pode realizar vários tipos de mudanças em seus métodos de trabalho, definindo também quatro tipos de inovações que incluem um amplo conjunto de mudanças nas atividades das empresas: inovações de produto, inovações de processo, inovações organizacionais e inovações de marketing. As definições completas dos quatro tipos de inovação definidas pelo Manual de Oslo (OECD, 2005) podem ser encontradas no Quadro 2. 
Quadro 2 - Tipos de inovação segundo o Manual de Oslo

\begin{tabular}{|l|l|}
\hline \multicolumn{1}{|c|}{ Tipos de Inovação } & \multicolumn{1}{c|}{ Definições Operacionais } \\
\hline Inovação de produto & $\begin{array}{l}\text { Introdução de um bem ou serviço novo ou } \\
\text { significativamente melhorado no que concerne a suas } \\
\text { características ou usos previstos. Incluem-se } \\
\text { melhoramentos significativos em especificações } \\
\text { técnicas, componentes e materiais, softwares } \\
\text { incorporados, facilidade de uso ou outras } \\
\text { características funcionais. }\end{array}$ \\
\hline Inovação de processo & $\begin{array}{l}\text { Implementação de um método de produção ou } \\
\text { distribuição novo ou significativamente melhorado. } \\
\text { Incluem-se mudanças significativas em técnicas, } \\
\text { equipamentos e/ou softwares. }\end{array}$ \\
\hline Inovação de marketing & $\begin{array}{l}\text { Implementação de um novo método de marketing com } \\
\text { mudanças significativas na concepção do produto ou } \\
\text { em sua embalagem, no posicionamento do produto, } \\
\text { em sua promoção ou na fixação de preços. }\end{array}$ \\
\hline Inovação organizacional & $\begin{array}{l}\text { Implementação de um novo método organizacional } \\
\text { nas práticas de negócios da empresa, na organização } \\
\text { do seu local de trabalho ou em suas relações externas. }\end{array}$ \\
\hline
\end{tabular}

Fonte: Manual de Oslo (OECD, 2005, p. 57, 58, 59 e 61).

A inovação tem se mostrado a mola mestra na dinâmica competitiva dos países, promovendo o crescimento e o desenvolvimento das nações e consequentemente, das organizações. Todavia, raras são as organizações que conseguem inovar isoladamente, porque em geral, esse processo não depende única e exclusivamente de competências internas, mas em grande parte do uso complementar dessas competências ou capacidades, geralmente externas às organizações (CORAL; CAMPAGNOLO; CARIONI, 2016). Este sistema de inovação, também conhecido como ecossistema de inovação, cujo conjunto de elementos e interligações são capazes de influenciar a produção, a difusão e a utilização de conhecimento novo e útil, será discutido mais a diante.

\subsubsection{Desempenho organizacional}

Na compreensão de Zahra e George (2002), as empresas não podem explorar o conhecimento sem primeiro adquiri-lo. Da mesma forma, as empresas podem adquirir e assimilar o conhecimento, mas podem não ter a capacidade de transformar e explorar esse conhecimento para geração de lucro ou vantagens. Portanto, a capacidade de absorção potencial elevada não implica necessariamente em um desempenho aprimorado. Não obstante, a capacidade de absorção realizada envolve a transformação e a exploração do conhecimento assimilado, incorporando-o às operações da empresa melhorando assim o desempenho organizacional. 
Como se pode observar, a capacidade de absorção realizada consiste em recursos de transformação, permitindo que as empresas desenvolvam novos processos ou adicionem mudanças nos processos existentes e às capacidades de exploração, que são usadas para converter o conhecimento em novos produtos ou serviços, para melhorar o desempenho e a vantagem competitiva (FLATTEN et al., 2011).

A influência da capacidade de absorção no desempenho da empresa é significativamente positiva e não têm apenas efeito direto sobre o desempenho, mas também um impacto indireto no sucesso das alianças estratégicas da firma (FLATTEN; GREVE; BRETTEL, 2011). Os autores concluíram que as empresas que possuem capacidade de absorção bem desenvolvida podem adicionalmente usá-la como instrumento para melhorar a eficácia das alianças estratégicas e, assim, melhorar o desempenho organizacional.

Tais considerações chamam a atenção para a necessidade de definir com clareza o que é um bom desempenho para a empresa e como mensurá-lo. Entende-se por desempenho organizacional os resultados que uma organização alcança em decorrência de seus esforços. Esses resultados são múltiplos, pois são vários os grupos interessados na atuação de uma organização, como os proprietários, os empregados, os clientes, a comunidade, o governo e os fornecedores. Nesse contexto de partes interessadas, os proprietários querem retorno sobre o investimento e os empregados buscam remuneração pelo seu esforço, além de sentido no seu trabalho. Os clientes desejam bons produtos e serviços a um preço justo, e assim por diante. Uma empresa não quer apenas maximizar seu retorno financeiro, mas também ser reconhecida a aceita no seu ambiente (FERNANDES, 2006).

Existem diversos modelos para avaliar o desempenho organizacional, provenientes das práticas da qualidade total e da área de mercado de capitais, por exemplo. Outros modelos surgem no campo acadêmico, na tentativa de ter uma abordagem mais completa para avaliar o desempenho de uma empresa, de acordo com Fernandes (2006). O balanced scorecard (BSC) é um exemplo desses modelos e surgiu com a preocupação de prover os gestores com informações abrangentes e essenciais sobre a performance organizacional, procurando balancear o predomínio no uso de indicadores financeiros.

No BSC, além das medidas financeiras, Kaplan e Norton (1992) propõem outras três perspectivas para avaliar o desempenho organizacional: clientes, processos internos e inovação e aprendizagem, também denominada perspectiva de aprendizado e crescimento. A lógica de utilização do BSC prevê que sejam desenvolvidos objetivos, medidas, metas e iniciativas para cada perspectiva, explicadas no Quadro 3. 
Quadro 3 - Perspectivas de avaliação do desempenho organizacional no BSC

\begin{tabular}{|c|c|}
\hline Perspectiva & Definição \\
\hline Financeira & $\begin{array}{l}\text { Considera o quanto a empresa cria valor e está } \\
\text { associada a bons indicadores financeiros, como } \\
\text { rentabilidade, crescimento e valor para o acionista. }\end{array}$ \\
\hline Clientes & $\begin{array}{l}\text { Ocupa-se dos mercados e clientes que as organizações } \\
\text { se propõem a atender e incluem medidas como } \\
\text { satisfação dos clientes, retenção de clientes, aquisição } \\
\text { de novos clientes, lucratividade dos clientes e } \\
\text { participação de mercado. }\end{array}$ \\
\hline Processos internos & $\begin{array}{l}\text { Integra os processos internos críticos nos quais a } \\
\text { organização deve alcançar a excelência, estabelecendo } \\
\text { medidas que permitam gerenciar a cadeia de valor da } \\
\text { empresa. Nessa perspectiva, devem ser incorporados } \\
\text { os processos de inovação e operacionais. }\end{array}$ \\
\hline Inovação e aprendizagem & $\begin{array}{l}\text { Identifica a infraestrutura que a empresa deve } \\
\text { construir para gerar crescimento e melhoria a longo } \\
\text { prazo, incluindo capacitação dos empregados, } \\
\text { sistemas de informações de capacitações e motivação, } \\
\text { empowerment e alinhhamento. }\end{array}$ \\
\hline
\end{tabular}

Fonte: Adaptado de Fernandes (2006).

\subsection{Aprendizagem organizacional}

As organizações são criadas e compostas por pessoas e perpetuam-se por meio delas. As pessoas são os alicerces da organização e utilizam suas habilidades, capacidades, experiências e conhecimentos como ferramentas para conseguir novos recursos e alcançar os resultados esperados pela empresa (KNAPIK, 2008). Pessoas são curiosas e, como seres sociais, são motivadas a interagir e aprender umas com as outras, compartilhando informações e sintetizando conhecimentos, promovendo o progresso individual e coletivo (GHOSHAL; TANURE, 2004).

Para conseguir um desempenho sustentado, as organizações precisam valorizar e buscar o aprendizado contínuo por meio das pessoas e, sob o ponto de vista de Ghoshal e Tanure (2004, p. 197), os empresários devem "olhar a empresa como uma instituição voltada ao aprendizado e reconhecer que a fonte da vantagem competitiva é a capacidade que as pessoas têm de aprimorar constantemente seus conhecimentos, seus talentos e suas capacidades".

Carvalho (1999) afirma que a única forma da sociedade organizacional manter sua vitalidade, principalmente em um ambiente de mudanças contínuas e imprevisíveis, é por meio de um constante processo de aprendizagem, que consiste na aquisição de conhecimento, distribuição, interpretação e retenção da informação dentro da organização. A aprendizagem organizacional caracteriza-se pela interação entre pessoas e suas criações, neste caso, as empresas, que desenvolvem a capacidade de se modificarem, adaptando-se e criando alternativas para a 
solução de problemas e tomadas de decisão. Ainda citando Carvalho (1999), essa adaptação envolve modificações das organizações e pessoas envolvidas, ou seja, a empresa "aprende", como condição de sua própria sobrevivência.

A literatura da aprendizagem organizacional tem-se concentrado na observação e análise distanciada dos processos envolvidos em aprendizagem individual e coletiva, tanto dentro como entre organizações. Os principais autores dessa teoria enfatizam a aprendizagem como um processo técnico ou social onde, na visão técnica, uma organização aprende quando consegue reconhecer que o conhecimento adquirido é potencialmente útil para a organização, ao mesmo tempo que o âmbito de seus comportamentos se modifica. Já na perspectiva social, a aprendizagem organizacional focaliza a maneira pela qual as pessoas atribuem significado a suas experiências de trabalho e emerge de interações sociais, normalmente no ambiente de trabalho (EASTERBY-SMITH; BURGOYNE; ARAUJO, 2001).

Sendo a aprendizagem organizacional um processo de internalização de informações internas e externas que serão utilizadas nas tomadas de decisão e solução de problemas organizacionais, dentro de poucos anos irá assumir um papel central na seleção de estratégias administrativas com o objetivo de melhorar o desempenho das empresas. Nesse contexto, muitas empresas estão buscando desenvolver sistemas formais de internalização de informações, com o objetivo de registrar todos os eventos importantes em um banco de dados (HAIR JR. et al., 2005).

Para delineamento da pesquisa, o constructo de capacidade de absorção foi utilizado para investigar os microprocessos de aprendizagem nos relacionamentos interorganizacionais, visto que o estudo da capacidade de absorção por meio de suas quatro dimensões possibilita enxergar a contribuição e relação de cada uma com o processo de aprendizagem organizacional (PICOLI; TAKAHASHI, 2016).

\subsection{Gerenciamento de processos de negócio}

De acordo com Teece, Pisano e Shuen (1997), o conceito de capacidades dinâmicas têm como essência os processos organizacionais da firma (jeito da empresa de fazer as coisas, ou seja, as rotinas e padrões de práticas e aprendizados da organização), que são, por sua vez, formados pelas posições (recursos e ativos disponíveis) e moldados pela própria evolução da história da firma (caminhos já percorridos pela empresa, considerando as ameaças e oportunidades produtivas identificadas). Analogamente, Zahra e George (2002) adotam uma perspectiva de processo sobre a capacidade de absorção, enfatizando o aproveitamento do conhecimento externo e a combinação com o conhecimento interno da firma, para influenciar os resultados 
organizacionais. Os autores afirmam que a capacidade de absorção é vista como uma capacidade dinâmica embutida em rotinas e processos de uma empresa, tornando possível analisar os estoques e fluxos de conhecimento, relacionando essas variáveis para a criação e sustentabilidade de vantagem competitiva. Como pode-se observar, existe uma relação latente entre o constructo capacidade de absorção e gerenciamento de processos de negócio.

O gerenciamento de processos de negócio, mais conhecido pelo termo em inglês Business Process Management (BPM) é uma abordagem gerencial e um conjunto de tecnologias que provê suporte ao gerenciamento por processos, que por sua vez está envolvido com o gerenciamento do desempenho corporativo. Cada vez mais, defende-se que é o desempenho de processos interfuncionais, e não de áreas funcionais ou um conjunto de ativos, que deve ser o foco central para a organização alcançar verdadeiros resultados (ABPMP, 2013). O BPM e as tecnologias habilitadoras amadureceram consideravelmente nas últimas três décadas, destacando que há uma vasta oferta de livros, artigos, apresentações, modelos de processo e melhores práticas, os quais são baseados em experiência prática, estudos acadêmicos e lições aprendidas (ABPMP, 2013; ROSEMANN, 2014).

O BPM tem suas raízes nos conceitos de gerenciamento de qualidade total (TQM) e reengenharia de processos de negócios (BPR). Pode ter vários significados, que vão desde uma abordagem Plan-Do-Check-Act-Lifecycle para uma abordagem de gestão (ROESER; KERN, 2015) onde, neste estudo, considera-se o BPM como uma abordagem de gestão focada em processos de negócio. Kohlborn et al. (2014), em sua entrevista com o especialista Michael Rosemann, chama a atenção para o fato de que a maior parte do trabalho acadêmico em BPM e sua aplicação prática em diversas organizações é focado em ferramentas, sistemas e técnicas e menos nos desafios gerenciais, organizacionais, estratégicos ou culturais de BPM.

Sob esse aspecto, o estudo de Iritani et al., (2015) contribuiu para um maior entendimento sobre as origens e tendências da área de BPM, destacando essa abordagem gerencial como um modelo de gestão que deve atuar tanto nos níveis estratégicos como nos níveis operacionais das organizações, podendo ser compreendida como uma abordagem para identificar, desenhar, executar, documentar, medir, monitorar, controlar e melhorar os processos de negócio para que os resultados desejados possam ser alcançados.

\subsubsection{Processos de negócio}

Para compreender o conceito de processos de negócio é necessário compreender a definição e contexto de alguns termos. Processos são compostos por atividades inter-relacionadas que 
solucionam uma questão específica. Essas atividades são subordinadas a regras de negócio e vistas no contexto de seu relacionamento com outras atividades, fornecendo uma visão de sequência e fluxo. Negócio abrange todos os tipos de organizações com ou sem fins lucrativos, públicas ou privadas, de qualquer porte e segmento de negócio, com o propósito de prover produtos, informações ou serviços (ABPMP, 2013).

Os processos de negócios descrevem como as empresas se organizam para realizar um determinado trabalho. Em uma concepção mais genérica, processos de negócio são qualquer conjunto de atividades realizadas por uma organização, sendo iniciados por um evento, transformando informações, materiais ou compromissos comerciais e produzindo uma saída de valor para a organização ou partes interessadas do processo (BPTRENDS, 2017). Esse trabalho organizado entrega valor para os clientes ou apoia/gerencia outros processos, podendo ser ponta a ponta, interfuncional e até mesmo interorganizacional (ABPMP, 2013). Não há uma classificação (taxonomia) única de processos, porém, o Quadro 4 mostra algumas definições para termos distintos, mas que são usualmente relacionados com processos de negócio.

Quadro 4 - Conceitos básicos relacionados a processos de negócio

\begin{tabular}{|c|c|}
\hline Conceito & Definições \\
\hline Atividade & $\begin{array}{l}\text { Termo genérico para o trabalho desempenhado pela empresa. Processos, } \\
\text { subprocessos e tarefas são tipos de atividades. }\end{array}$ \\
\hline Tarefa & $\begin{array}{l}\text { Tarefa é uma atividade incluída num processo. No modelo de processos, } \\
\text { a tarefa é o desdobramento máximo do trabalho executado no processo. }\end{array}$ \\
\hline Processo & $\begin{array}{l}\text { Qualquer atividade desempenhada pela organização. No modelo de } \\
\text { processos, é retratada como uma rede constituída por outras atividades em } \\
\text { fluxo e por seus respectivos controles de sequenciamento (eventos e } \\
\text { junções). Um processo de negócio contém um ou mais processos. }\end{array}$ \\
\hline Evento & $\begin{array}{l}\text { Algo que "acontece" no curso do processo de negócio, influenciando seu } \\
\text { fluxo. Há o evento inicial, o evento final e eventos intermediários. }\end{array}$ \\
\hline
\end{tabular}

Fonte: Valle e Oliveira (2016, p. 9).

Os processos de negócio podem ser classificados em três tipos, de acordo com a Association of Business Process Management Professionals (ABPMP, 2013): a) processo primário; b) processo de suporte; c) processo de gerenciamento. Enquanto o processo primário caracterizase como interfuncional ponta a ponta, agregando valor diretamente ao cliente, o processo de gerenciamento tem o propósito de medir, monitorar, controlar atividades e administrar o presente e o futuro do negócio. Destaca-se, para realização deste trabalho, o estudo dos processos de suporte, que tem como função entregar valor para outros processos e não diretamente para os clientes, sendo fundamentais e estratégicos para a organização na medida em que aumentam sua capacidade de efetivamente realizar os processos primários e de gerenciamento (ABPMP, 2013). Sendo as atividades de inovação etapas científicas, 
tecnológicas, organizacionais, financeiras e comerciais que conduzem, ou visam conduzir, à implementação de inovações, segundo o Manual de Oslo (OECD, 2005), pode-se inferir que a análise dos processos de negócio de suporte pode auxiliar a compreensão e operacionalização do conceito de capacidade de absorção aplicado às organizações que buscam vantagens competitivas, considerando a inovação como um processo primário.

\subsubsection{Ciclo de gerenciamento de BPM}

A implantação do gerenciamento de processos de negócio em organizações varia conforme a maturidade e estrutura organizacional da empresa, porém, pode-se utilizar um modelo ou ciclo de gerenciamento de BPM para embasar as discussões (VALLE; OLIVEIRA, 2016), conforme mostra a Figura 2.

Figura 2 - Ciclo de BPM

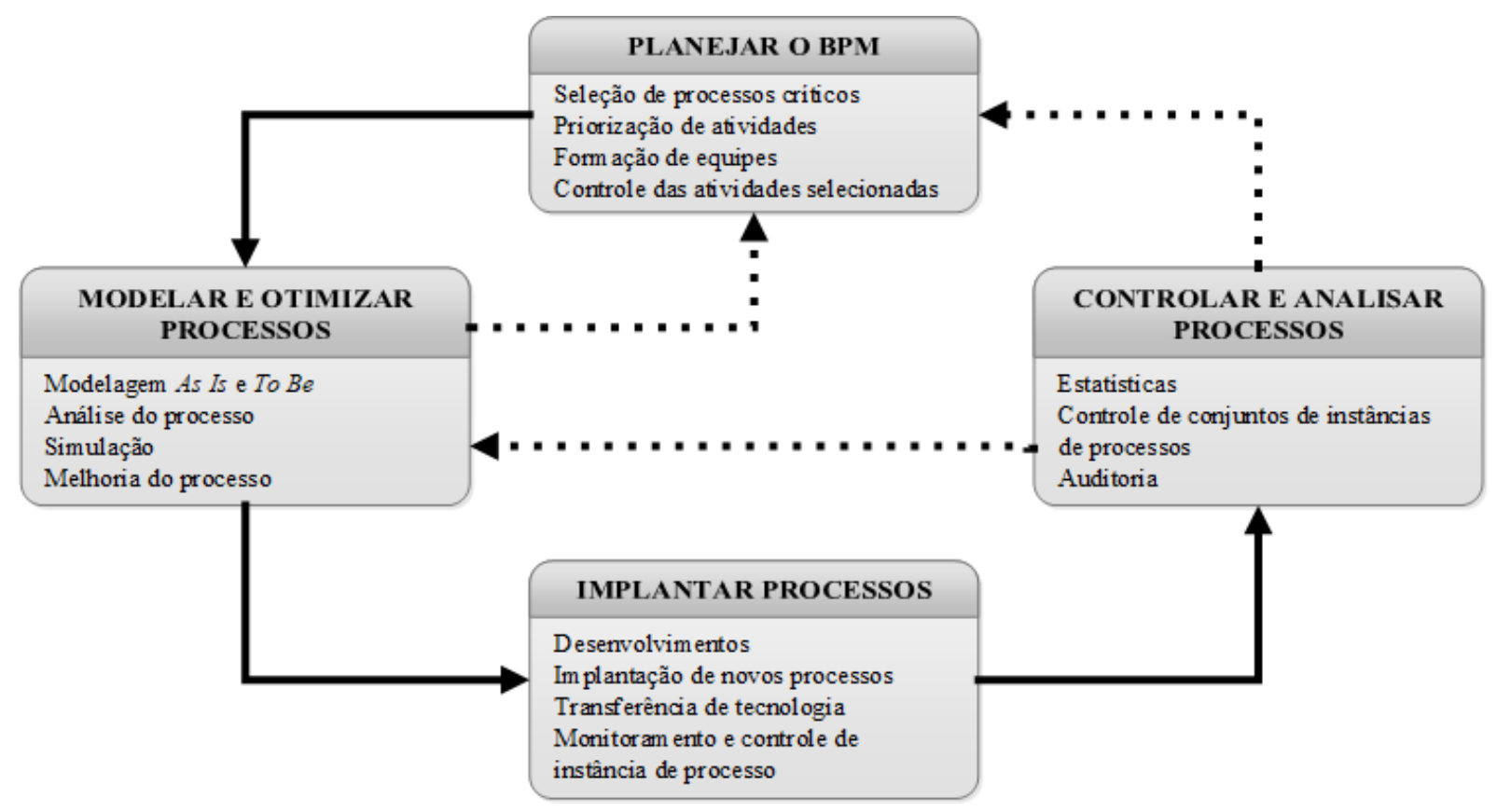

Fonte: Adaptado de Valle e Oliveira (2016).

O ciclo de BPM inicia-se com o planejamento, onde são definidas as atividades de BPM que irão contribuir para o alcance das metas organizacionais, seja da estratégica à operacional. A modelagem e otimização de processos engloba as atividades que permitem gerar informações sobre o processo atual (As Is) e a proposta de processo futuro ( $\mathrm{To} \mathrm{Be}$ ), além de realimentar o planejamento do BPM. A próxima etapa garante suporte à implantação e à execução dos processos, além de estabelecer critérios de fornecimento de dados para controle e análise dos 
processos. Já essa última etapa inclui as atividades relacionadas ao controle geral do processo, gerando informações que posteriormente realimentarão as atividades de otimização e planejamento (VALLE; OLIVEIRA, 2016).

Partindo da base teórica apresentada no ciclo de BPM, a pesquisa empírica buscou evidenciar como o gerenciamento de processos de negócio é utilizado pelas startups para efetiva implementação e realização da capacidade de absorção e obtenção de vantagem competitiva, por meio da análise e modelagem de processos.

\subsubsection{Análise e modelagem de processos}

Valle e Oliveira (2016) afirmam que a evolução dos modelos de gestão está intimamente ligada à capacidade de simular o comportamento das empresas, seu mercado e sua estrutura. Esse movimento ganhou impulso à medida em que avançaram as técnicas de modelagem, bem como toda a estrutura adicional que suporta essas mudanças. A modelagem de processos requer um conjunto de habilidades e técnicas que permitem compreender, comunicar e gerenciar componentes de processos de negócio (ABPMP, 2013).

Sob esse aspecto, a modelagem de processos de negócio compreende um conjunto de atividades envolvidas na criação de representações de processos de negócio existentes ou propostos, podendo ser prover uma perspectiva ponta a ponta ou uma parte dos processos primários, de suporte ou de gerenciamento, segundo a ABPMP (2013, p. 72)

\footnotetext{
O propósito da modelagem é criar uma representação do processo de maneira completa e precisa sobre seu funcionamento. Por esse motivo, o nível de detalhamento e o tipo específico de modelo têm como base o que é esperado da iniciativa de modelagem. Um diagrama simples pode ser suficiente em alguns casos, enquanto um modelo completo e detalhado pode ser necessário em outros.
}

Com o propósito de analisar os processos de negócio que constituem a capacidade de absorção das startups, buscando descrever como são realizados e implementados, este estudo utilizou uma abordagem especializada para a iniciativa de modelar os processos encontrados na pesquisa, proporcionando uma análise de perspectiva organizacional. Tal abordagem envolveu o estilo de documentação SIPOC, que é a sigla para Supplier, Input, Process, Output e Customer, aplicada por meio do preenchimento de uma tabela com os elementos que compõem a sigla, representada na Figura 3. 
Figura 3 - Matriz SIPOC

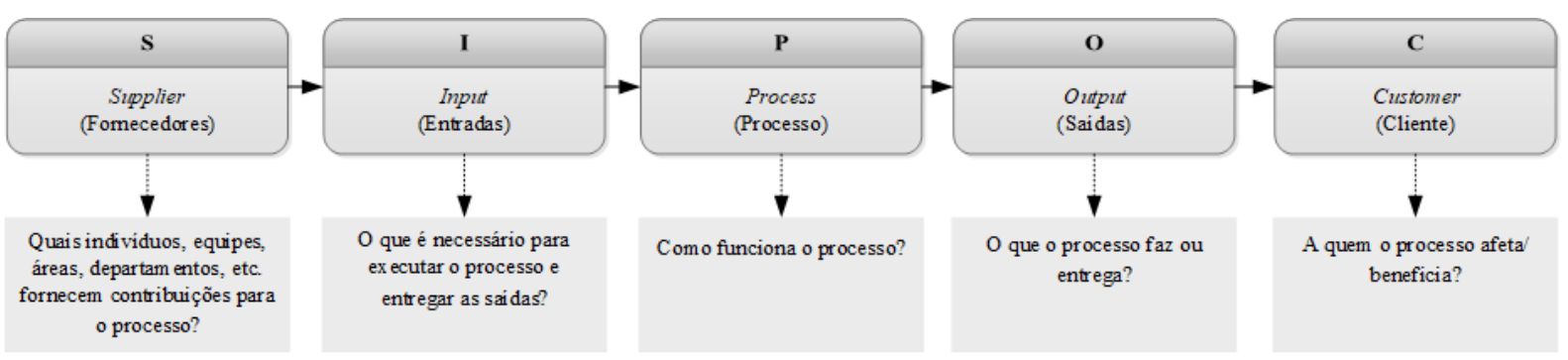

Fonte: Adaptado de ASQ (2018).

O estabelecimento da estrutura SIPOC implica a identificação dos processos de negócio que constituem a capacidade de absorção das startups, sendo uma ferramenta que permite a visualização das entradas e saídas do processo em uma forma tabular.

\subsection{Relação entre gerenciamento de processos de negócio e capacidade de absorção}

É importante ressaltar que, neste estudo, assume-se que existe uma relação entre o constructo capacidade de absorção e o gerenciamento de processos de negócio. Tal afirmação foi identificada por meio de uma revisão sistemática da literatura realizada no mês de setembro de 2017, cujo objetivo foi identificar e analisar como estava se desenvolvendo os temas capacidade de absorção e gerenciamento de processos de negócio em conjunto, bem como mostrar o estado da arte nessa temática.

O gerenciamento de processos de negócio e seu papel no aumento da capacidade de absorção recebeu atenção especial no trabalho de Manfreda et al. (2012), no qual o gerenciamento de processos e seus benefícios manifestaram-se especificamente em termos de capacidade dos funcionários para entender o trabalho de outros, propor novas mudanças ou aceitar as propostas de outros, todos eles aumentando o nível de capacidade de absorção. Uma capacidade de absorção elevada denota que as organizações podem aprender a usar novos conhecimentos em seus processos e implementar mudanças que melhorem suas operações.

Para Srivardhana e Pawlowski (2007), o nível de capacidade de absorção de uma empresa não é simplesmente uma soma das "capacidades de absorção" de funcionários individuais e uma empresa não pode depender apenas de seus funcionários para desenvolver a capacidade de absorção. A fim de melhorar e sustentar a capacidade de absorção, as empresas devem ir além das estratégias de desenvolvimento humano para desenvolver rotinas e processos organizacionais para adquirir, assimilar, transformar e explorar o conhecimento e nesse contexto, entra um vasto conjunto de técnicas de análise de processos como o Lean 
Management, Six Sigma, Workflow Management e Process Modeling, para citar alguns exemplos.

Gutiérrez, Bustinza e Molina (2012) consideram o gerenciamento de processos importantes práticas de Six Sigma e observam seus efeitos positivos sobre o desempenho organizacional, por meio da capacidade de absorção. Como consequência, visualizar o Six Sigma através da lente do gerenciamento do conhecimento e da aprendizagem organizacional pode levar a insights sobre como criar, reter e difundir o conhecimento usando um método estruturado. $\mathrm{O}$ gerenciamento de processos Six Sigma procura detectar e corrigir erros, estimulando a absorção de conhecimento sobre processos, a medida em que a criação de conhecimento ocorre por meio da aprendizagem gerada pelos processos formais de melhoria. O conhecimento também pode ser criado mediante a resolução de problemas de forma programável, como por exemplo, uma sequência de etapas e um conjunto de ferramentas. Assim, o uso de procedimentos e técnicas estruturadas, bem como ferramentas associadas ao gerenciamento de processos Six Sigma facilitam a aquisição de conhecimento, pois a existência de uma linguagem comum, metas ou ferramentas compartilhadas, etc., favorecem a absorção do conhecimento.

Corroborando com o pensamento de Manfreda et al. (2012), Gutiérrez, Bustinza e Molina (2012) argumentam que vários estudos observaram que o uso de mecanismos para integrar os trabalhadores tem um efeito positivo na capacidade de absorção, levando em consideração o gerenciamento de processos incluídos na metodologia Six Sigma. As equipes que utilizam mecanismos de comunicação lateral, que facilitam o fluxo de conhecimento por meio de fronteiras funcionais, permitem que os funcionários combinem o conhecimento existente ao adquirido recentemente, auxiliando a integrar os diferentes corpos de conhecimento e a criar rotinas dentro das unidades.

Um dos fatores mais importantes que influenciam o sucesso do processo de absorção é a existência de conhecimento anterior relacionado com o novo conhecimento que irá ser absorvido. O conhecimento prévio facilita a aprendizagem, pois a memória ajuda a estabelecer relações entre conceitos novos e existentes e a gestão de processos pode ajudar a gerar e armazenar informações sobre o funcionamento dos processos organizacionais, a fim de melhorá-los posteriormente. A gestão de processos impulsiona a fase de transformação do conhecimento, por meio do desenvolvimento de rotinas que permitem uma melhor absorção dos novos conhecimentos provenientes de fontes externas e facilitam a combinação do conhecimento de outras fontes, como clientes, fornecedores ou concorrentes aos conhecimentos já adquiridos e assimilados (GUTIÉRREZ; BUSTINZA; MOLINA, 2012). 
Manfreda et al. (2012) ressaltam que a capacidade de absorção pode ser usada para dar suporte à criação de conhecimento em cadeias de fornecimento ligadas à tecnologia da informação e processos de negócio que suportam parcerias interorganizacionais eficazes. Os autores afirmam que as empresas organizam seus processos e infraestruturas de tecnologia da informação para construir capacidade de assimilar e explorar recursos de informação, onde os mecanismos de processos interorganizacionais podem influenciar a capacidade de absorção, permitindo uma melhor aquisição e assimilação de informações externas.

Srivardhana e Pawlowski (2007) destacam que a capacidade de absorção não depende apenas da disponibilidade de novos conhecimentos ou informações, mas os membros da organização também precisam da capacidade de transmitir sua aprendizagem entre si e desenvolver estruturas cognitivas comuns sobre a aplicação do conhecimento compartilhado. Em última análise, o desenvolvimento da capacidade de absorção pode proporcionar às organizações condições favoráveis para a construção de novas capacidades para criar e implantar conhecimento, melhorando os processos de negócios.

Pode-se afirmar, então, que existe uma relação entre os dois temas, com base na revisão sistemática da literatura, onde o gerenciamento de processos de negócio pode auxiliar a operacionalizar e potencializar os processos de aprendizagem organizacional, por meio da capacidade de absorção, da mesma forma que o desenvolvimento da capacidade de absorção pode proporcionar às organizações condições favoráveis para melhoria contínua dos processos críticos. Sendo a capacidade de absorção um conjunto de rotinas que envolvem a capacidade das empresas em iniciar mudanças a partir de dentro, bem como identificar e assimilar as ideias do ambiente externo, a gestão de processos de negócio conduz à aplicação sistemática destas rotinas organizacionais específicas e processos que constituem a capacidade de absorção das empresas, para geração de valor e vantagem competitiva.

\subsubsection{Influências e efeitos do BPM no desenvolvimento da capacidade de absorção}

O Quadro 5 apresenta uma síntese dos resultados encontrados na revisão sistemática da literatura, relacionando a influência e os efeitos do gerenciamento de processos de negócio no desenvolvimento da capacidade de absorção tanto potencial quanto realizada, em cada etapa do ciclo de BPM. 
Quadro 5 - Influência do ciclo de BPM no desenvolvimento da capacidade de absorção

\begin{tabular}{|c|c|c|c|}
\hline & & Capacidade de Absorção Potencial & Capacidade de Absorção Realizada \\
\hline \multirow{4}{*}{ 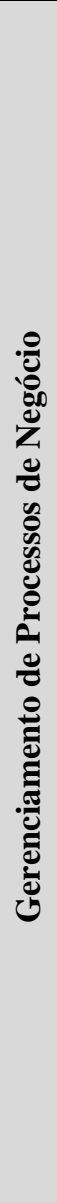 } & 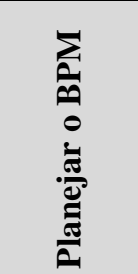 & $\begin{array}{l}\text { - Promove a criação de estruturas cognitivas comuns entre funcionários } \\
\text { de diferentes áreas funcionais } \\
\text { - Aumenta a boa vontade dos funcionários, à medida em que esses } \\
\text { diferentes indivíduos ficam mais dispostos a cooperar }\end{array}$ & \\
\hline & 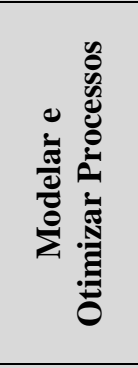 & $\begin{array}{l}\text { - Aumenta a capacidade dos funcionários para entender o trabalho dos } \\
\text { outros } \\
\text { - Promove a disseminação do conhecimento e aumento da experiência } \\
\text { entre os empregados } \\
\text { - Facilita a aquisição de conhecimento por meio do uso de } \\
\text { procedimentos e técnicas estruturadas } \\
\text { - Facilita a comunicação entre os trabalhadores, desenvolve uma } \\
\text { linguagem compartilhada, elimina possíveis conflitos e mal-entendidos } \\
\text { e aumenta a coesão das equipes }\end{array}$ & $\begin{array}{l}\text { - Aumenta a capacidade dos empregados em propor novas mudanças ou } \\
\text { aceitar novas propostas } \\
\text { - Promove o uso de mecanismos para integrar os trabalhadores, } \\
\text { permitindo a combinação do conhecimento existente ao adquirido } \\
\text { recentemente }\end{array}$ \\
\hline & 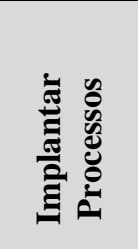 & $\begin{array}{l}\text { - Prepara e treina funcionários para implementação da nova } \\
\text { metodologia e futuras mudanças }\end{array}$ & $\begin{array}{l}\text { - Promove uma mudança cultural na organização } \\
\text { - Integra os diferentes corpos de conhecimento e cria rotinas dentro da } \\
\text { organização, por meio das interfaces multifuncionais }\end{array}$ \\
\hline & 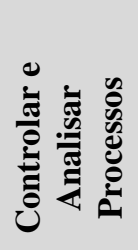 & $\begin{array}{l}\text { - Estimula os contatos formais e informais entre funcionários e } \\
\text { consultores externos } \\
\text { - Melhora a aprendizagem por meio da detecção e correção de erros, } \\
\text { auxiliando a resolução de problemas de forma programável }\end{array}$ & \\
\hline
\end{tabular}

Fonte: Gutiérrez, Bustinza e Molina (2012); Manfreda et al. (2012). 
A contribuição dos resultados da revisão sistemática da literatura reside na observação dessa relação no contexto das iniciativas de implementação do gerenciamento de processos de negócio, estabelecendo assim uma conexão entre as práticas de gerenciamento de processos de negócio e o aprendizado organizacional, por meio da capacidade de absorção. As evidências encontradas nos estudos demonstram que a modelagem e otimização de processos, bem como a etapa de implantação dos processos exercem uma influência significativa no desenvolvimento da capacidade de absorção tanto potencial quanto realizada.

\subsection{Relacionamentos interorganizacionais}

Barringer e Harrison (2000) explicam que, embora a literatura sobre relações interorganizacionais seja extensa, existe um tema generalizado na maioria dos estudos, onde questiona-se se as relações interorganizacionais fazem sentido e se as vantagens superam as desvantagens. Com base nessa premissa, os autores abordam seis paradigmas teóricos amplamente utilizados e que explicam a formação de relacionamentos interorganizacionais, incluindo economia de custos de transação, dependência de recursos, escolha estratégica, teoria de partes interessadas, aprendizado organizacional e teoria institucional.

O aprendizado organizacional modela o recorte teórico deste estudo, pois as empresas formam parcerias para capitalizar as oportunidades de aprendizagem organizacional e, como já foi visto anteriormente, a inovação é um processo baseado no conhecimento. O Manual de Oslo (OECD, 2005) enfatiza o papel das interações entre empresas no processo de inovação, em virtude da importância dos fluxos de conhecimento entre as organizações para o desenvolvimento e a difusão de inovações.

Segundo Freeman (1995) são raras as organizações que conseguem inovar isoladamente porque, em geral, o processo de inovação não depende única e exclusivamente de competências internas, mas, em grande parte, do uso complementar da diversidade de competências, geralmente externas às organizações. $\mathrm{O}$ autor supracitado esclarece que estas competências são desenvolvidas e acumuladas a partir de interações econômicas e sociais com diversos atores externos, culminando em geração/criação de conhecimento novo. Essa perspectiva integrada do processo de inovação conduz os pesquisadores a buscarem identificar estes outros atores e, sobretudo, de que forma ocorrem estas alianças organizacionais. $\mathrm{O}$ crescente interesse nas redes de colaboração para inovação representa um fenômeno econômico relevante e consequentemente, gestores e profissionais estão cada vez mais sendo solicitados a descobrirem opções estratégicas para criar e capturar valor nas relações de rede (DAGNINO et al., 2015). 


\subsubsection{Redes de colaboração}

Nos últimos anos, grandes empresas em diferentes segmentos criaram redes globais de parceiros ou ecossistemas para aumentar o alcance de mercado e variedade de seus produtos, serviços e tecnologia (NAMBISAN; BARON, 2013). Muitas destas empresas, segundo Gereffi, Humphrey e Sturgeon (2005) têm como estratégia a externalização de atividades secundárias (não core) junto às startups, com o objetivo de desenvolver formas de exercer e preservar um poder de mercado sem os custos fixos inerentes à manutenção de uma estrutura organizacional complexa. Além da fragmentação geográfica das redes de produção, com objetivo de reduzir custos, as organizações de grande porte têm cada vez mais deslocado iniciativas de inovação para redes externas (NAMBISAN; SAWHNEY, 2011), visando complementar recursos internos, ampliar o âmbito e a velocidade das capacidades de inovação e geração de valor, atender as expectativas dos consumidores e sustentar uma vantagem competitiva, como afirma Catalina e Marin (2012). A esse respeito, Nambisan e Baron (2013) esclarecem que os ecossistemas de inovação se referem a uma rede interconectada de empresas e outras entidades, que desenvolvem de forma compartilhada um conjunto de tecnologias, conhecimentos ou habilidades, trabalhando cooperativamente para desenvolver novos produtos e serviços.

Quase todas as inovações exigem algum tipo de arranjo cooperativo para seu desenvolvimento ou comercialização e uma empresa terá múltiplos motivos para realizar uma aliança com outra organização (TIDD; BESSANT; PAVITT, 2008). Essencialmente, empresas colaboram para reduzir custos, tempo ou risco de acesso a tecnologia e mercados que não lhe são familiares, da mesma forma que analisam o trade-off entre desenvolver uma inovação internamente ou por meio de mecanismos externos. A terceira edição do Manual de Oslo (OECD, 2005) reforça o aumento das interações entre empresas e instituições no processo de inovação, destacando também a importância dos fluxos de conhecimento entre organizações, para o desenvolvimento e a difusão de inovação.

Existem dois modos muito distintos da empresa abordar seus relacionamentos, de acordo com Ghoshal e Tanure (2004). O primeiro modo de relacionamento utiliza-se do uso do poder de compra e da capacidade de barganha para conseguir resultados, seja para reduzir custos ou para aumentar capacidade de agregar valor. Este tipo de relacionamento baseado no poder representa uma relação ganha-perde, ou seja, uma situação em que um lado ganha e o outro perde. O outro modo de relacionamento é construído com base na confiança mútua e num comprometimento com a interdependência das duas ou mais partes, exigindo capacidade de aprender e de resolver problemas juntos. 
Nessas redes de colaboração, alguns casos estão se destacando, como as alianças entre grandes empresas e startups. Quando se trata de agilidade, startups têm uma vantagem adicional sobre as grandes corporações, ao passo que as grandes corporações possuem controle sobre recursos que as startups estão longe de alcançar. Percebe-se uma tendência, na qual as grandes corporações começaram a enxergar oportunidades de inovação empresarial nas startups, substituindo capital próprio por tecnologia compartilhada, para conectar dois mundos com menos custos organizacionais e maior velocidade e agilidade (WEIBLEN; CHESBROUGH, 2015). Estudos recentes mostram traços opostos de inovação entre grandes empresas e startups, sugerindo que essas últimas precisam de colaboração para entrada no mercado com suas novas tecnologias e que as grandes empresas possuem sucesso tecnológico com base em sua grande escala de mercado e canais de distribuição. Esses traços opostos, não obstante, implicam em possibilidades vantajosas de inovação aberta complementar entre grandes empresas e startups (JANG; LEE; YOON, 2017).

Em última análise, no seu artigo seminal, Freeman (1991) define organização em rede como um arranjo institucional básico para lidar com a inovação sistêmica, ressaltando a importância das relações de cooperação entre as empresas. Acrescenta também que essas relações não são exclusivas às grandes empresas, de modo que pequenas organizações também estão envolvidas nessas redes de colaboração. As grandes empresas enfrentam desafios de competir em mercados globais em constante mudança, por exemplo, ao passo que pequenas empresas são geralmente flexíveis e capazes de responder mais rapidamente às novas necessidades, na afirmação de Lawton Smith, Dickson e Smith (1991).

\subsection{Modelo conceitual}

Com base nos argumentos já considerados na introdução deste estudo, há uma falta de observação direta ou análise dos processos que compõem a capacidade de absorção de startups que se relacionam com grandes empresas, para obtenção de vantagem competitiva. Assim, a questão de pesquisa procura responder como as startups absorvem conhecimento das grandes empresas, buscando descrever os processos de negócio relacionados à operacionalização do conceito de capacidade de absorção nas startups. A Figura 4 mostra o modelo conceitual adotado neste estudo. 


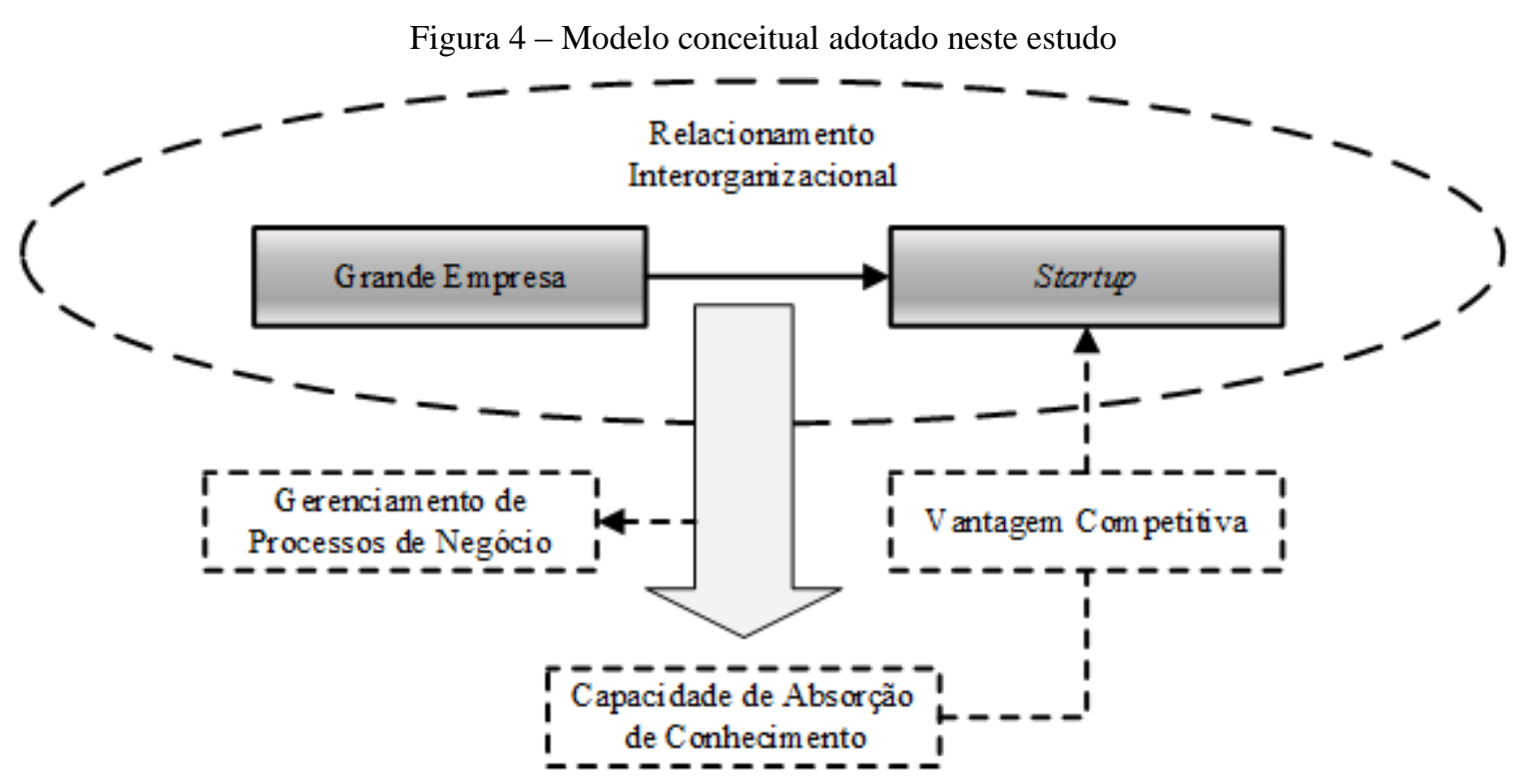

Fonte: Elaborado pelo autor.

O conjunto de rotinas organizacionais e processos pelos quais as startups adquirem, assimilam, transformam e utilizam os conhecimentos da grande empresa, para obtenção de vantagem competitiva, foram analisados neste estudo sob a perspectiva do gerenciamento de processos de negócio, como o objetivo de fornecer uma compreensão de como a capacidade de absorção ocorre nas startups que mantém relacionamentos interorganizacionais com grandes empresas. 


\section{MÉTODO}

De acordo com Lakatos e Marconi (2007) método é o conjunto das atividades sistemáticas e racionais que, com maior segurança, permite alcançar os objetivos. Os métodos de pesquisa constituem as etapas mais concretas da investigação, com finalidade mais restrita em termos de explicação geral dos fenômenos menos abstratos. Existem diferentes métodos de pesquisa e cada um apresenta uma maneira diferente de coletar e analisar evidências empíricas, seguindo sua própria lógica e seus procedimentos (YIN, 2015).

O Quadro 6 apresenta o resumo dos métodos de pesquisa empregados neste trabalho e nas próximas seções, o detalhamento desses métodos.

Quadro 6 - Resumo dos métodos de pesquisa empregados no trabalho

\begin{tabular}{|l|l|l|l|l|}
\hline $\begin{array}{c}\text { Tipo e } \\
\text { Abordagem da } \\
\text { Pesquisa }\end{array}$ & \multicolumn{1}{|c|}{$\begin{array}{c}\text { Métodos de } \\
\text { Pesquisa }\end{array}$} & \multicolumn{1}{|c|}{$\begin{array}{c}\text { Fontes de } \\
\text { Informação }\end{array}$} & $\begin{array}{c}\text { Técnicas de } \\
\text { Coleta de Dados }\end{array}$ & $\begin{array}{c}\text { Técnicas de } \\
\text { Análise de Dados }\end{array}$ \\
\hline $\begin{array}{l}\text { Empírica; } \\
\text { Exploratória; } \\
\text { Qualitativa. }\end{array}$ & $\begin{array}{l}\text { Pesquisa } \\
\text { bibliográfica; } \\
\text { Estudo de caso. }\end{array}$ & $\begin{array}{l}\text { Pesquisa de campo; } \\
\text { Pesquisa survey; } \\
\text { Pesquisa } \\
\text { bibliográfica. }\end{array}$ & $\begin{array}{l}\text { Pesquisa survey; } \\
\text { Entrevista; } \\
\text { Observação não- } \\
\text { participante; } \\
\text { Análise } \\
\text { documental. }\end{array}$ & $\begin{array}{l}\text { Análise de } \\
\text { conteúdo; } \\
\text { Análise estatística; } \\
\text { Modelagem de } \\
\text { processos de } \\
\text { negócio. }\end{array}$ \\
\hline
\end{tabular}

Fonte: Elaborado pelo autor.

\subsection{Tipo e abordagem da pesquisa}

A pesquisa deste estudo classifica-se como exploratória qualitativa, pois trouxe uma visão geral acerca das parcerias entre grandes empresas e startups, explorando um problema ainda pouco estudado, pois grande parte das pesquisas sobre relacionamentos interorganizacionais para ganho de vantagem competitiva foram realizadas sob a perspectiva das grandes empresas, revelando uma escassez de estudos focados em startups. Ademais, foi investigado como o gerenciamento de processos de negócio pode auxiliar a operacionalizar e potencializar os processos de aprendizagem organizacional, por meio da capacidade de absorção, da mesma forma que foi observado como o desenvolvimento da capacidade de absorção pode proporcionar às organizações condições favoráveis para melhoria contínua dos processos críticos.

Os estudos exploratórios são particularmente utilizados quando a área de investigação pode ser tão nova ou tão vaga que necessite fazer uma exploração, a fim de saber algo sobre um determinado problema. Além disso, variáveis importantes podem não ser conhecidas ou não 
estar totalmente definidas (COOPER; SCHINDLER, 2003) corroborando com o pensamento de Hair Jr. et al. (2005), que afirmam que a pesquisa exploratória é particularmente utilizada quando o pesquisador dispõe de poucas informações sobre o fenômeno que está sendo estudado, orientado os estudos para a descoberta, sem ter a intenção de testar hipóteses específicas de pesquisa.

Flick (2009) explica que a pesquisa qualitativa está consolidada no campo acadêmico relacionado à produção de conhecimento ou a descobertas com propósitos científicos. O mesmo autor argumenta que a pesquisa qualitativa usa o texto como material empírico, assim como notas de campo, entrevistas, conversas, gravações, dentre outras representações, na tentativa de entender ou interpretar os fenômenos em termos dos sentidos que as pessoas lhes atribuem. Em concordância com Bardin (2016), a abordagem qualitativa corresponde a um procedimento mais intuitivo, mais maleável e adaptável a índices não previstos. Este tipo de análise deve ser então utilizado nas fases de lançamento das hipóteses, já que permite sugerir possíveis relações entre os constructos teóricos e uma ou diversas variáveis dos investigados. A pesquisa qualitativa começa com a intenção de explorar uma área específica, coleta dados como observações e entrevistas com o intuito de gerar ideias e hipóteses desses dados, em grande parte através do que é conhecido como raciocínio indutivo (GREENHALGH; TAYLOR, 1997). O estudo de caso é um método de pesquisa reconhecido entre uma variedade de opções da pesquisa qualitativa e pode ser usado para propósitos exploratórios de acordo com Yin (2015) e será explicado na próxima seção.

\subsection{Métodos de pesquisa}

Nesta investigação, a escolha do estudo de caso como método de pesquisa levou em conta as considerações de Yin (2015), que consistem em: a) tipo de questão de pesquisa; b) extensão do controle sobre os eventos comportamentais; c) grau de enfoque sobre os eventos contemporâneos. Em suma, “o estudo de caso é uma investigação empírica que investiga um fenômeno contemporâneo em profundidade e em seu contexto de mundo real, especialmente quando os limites entre o fenômeno e o contexto não puderem ser claramente evidentes" (YIN, 2015, p. 17).

Como em toda pesquisa acadêmica, foi realizada neste estudo a pesquisa bibliográfica relacionada ao tema delimitado, com base em material já publicado, constituído principalmente de livros e artigos científicos. O principal objetivo da pesquisa bibliográfica é fornecer fundamentação teórica ao trabalho, bem como a identificação do estágio atual do conhecimento 
referente ao tema. O Quadro 7 mostra as etapas para a pesquisa exploratória qualitativa definida como estudo de caso.

Quadro 7 - Etapas para a pesquisa exploratória qualitativa definida como estudo de caso

\begin{tabular}{|c|c|}
\hline Formulação do problema & $\begin{array}{l}\text { Nos relacionamentos interorganizacionais entre grandes empresas e } \\
\text { startups, como as startups absorvem conhecimento das grandes } \\
\text { empresas, sob a perspectiva do gerenciamento de processos de } \\
\text { negócio, com o objetivo de criar vantagem competitiva? }\end{array}$ \\
\hline Definição da unidade-caso & $\begin{array}{l}\text { Startups que mantém relacionamento interorganizacional para } \\
\text { inovação com grandes empresas. }\end{array}$ \\
\hline Determinação do número de casos & Caso múltiplo. \\
\hline Elaboração do protocolo & $\begin{array}{l}\text { Documento que trata dos procedimentos a serem adotados na coleta de } \\
\text { dados, destacando o trabalho de campo, questões específicas, previsão } \\
\text { de análise de dados e guia para elaboração do relatório (APÊNDICE } \\
\text { A). }\end{array}$ \\
\hline Coleta de dados & $\begin{array}{l}\text { Entrevistas semiestruturadas, observação direta não-participante, } \\
\text { análise de documentos e pesquisa survey. }\end{array}$ \\
\hline Avaliação e análise dos dados & $\begin{array}{l}\text { Ocorre simultaneamente à coleta de dados, compreendendo a } \\
\text { codificação dos dados, estabelecimento de categorias analíticas, } \\
\text { exibição dos dados, busca de significados e credibilidade, por meio da } \\
\text { análise de conteúdo, análise estatística e classificação de processos. }\end{array}$ \\
\hline Preparação do relatório & $\begin{array}{l}\text { O relatório final deste estudo de caso classifica-se como analítico } \\
\text { linear, pois seguiu uma sequência de capítulos, seções e subtópicos } \\
\text { iniciando com o problema sendo estudado e uma revisão de literatura. } \\
\text { Os subtópicos que seguiram o relatório cobriram os métodos } \\
\text { utilizados, os dados coletados, a análise de dados e as descobertas, } \\
\text { sendo finalizado com as conclusões e suas implicações para o } \\
\text { problema original estudado. }\end{array}$ \\
\hline
\end{tabular}

Fonte: Adaptado de Yin (2015).

\subsection{Coleta de dados}

Foram seguidas as recomendações de Yin (2015) quanto à utilização de estudo de caso para investigar o fenômeno, dentro da realidade vivenciada pelas empresas pesquisadas. As evidências coletadas neste estudo vieram de fontes distintas e potencialmente relevantes, de onde criou-se uma base de dados do estudo de caso para garantir a manutenção de um encadeamento de evidências, de acordo com os princípios para coleta de dados do mesmo autor. A primeira etapa da coleta de dados foi uma pesquisa de levantamento (survey) utilizando um questionário online gerenciado pela ferramenta LimeSurvey (APÊNDICE B), com o objetivo de direcionar o mapeamento em busca de startups que indicassem um grau razoável de capacidade de absorção, além de informações relevantes para caracterizar o relacionamento interorganizacional com a grande empresa. Tanto essa etapa quanto as seguintes foram utilizadas para obtenção de informações e dados primários das startups. 
Em um segundo momento, foram realizadas entrevistas semiestruturadas com os gestores das startups, de onde pode-se obter informações detalhadas que foram utilizadas na análise qualitativa. As entrevistas foram gravadas e transcritas para evitar erros de interpretação, permitindo uma análise mais aprofundada. O roteiro de entrevista, preconizado no protocolo para o estudo de caso (APÊNDICE A), foi baseado na escala de Pavlou e El Sawy (2006), apresentada no Quadro 8.

Quadro 8 - Itens de medição para o constructo capacidade de absorção

\begin{tabular}{|c|c|}
\hline Aquisiç̧̃a & Assimilação \\
\hline $\begin{array}{l}\text { 1. A startup tem sucesso em aprender coisas novas } \\
\text { dentro desse grupo? } \\
\text { 2. A startup possui rotinas efetivas para identificar, } \\
\text { valorizar e importar novas informações e } \\
\text { conhecimentos? }\end{array}$ & $\begin{array}{l}\text { 3. A startup conta com rotinas adequadas para analisar } \\
\text { as informações e os conhecimentos obtidos? } \\
\text { 4. A startup conta com rotinas adequadas para } \\
\text { assimilar novas informações e conhecimentos? }\end{array}$ \\
\hline Transformação & \\
\hline $\begin{array}{l}\text { 5. A startup consegue integrar os conhecimentos } \\
\text { internos já existentes com as novas informações e } \\
\text { conhecimentos adquiridos? } \\
\text { 6. A startup é eficaz em transformar a informação } \\
\text { existente em novos conhecimentos? }\end{array}$ & $\begin{array}{l}\text { 7. A startup consegue explorar com sucesso } \\
\text { informações e conhecimento internos e externos em } \\
\text { aplicações concretas? } \\
\text { 8. A startup é eficaz em utilizar o conhecimento em } \\
\text { novos produtos? }\end{array}$ \\
\hline
\end{tabular}

Fonte: Adaptado de Pavlou e El Sawy (2006).

Além das entrevistas semiestruturadas, foram utilizadas como fontes de evidências a observação direta não-participante e análise de documentos. Com relação a observação direta não-participante, a abordagem ocorreu com o pesquisador fisicamente presente na sede da startup e em contato direto com o gestor da organização, onde foi possível monitorar e registrar aspectos de fatos e comportamentos à medida que ocorreram, com anotações em um diário de campo. Já na análise de documentos, foram acessados diferentes tipos de documentos como atas de reuniões, arquivos incluindo contratos, sites corporativos, artigos de notícias sobre a startup e panfletos do negócio.

A decisão de adotar uma combinação de abordagens qualitativas e quantitativas, nesse caso, a pesquisa survey, levou em consideração que a pesquisa quantitativa pode apoiar a pesquisa qualitativa como uma estratégia de validação dos resultados (FLICK, 2013), fortalecendo a triangulação dos dados.

Verifica-se nesta pesquisa uma combinação de múltiplas fontes de evidências para estudar o mesmo fenômeno, com o intuito de garantir a triangulação dos dados. A finalidade da triangulação é obter a confirmação dos resultados por meio da convergência de diferentes perspectivas. O ponto para onde as perspectivas convergem é visto como representativo da 
realidade (JACK; RATURI, 2006). A Figura 5 apresenta o detalhamento da etapa de coleta de dados de fontes múltiplas.

Figura 5 - Estudo triangulado de fontes de evidências

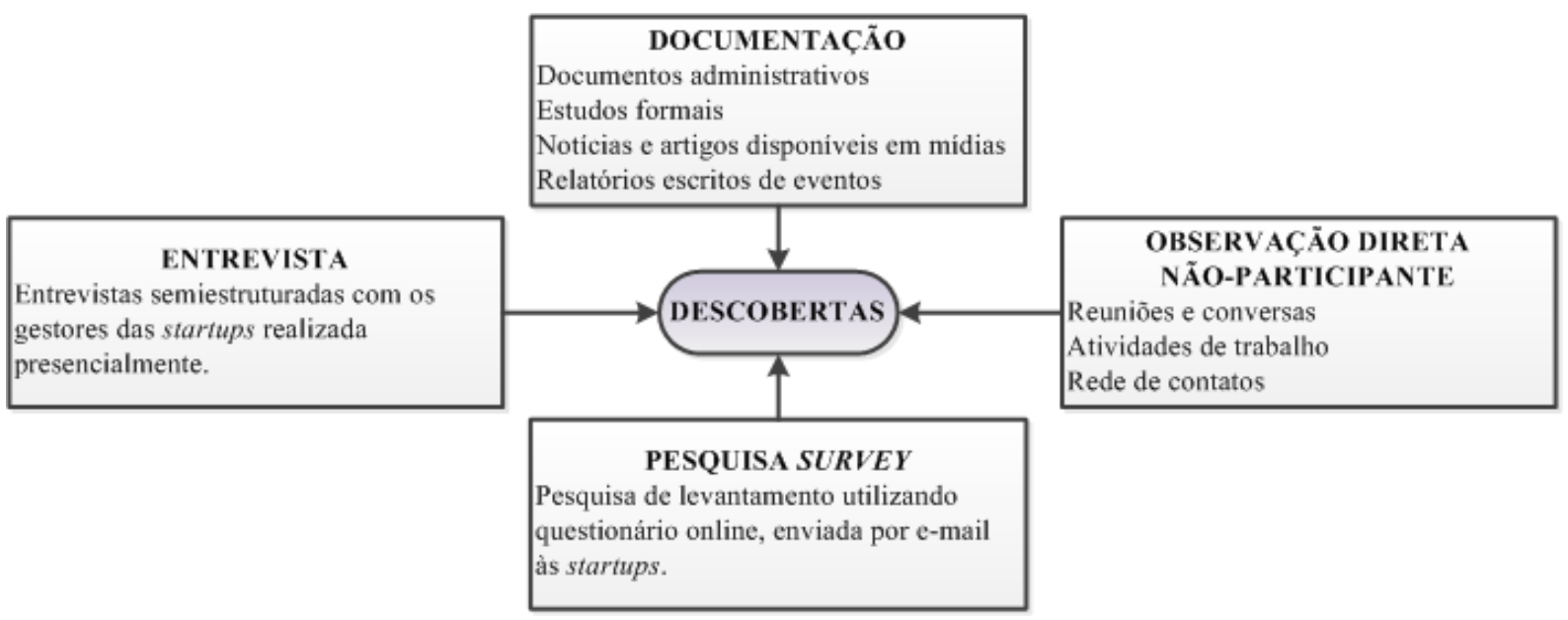

Fonte: Adaptado de Yin (2015).

O estudo triangulado conduz o pesquisador a coletar informações de fontes múltiplas que visem corroborar com a mesma descoberta. Com a convergência de evidências, a triangulação dos dados ajuda a reforçar a validade do constructo do estudo, proporcionando várias avaliações do mesmo fenômeno e assumindo implicitamente uma única realidade (YIN, 2015).

O protocolo para o estudo de caso no Apêndice A apresenta as questões utilizadas nas entrevistas semiestruturadas e o Apêndice B, o questionário online utilizado na pesquisa survey.

\subsection{Análise de dados}

A análise de dados de estudo de caso consiste no exame, na categorização, na tabulação, no teste ou nas evidências recombinadas, para produzir descobertas baseadas em empirismo (YIN, 2015). Seguindo as recomendações do referido autor, foi definida uma estratégia analítica para condução da análise do estudo de caso, bem como técnicas específicas para a análise dos dados coletados.

A análise de conteúdo é considerada uma técnica para o tratamento de dados que visa identificar o que está sendo dito a respeito de determinado tema e Bardin (2016, p. 44) conceitua a análise de conteúdo como "conjunto de técnicas de análise das comunicações que utiliza procedimentos sistemáticos e objetivos de descrição do conteúdo das mensagens”. Operacionalmente, a análise 
de conteúdo organiza-se em torno de três etapas: a) pré-análise; b) exploração do material; c) tratamento dos resultados, inferência e interpretação (BARDIN, 2016).

A pré-análise foi a fase de organização, onde ocorreu a escolha do material que foi submetido à análise, já descritos na etapa de coleta de dados. A formulação das proposições de estudo, variáveis e objetivos serviram de indicadores para fundamentação da interpretação final. A etapa de exploração do material foi a análise propriamente dita e contou com operações auxiliadas por computador, constituída essencialmente pela codificação e categorização das informações coletadas. A Figura 6 ilustra as regras previamente formuladas que conduziram as operações de codificação do material, bem como a visão geral da análise de dados. A codificação é o processo pelo qual os dados brutos, seja um corpo textual ou material audiovisual, são transformados sistematicamente e agregados em unidades, as quais permitem uma descrição exata das características pertinentes do conteúdo (HOLSTI³, 1969 apud BARDIN, 2016).

Figura 6 - Unidades de registro e de contexto na análise categorial temática

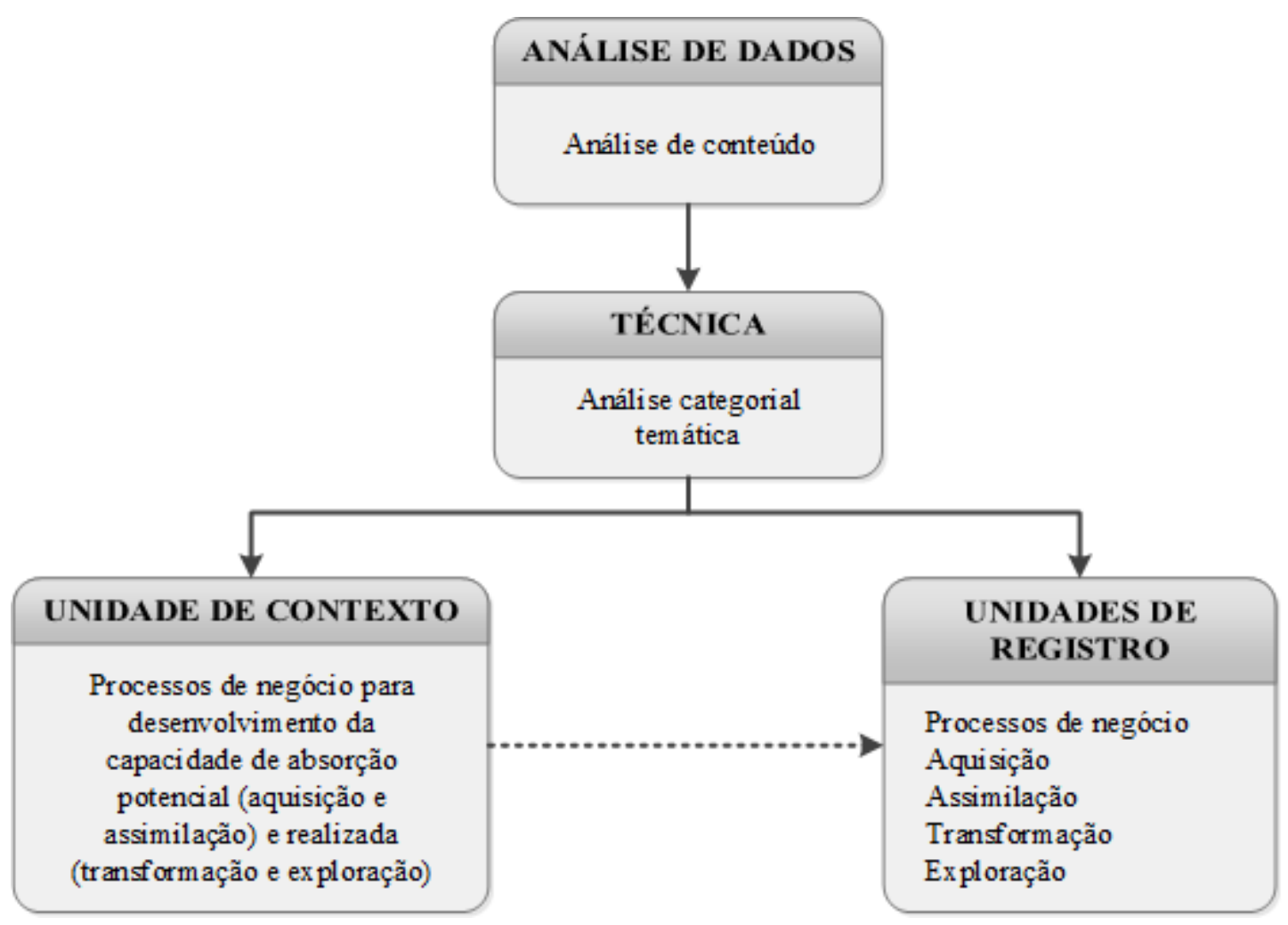

Fonte: Adaptado de Bardin (2016).

\footnotetext{
${ }^{3}$ HOLSTI, O. R. Content analysis for the social sciences and humanities. Addison-Wesley Pub. Co., 1969.
} 
Segundo Bardin (2016, p. 135), “fazer uma análise temática consiste em descobrir os núcleos de sentido que compõem a comunicação e cuja presença, ou frequência de aparição, podem significar alguma coisa para o objetivo analítico escolhido". O tema, enquanto unidade de registro, corresponde a uma regra de recorte deste estudo e foi utilizado para estudar como o gerenciamento de processos de negócio é utilizado pelas startups para desenvolvimento da capacidade de absorção tanto potencial quanto realizada, em suas quatro dimensões.

A última etapa constituiu-se do tratamento dos resultados, a partir de onde o pesquisador propôs inferências e realizou interpretações, inter-relacionando os resultados com o quadro teórico desenhado inicialmente. Essa etapa encontra-se detalhada na seção de apresentação e discussão dos resultados.

A análise estatística dos dados foi utilizada como uma técnica complementar, devido ao uso do método de pesquisa survey para produzir descrições quantitativas das unidades de análise. Utilizou-se uma escala Likert de cinco pontos com uma série de perguntas que, quando combinadas, mediram como as startups exploram e utilizam os conhecimentos obtidos junto à grande empresa, com o propósito de obter vantagens competitivas como inovação, melhoria de desempenho organizacional, etc. Os dados das variáveis quantitativas foram apresentados na forma de valores numéricos, denominados medidas descritivas, destacando as medidas de tendência central.

No que se refere ao uso da informática como ferramenta de auxílio à análise dos dados assistidos por computador (CAQDAS - computer-assisted quantitative data analysis software), evidencia-se neste estudo o uso do software Iramuteq 0.7 alpha 2 (Interface de $R$ pour les Analyses Multidimensionnelles de Textes et de Questionnaires) e NVivo 11 para a análise qualitativa dos dados textuais, auxiliando na codificação dos significados do material reunido. Outro software importante na pesquisa, para a análise estatística dos dados coletados na survey, foi o IBM SPSS Statistics 17.0 utilizado para o cálculo e apresentação das medidas descritivas.

É válido ressaltar que os softwares foram utilizados apenas como apoio ao pesquisador para análise e interpretação dos dados coletados, auxiliando na categorização e busca de significados para construção de cadeias lógicas de evidências.

\subsection{Proposição de estudo e variáveis}

Segundo Yin (2015), a questão elaborada no problema de pesquisa muitas vezes não aponta suficientemente para o que se deve estudar, forçando o pesquisador a estabelecer algumas proposições. Cada proposição dirige a atenção para algo que deve ser examinado dentro do 
escopo do estudo. $\mathrm{O}$ autor defende que o pesquisador deve construir uma questão inicial relativa ao estudo a ser empreendido que, formulada antes do início da coleta de dados, irá auxiliar a cobrir de forma incremental os objetivos e as proposições do estudo, fornecendo critérios para a definição dos dados a serem coletados e estratégias para a sua análise.

Complementando estas afirmações, criam-se proposições na tentativa de verificar a validade de resposta existente para um problema, sendo uma suposição que antecede a constatação dos fatos, tendo como característica uma formulação provisória (LAKATOS; MARCONI, 2007).

A proposição básica de que existe uma relação entre o constructo capacidade de absorção e o gerenciamento de processos de negócio, nos relacionamentos interorganizacionais entre grandes empresas e startups para obtenção de vantagens competitivas, foi traçada com base nas orientações teóricas e ajudou a organizar toda a análise, apontando condições relevantes a serem descritas, bem como explicações a serem examinadas. Para melhor entendimento da relação das proposições com os objetivos e teorias aplicadas, foi elaborada a Figura 7.

Figura 7 - Relação da proposição de estudo com objetivos e teorias aplicadas

\begin{tabular}{|c|c|c|c|}
\hline Objetivo Geral & Objetivos Específicos & Proposição & Embasamento Teórico \\
\hline & $\begin{array}{c}\text { Mapear a rede de } \\
\text { colaboração constituida } \\
\text { pelos relacionamentos } \\
\text { interorganizacionais entre } \\
\text { as startups e grandes } \\
\text { empresas. }\end{array}$ & & \\
\hline $\begin{array}{l}\text { Fornecer um a } \\
\text { compreensão de como a } \\
\text { capacidade de absorção } \\
\text { ocorre nas startups que } \\
\text { mantém relacionam entos } \\
\text { interorganizacionais com } \\
\text { grandes empresas, para } \\
\text { obtenção de vantagem } \\
\text { competitiva. }\end{array}$ & $\begin{array}{c}\text { Descrever como os } \\
\text { processos de negócio são } \\
\text { utilizados pelas startups } \\
\text { para adquirir, assimilar, } \\
\text { tranfform ar e utilizar os } \\
\text { conhecim entos adquiridos } \\
\text { da grande em presa. }\end{array}$ & $\begin{array}{l}\text { Existe um a relação entre o } \\
\text { constructo capacidade de } \\
\text { absorção e o gerenciam ento } \\
\text { de proces sos de negócio, } \\
\text { nos relacionamentos } \\
\text { interorganizacionais entre } \\
\text { grandes empresas e startups } \\
\text { para obtenção de vantagens } \\
\text { competitivas. }\end{array}$ & $\begin{array}{l}\text { Cohen e L evinthal } \\
(1990) \\
\text { Zahra e George (2002) } \\
\text { Srivar dhana e } \\
\text { Pawlow ski (2007) } \\
\text { Gutiérrez, Bustinza e } \\
\text { Molina (2012) }\end{array}$ \\
\hline & $\begin{array}{l}\text { capacidade de absorção } \\
\text { das startups, bem como } \\
\text { sua implem entação e } \\
\text { realização, a fim de } \\
\text { prom over vantagens } \\
\text { competitivas. }\end{array}$ & & \\
\hline
\end{tabular}

Fonte: Elaborado pelo autor.

Por outro lado, variável é um conceito operacional que contém ou apresenta valores. Em uma pesquisa qualitativa, estes valores podem ser qualidades ou características do fenômeno que está sendo estudado, passíveis de mensuração. Na pesquisa científica, ocorrem observações de 
fatos, fenômenos, comportamentos e atividades reais, da mesma maneira que surgem, em um lado oposto, as teorias, hipóteses válidas e sustentáveis. O papel do pesquisador é fazer a ligação entre as teorias e observações, por meio do enunciado das variáveis (LAKATOS; MARCONI, 2007). Definidas as proposições de estudo, são indicadas no Quadro 9 as variáveis que relacionam os objetivos da pesquisa e os dados coletados e analisados. 
Quadro 9 - Indicação das variáveis do estudo

\begin{tabular}{|c|c|c|c|}
\hline Perguntas no Questionário & Constructo das Variáveis & Objetivos Específicos & Trabalhos Acadêmicos Estruturantes \\
\hline $\begin{array}{l}\text { 1. A startup tem sucesso em aprender } \\
\text { coisas novas dentro desse grupo? } \\
\text { 2. A startup possui rotinas efetivas para } \\
\text { identificar, valorizar e importar novas } \\
\text { informações e conhecimentos? }\end{array}$ & $\begin{array}{l}\text { Habilidade da startup em criar processos } \\
\text { para identificar e obter conhecimentos a } \\
\text { partir de fontes externas. }\end{array}$ & \multirow{2}{*}{$\begin{array}{l}\text { Descrever e analisar como os processos de } \\
\text { negócio são utilizados pelas startups para } \\
\text { adquirir e assimilar conhecimentos da } \\
\text { grande empresa. }\end{array}$} & \multirow{4}{*}{$\begin{array}{l}\text { Cohen e Levinthal (1990) } \\
\text { Zahra e George (2002) } \\
\text { Pavlou e El Sawy (2006) }\end{array}$} \\
\hline $\begin{array}{l}\text { 3. A startup conta com rotinas adequadas } \\
\text { para analisar as informações e os } \\
\text { conhecimentos obtidos? } \\
\text { 4. A startup conta com rotinas adequadas } \\
\text { para assimilar novas informações e } \\
\text { conhecimentos? }\end{array}$ & $\begin{array}{l}\text { Habilidade da startup para desenvolver } \\
\text { processos e rotinas úteis na análise, } \\
\text { interpretação e compreensão dos } \\
\text { conhecimentos adquiridos externamente. }\end{array}$ & & \\
\hline $\begin{array}{l}\text { 5. A startup consegue integrar os } \\
\text { conhecimentos internos já existentes com } \\
\text { as novas informações e conhecimentos } \\
\text { adquiridos? } \\
\text { 6. A startup é eficaz em transformar a } \\
\text { informação existente em novos } \\
\text { conhecimentos? }\end{array}$ & $\begin{array}{l}\text { Capacidade da startup em refinar as } \\
\text { rotinas e processos que facilitam a } \\
\text { combinação dos conhecimentos existentes } \\
\text { (internos) com os conhecimentos } \\
\text { adquiridos externamente. }\end{array}$ & \multirow{2}{*}{$\begin{array}{l}\text { Descrever e analisar como os processos de } \\
\text { negócio são utilizados pelas startups para } \\
\text { transformar e utilizar conhecimentos da } \\
\text { grande empresa, a fim de obter vantagem } \\
\text { competitiva. }\end{array}$} & \\
\hline $\begin{array}{l}\text { 7. A startup consegue explorar com } \\
\text { sucesso informações e conhecimento } \\
\text { internos e externos em aplicações } \\
\text { concretas? } \\
\text { 8. A startup é eficaz em utilizar o } \\
\text { conhecimento em novos produtos? }\end{array}$ & $\begin{array}{l}\text { Capacidade da startup em melhorar, } \\
\text { expandir e utilizar as rotinas existentes e } \\
\text { processos para criar algo, com base no } \\
\text { conhecimento transformado. }\end{array}$ & & \\
\hline
\end{tabular}

Fonte: Elaborado pelo autor. 


\subsection{Unidades de análise}

Como já foi descrito, o método de pesquisa adotado neste trabalho foi o estudo de caso e seguindo a base teórica proposta por Yin (2015), não se pretende generalizar os casos de estudo, pela limitação do método.

Nesse contexto, o caso estudado nesta pesquisa são os relacionamentos interorganizacionais entre grandes empresas e startups, com foco nos processos relacionados ao desenvolvimento da capacidade de absorção para criação de vantagem competitiva para as startups. As unidades de análise (ou unidade-caso) são startups que mantém algum tipo de relacionamento interorganizacional para inovação com grandes empresas. A escolha dos casos buscou elucidar as proposições teóricas e variáveis do estudo e foram selecionados intencionalmente, de acordo com certas características estabelecidas no problema de pesquisa e objetivos propostos (RICHARDSON, 2011).

Os estudos de casos múltiplos seguem a lógica da replicação (literal ou teórica) e não da amostragem, onde cada caso deve ser selecionado para que se possa predizer resultados similares (replicação literal ou direta) ou possa produzir resultados contrastantes para razões previsíveis (replicação teórica). A Figura 8 ilustra a abordagem da replicação aos estudos de casos múltiplos.

Figura 8 - Abordagem da replicação aos estudos de casos múltiplos

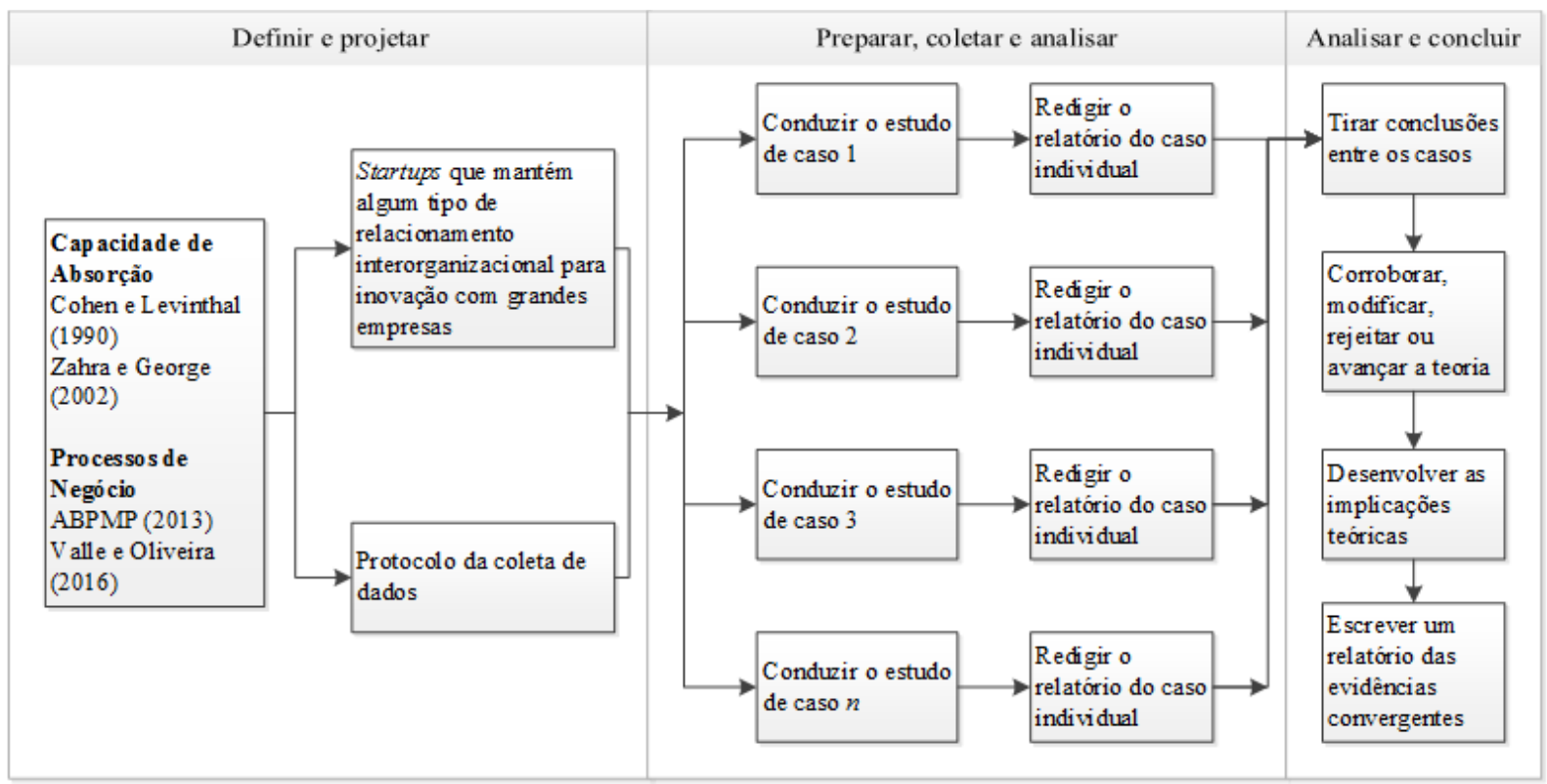

Fonte: Adaptado de Yin (2015). 
A Figura 8 indica que o passo inicial do projeto consistiu no desenvolvimento das proposições teóricas relacionadas aos tópicos principais do estudo, ou seja, o conceito de capacidade de absorção proposto por Cohen e Levinthal (1990) e Zahra e George (2002), bem como a análise teórica da abordagem gerencial BPM, na visão da ABPMP (2013) e Valle e Oliveira (2016). Então, a seleção dos casos estudados buscou elucidar as proposições teóricas construídas. Neste estudo, os casos estudados foram definidos como startups que mantém um relacionamento interorganizacional para inovação com grandes empresas. Definidas as unidades de análise, medidas específicas foram desenvolvidas no protocolo de estudo de caso para guiar a coleta de dados em cada unidade de análise (APÊNDICE A). Dando continuidade a exploração da Figura 8, cada estudo de caso individual consiste em um estudo completo, no qual a evidência convergente é procurada em relação aos fatos e às conclusões de cada caso, sendo estas consideradas a informação que precisa ser replicada por outros casos individuais (YIN, 2015). 


\section{APRESENTAÇÃO DOS CASOS E UNIDADES DE ANÁLISE}

O caso estudado nesta pesquisa são os relacionamentos interorganizacionais entre grandes empresas e startups e as unidades de análise são startups que mantém algum tipo de relacionamento interorganizacional para inovação com grandes empresas. Sendo assim, esta seção irá apresentar um panorama geral das aceleradoras de startups no Brasil e empresas que investem em programas corporativos de aceleração de startups. Na sequência, um recorte das startups inseridas nos programas corporativos de aceleração e os critérios definidos para seleção das unidades de análise.

\subsection{Relacionamentos interorganizacionais em aceleradoras: cenário para o caso}

De acordo com o que já foi exposto na introdução deste estudo, nos últimos anos observou-se no Brasil o surgimento de aceleradoras de empresas criadas por grandes empresas, com o objetivo de fomentar ambientes de empreendedorismo e inovação. Esses ambientes, também conhecidos como ecossistemas, pois envolvem empresas líderes que se utilizam dos relacionamentos com múltiplos parceiros para criar inovações mais amplas e influentes (DAVIS, 2016), configuram-se como ambientes propícios para troca de conhecimentos, favorecendo a aprendizagem organizacional. Nesse contexto, as aceleradoras desempenham um papel importante no estímulo ao empreendedorismo e segundo Pauwels et al. (2016), a atividade de aceleração pode ser considerada um fenômeno extremamente recente no mundo. No período de outubro de 2015 a janeiro de 2016, Abreu e Campos (2016) realizaram uma pesquisa documental exploratória com o objetivo de levantar uma lista de aceleradoras presentes no ecossistema empreendedor brasileiro. Foram localizadas 45 aceleradoras brasileiras, das quais 31 participaram da pesquisa. Quanto à localização geográfica, a região Sudeste concentra $71 \%$ das aceleradoras do país, seguida pela região Nordeste com $16 \%$, região Sul com 10\%, região Norte com $3 \%$ e a região Centro-Oeste não possuiu nenhuma aceleradora. Os autores destacam o estado de São Paulo com 16 aceleradoras (52\%), Minas Gerais com três (10\%) e Rio de Janeiro, Rio Grande do Sul, Pernambuco e Bahia com duas aceleradoras (6\%), respectivamente. Convém, no entanto, ressaltar que o estudo supracitado não descreve se as aceleradoras foram criadas ou não por grandes empresas e para atender ao objetivo deste estudo, buscou-se aceleradoras corporativas que visam apoiar empreendedores e startups com projetos alinhados aos interesses e estratégias de uma determinada corporação. 


\subsubsection{Aceleradoras e suas startups}

Considerando um dos objetivos específicos deste trabalho, que é mapear a rede de colaboração constituída pelos relacionamentos interorganizacionais entre grandes empresas e startups, iniciou-se uma busca por grandes empresas que investem em programas corporativos de aceleração de startups. Essa pesquisa inicial foi realizada em jornais e revistas de grande circulação nacional, em suas versões digitais disponibilizadas pela internet ou impressas, de onde surgiram as primeiras informações sintetizadas no Quadro 10. Essas pesquisas tiveram início em julho de 2016 e foram concluídas no mês de setembro de 2017.

No total, até essa data, foram localizadas 12 sedes de aceleradoras corporativas ${ }^{4}$, ou seja, que foram criadas por grandes empresas. A distribuição geográfica no Brasil da sede das aceleradoras se apresenta, de forma predominante, na região Sudeste, com dez aceleradoras ou, $84 \%$ da amostra, seguida pela região Norte e Sul com uma aceleradora cada (8\%, respectivamente). Em destaque, pode-se observar o estado de São Paulo com oito aceleradoras (67\%), seguido pelo Rio de Janeiro com duas aceleradoras (17\%) e Amazonas e Santa Catarina com uma aceleradora cada (8\%, respectivamente). O Gráfico 1 e Gráfico 2 ilustram um quadro comparativo entre o estudo de Abreu e Campos (2016) e o mapeamento realizado nesta pesquisa, com relação ao estado onde está localizada a sede da aceleradora.

Gráfico 1 - Estado sede da aceleradora (dados secundários)

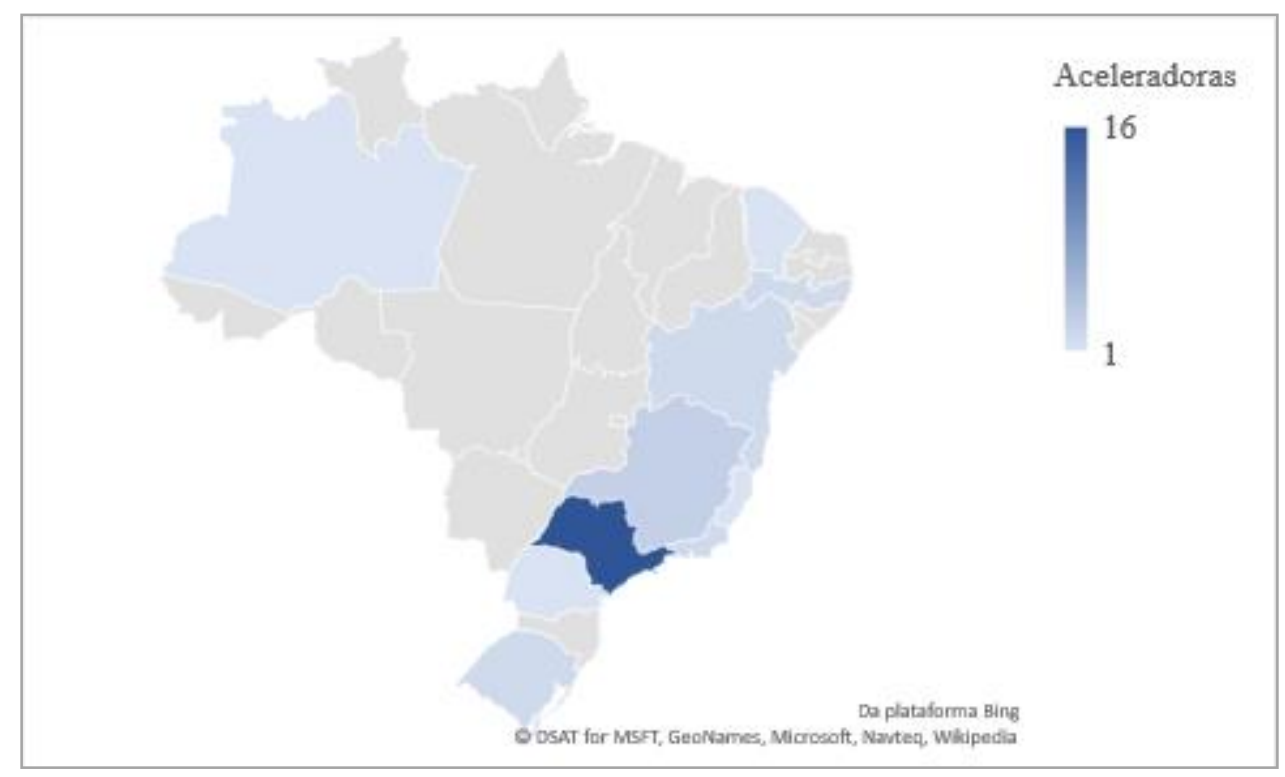

Fonte: Abreu e Campos (2016).

\footnotetext{
${ }^{4}$ A Samsung com o programa Ocean está localizada em São Paulo, SP e Manaus, AM e para localização geográfica da sede, foram considerados os dois estados.
} 
Gráfico 2 - Estado sede da aceleradora (dados do levantamento)

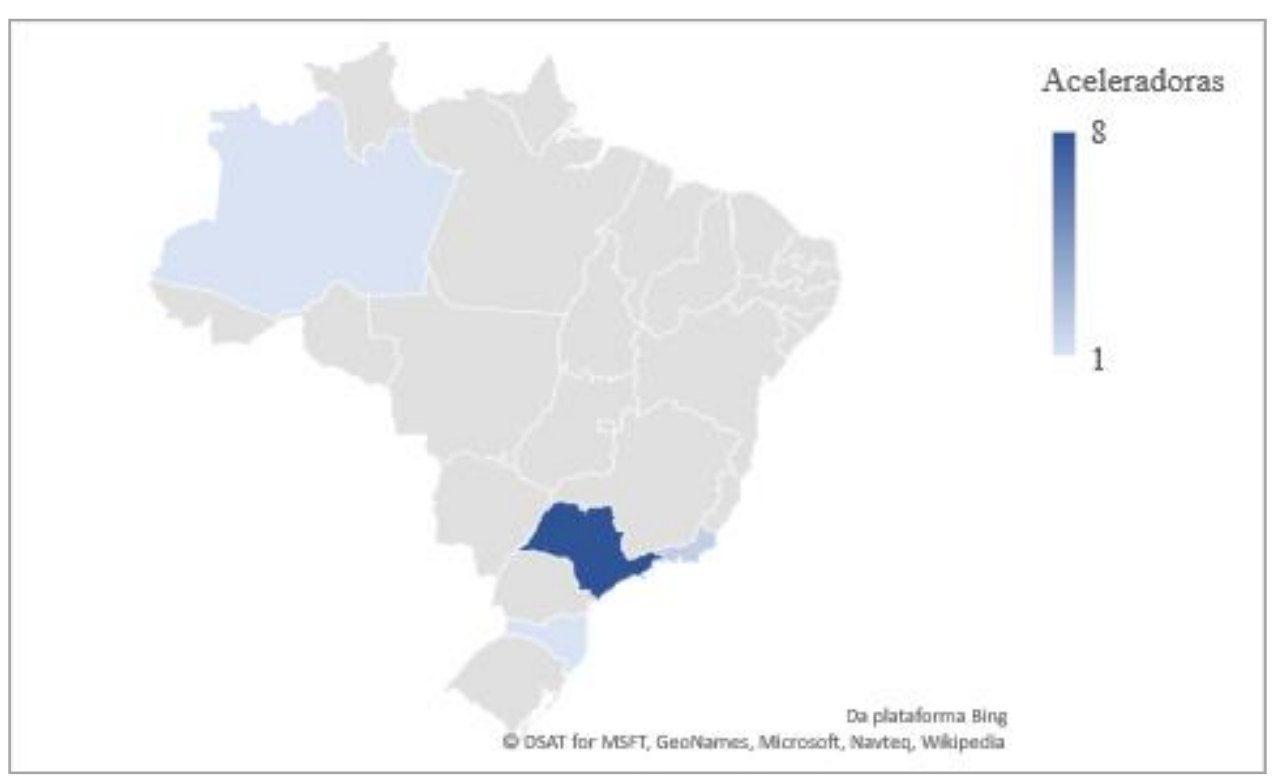

Fonte: Elaborado pelo autor.

Ambos os estudos destacam o estado de São Paulo como uma região de concentração de aceleradoras de startups, sugerindo um ambiente propício e significativo para a realização da pesquisa. Observando o Quadro 10, verifica-se que na cidade de São Paulo encontram-se 66,8\% das aceleradoras corporativas, de acordo com os dados coletados nesta pesquisa.

Realizando outro comparativo com o estudo de Abreu e Campos (2016), onde os autores afirmam que no Brasil existem 45 aceleradoras de empresas, o levantamento deste estudo representa uma amostra de $26,7 \%$ dessa população, ou seja, estima-se que um quarto das aceleradoras estabelecidas no Brasil são aceleradoras corporativas. 
Quadro 10 - Grandes empresas e seus programas de aceleração

\begin{tabular}{|c|c|c|c|c|c|}
\hline Empresa & Setor de Atuação & Localização da Aceleradora & Programa de Aceleração & Objetivos do Programa & Benefícios para a Startup \\
\hline AES Brasil & Energia & São Paulo, SP & AES Brasil Inovação & $\begin{array}{l}\text { Iniciativa para aceleração de projetos } \\
\text { de startups que busquem o } \\
\text { desenvolvimento de produtos e } \\
\text { modelos de negócios inovadores para } \\
\text { criar valor ao setor de energia elétrica. }\end{array}$ & $\begin{array}{l}\text { Apoio financeiro para o } \\
\text { desenvolvimento do projeto, } \\
\text { aceleração com mentorias, } \\
\text { possibilidade de acesso ao } \\
\text { mercado e de fazer negócios com } \\
\text { a AES, escritório equipado, } \\
\text { possibilidade de contar com força } \\
\text { técnica no campo, know how do } \\
\text { mercado e tecnologia, apoio e } \\
\text { utilização de laboratórios. }\end{array}$ \\
\hline Bradesco & Finanças & São Paulo, SP & Inovabra Startups & $\begin{array}{l}\text { Fomentar a criação de novas } \\
\text { tecnologias e aproximar o banco e } \\
\text { empresas inovadoras que possuam } \\
\text { soluções tecnológicas aplicáveis ao } \\
\text { setor de serviços bancários, serviços } \\
\text { financeiros no segmento varejo. }\end{array}$ & $\begin{array}{l}\text { Acesso a profissionais e empresas } \\
\text { de assessoria especializada, bem } \\
\text { como acesso a profissionais de } \\
\text { áreas internas da organização a } \\
\text { fim de aprofundar o conhecimento } \\
\text { para um melhor desenvolvimento } \\
\text { do MVP. }\end{array}$ \\
\hline Braskem & $\begin{array}{l}\text { Química e } \\
\text { petroquímica }\end{array}$ & São Paulo, SP & Braskem Labs & $\begin{array}{l}\text { Programa de aceleração com soluções } \\
\text { inovadoras que melhoram a } \\
\text { vida das pessoas por meio da química } \\
\text { e/ou do plástico. }\end{array}$ & $\begin{array}{l}\text { Capacitação com disponibilização } \\
\text { de conteúdos exclusivos, } \\
\text { eventos presenciais e mentorias } \\
\text { coletivas e individuais. }\end{array}$ \\
\hline Enel & Energia & Niterói, RJ & Energy Start & $\begin{array}{l}\text { Prospectar startups, pequenas e médias } \\
\text { empresas que apresentem soluções } \\
\text { inovadoras e com potencial de impacto } \\
\text { positivo no mercado, além de fomentar } \\
\text { o ecossistema de startups no setor } \\
\text { elétrico. }\end{array}$ & $\begin{array}{l}\text { Oportunidade de investimento, } \\
\text { parcerias comerciais, imersão no } \\
\text { Vale do Silício e aceleração. }\end{array}$ \\
\hline Google & $\begin{array}{l}\text { Tecnologia da } \\
\text { informação }\end{array}$ & São Paulo, SP & Campus São Paulo & $\begin{array}{l}\text { O programa de residência busca por } \\
\text { startups e empreendedores inovadores, } \\
\text { com times talentosos e diversos que } \\
\text { estejam desenvolvendo produtos } \\
\text { excepcionais, e cujos negócios estejam } \\
\text { em estágio de crescimento avançado. }\end{array}$ & $\begin{array}{l}\text { Espaço de trabalho permanente, } \\
\text { acesso prioritário à rede de } \\
\text { experts do Google, oportunidades } \\
\text { para participar de programas de } \\
\text { imersão globais, além de eventos } \\
\text { e conteúdos exclusivos. }\end{array}$ \\
\hline
\end{tabular}

Continua 
Continuação

\begin{tabular}{|c|c|c|c|c|c|}
\hline Empresa & Setor de Atuação & Localização da Aceleradora & Programa de Aceleração & Objetivos do Programa & Benefícios para a Startup \\
\hline Itaú Unibanco & Finanças & São Paulo, SP & Cubo & $\begin{array}{l}\text { Fomentar o ecossistema de } \\
\text { empreendedorismo digital no Brasil, } \\
\text { sendo um } h u b \text { com um ambiente } \\
\text { inspirador para conectar pessoas } \\
\text { brilhantes, com vontade de aprender, } \\
\text { compartilhar ideias e lançar novas } \\
\text { empresas com potencial de } \\
\text { transformar negócios, tecnologia e a } \\
\text { vida das pessoas para melhor. }\end{array}$ & $\begin{array}{l}\text { As startups residentes contam } \\
\text { endereço físico e comercial, } \\
\text { acesso a espaços diferenciados e } \\
\text { para realização de eventos e } \\
\text { reuniões, dentre outros benefícios, } \\
\text { além da rede de conexão entre } \\
\text { empreendedores, } \\
\text { investidores, mentores, empresas } \\
\text { de tecnologia, universidades e } \\
\text { estudantes. }\end{array}$ \\
\hline Oi & Telecomunicações & Rio de Janeiro, RJ & Oito & $\begin{array}{l}\text { Promover a evolução contínua do } \\
\text { ecossistema de inovação no país e a } \\
\text { aceleração de P\&D de novos } \\
\text { produtos, serviços e negócios com alto } \\
\text { potencial de crescimento tecnológico } \\
\text { para a indústria de telecomunicações, } \\
\text { através de um processo estruturado de } \\
\text { incubação de startups. }\end{array}$ & $\begin{array}{l}\text { Programa de incubação e } \\
\text { aceleração, mentoria e } \\
\text { aconselhamento com executivos } \\
\text { da Oi e de empresas parceiras, até } \\
\text { três posições de trabalho junto à } \\
\text { área de coworking, investimento } \\
\text { em P\&D, e corporate venturing, } \\
\text { na forma de aporte financeiro na } \\
\text { startup. }\end{array}$ \\
\hline Porto Seguro & $\begin{array}{l}\text { Serviços } \\
\text { financeiros e } \\
\text { seguros }\end{array}$ & São Paulo, SP & Oxigênio Aceleradora & $\begin{array}{l}\text { Promover um programa intenso de } \\
\text { aceleração, onde os empreendedores se } \\
\text { dedicam ao crescimento do negócio, à } \\
\text { aquisição de usuários e } \\
\text { posicionamento de produto, } \\
\text { alavancados pela aceleradora através } \\
\text { de mentorias e apoio de profissionais } \\
\text { que são referência no mercado. }\end{array}$ & $\begin{array}{l}\text { Além do investimento-semente, } \\
\text { as empresas têm acesso a sessões } \\
\text { com mentores e especialistas em } \\
\text { várias áreas, acesso aos mercados } \\
\text { de atuação da Porto Seguro, } \\
\text { serviços e ferramentas, espaço de } \\
\text { escritório, suporte para identificar } \\
\text { oportunidades adicionais de } \\
\text { levantamento de fundos e } \\
\text { parcerias estratégicas com as } \\
\text { empresas, além do } \\
\text { acompanhamento da evolução da } \\
\text { startup. }\end{array}$ \\
\hline
\end{tabular}

Continua 
Conclusão

\begin{tabular}{|c|c|c|c|c|c|}
\hline Empresa & Setor de Atuação & Localização da Aceleradora & Programa de Aceleração & Objetivos do Programa & Benefícios para a Startup \\
\hline Samsung & $\begin{array}{l}\text { Tecnologia da } \\
\text { informação }\end{array}$ & $\begin{array}{l}\text { São Paulo, SP e } \\
\text { Manaus, AM }\end{array}$ & Ocean & $\begin{array}{l}\text { Incentivar o desenvolvimento de } \\
\text { soluções em tecnologia móvel, } \\
\text { utilizando plataformas e ferramentas } \\
\text { da Samsung, e fomentar a criação de } \\
\text { novas empresas de base tecnológica } \\
\text { (startups). }\end{array}$ & $\begin{array}{l}\text { Capacitação técnica combinada } \\
\text { com temas relacionados à } \\
\text { usabilidade e empreendedorismo, } \\
\text { além do contato com especialistas } \\
\text { da Samsung e do mercado. }\end{array}$ \\
\hline Senior Solution & $\begin{array}{l}\text { Tecnologia da } \\
\text { informação }\end{array}$ & Blumenau, SC & Inove Senior & $\begin{array}{l}\text { Identificação de negócios e de } \\
\text { soluções inovadoras em hardware, } \\
\text { software e serviços, alinhados com as } \\
\text { diretrizes estratégicas } \\
\text { da Senior, que poderão se tornar } \\
\text { parceiros estratégicos ou } \\
\text { unidades de negócio. }\end{array}$ & $\begin{array}{l}\text { Assessoria de imprensa e } \\
\text { comunicação, assessoria contábil } \\
\text { e jurídica, espaço de coworking, } \\
\text { capacitações e treinamentos, } \\
\text { consultorias técnicas } \\
\text { individualizadas, comercialização } \\
\text { pioneira, serviços de hospedagem } \\
\text { e internet e acesso aos parceiros } \\
\text { tecnológicos e comerciais. }\end{array}$ \\
\hline Telefônica Brasil & Telecomunicações & São Paulo, SP & Wayra & $\begin{array}{l}\text { Aceleradora corporativa que investe } \\
\text { em startups digitais. }\end{array}$ & $\begin{array}{l}\text { Financiamento, mentoria, espaço } \\
\text { de trabalho, conexão com a rede } \\
\text { global, networking entre } \\
\text { empreendedores e investidores e a } \\
\text { possibilidade produtos chegarem } \\
\text { a clientes em todo o mundo. }\end{array}$ \\
\hline
\end{tabular}

Fonte: Elaborado pelo autor, com base em notícias na área e nos sites das próprias aceleradoras. 
Dando continuidade à coleta de dados, foi realizado na primeira quinzena do mês de outubro de 2017 um levantamento exploratório via internet das startups inseridas nos programas corporativos de aceleração. O website de 11 aceleradoras foi consultado, dos quais puderam ser extraídas informações das startups inseridas nos programas. Normalmente, essa informação encontra-se nas abas "portfólio", "startups" ou "startups residentes" desses websites de cada aceleradora. É importante ressaltar que, das 11 aceleradoras pesquisadas, seis não disponibilizaram em seus websites informações sobre as startups inseridas nos programas, impossibilitando o avanço do mapeamento da rede de startups e coleta de informações. Como mostra a Figura 9, foi possível levantar um total de 175 startups, distribuídas em cinco aceleradoras, destacando que, estas últimas, estão localizadas na cidade de São Paulo.

Figura 9 - Startups inseridas nos programas de aceleração (novembro 2017)

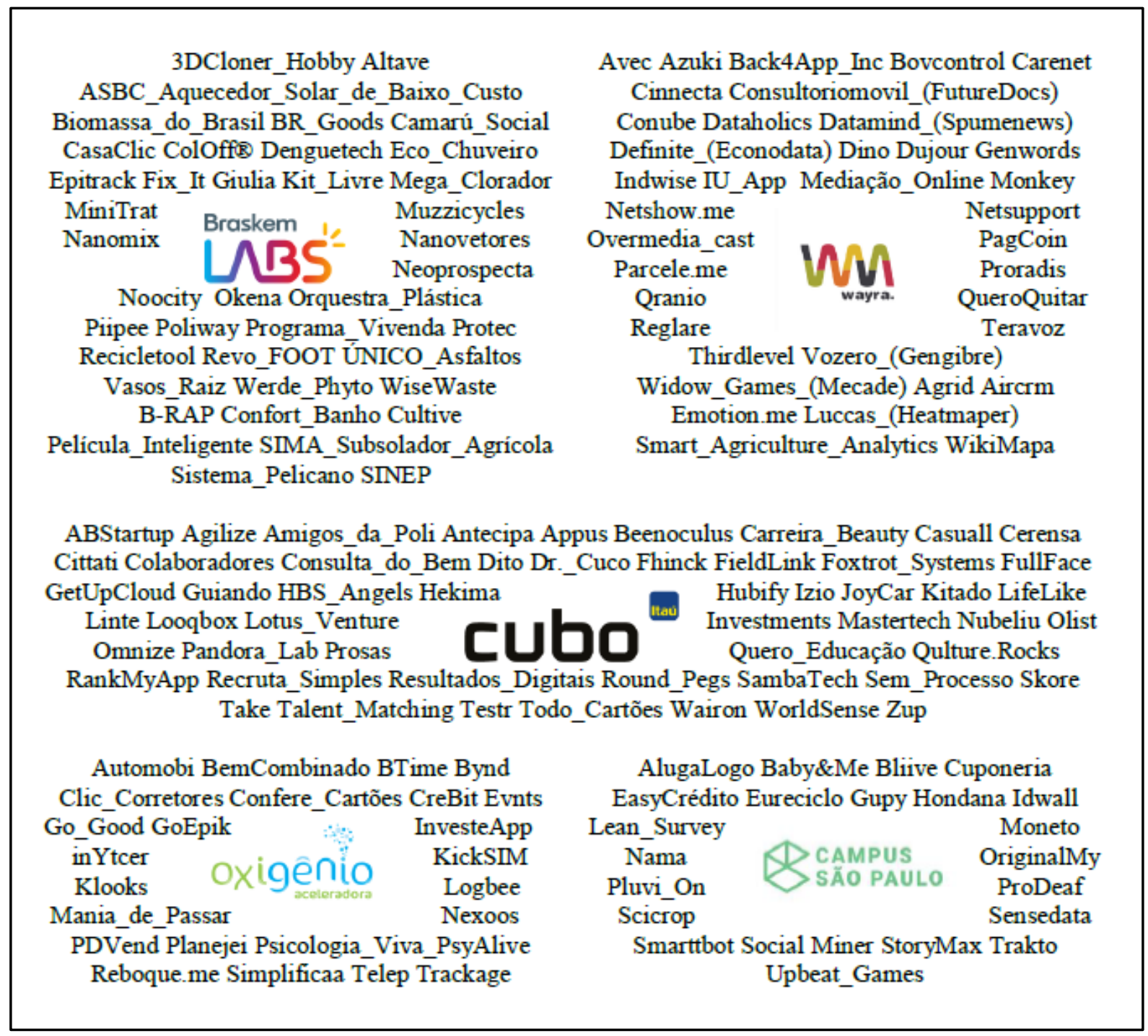

Fonte: Elaborado pelo autor. 
Considerando que no Brasil 1.153 startups passaram por um processo de aceleração ${ }^{5}$ (ABREU; CAMPOS, 2016), a amostra de 175 startups representa 15,2\% desse total. Essa etapa da pesquisa foi decisiva para levantar as grandes empresas que se relacionam ou mantém parcerias com startups, por intermédio das aceleradoras.

\subsubsection{As empresas por trás das aceleradoras estudadas}

Criada em agosto de 2002 pela integração de seis empresas da Organização Odebrecht e do Grupo Mariani, a Braskem é, nos dias de hoje, a maior produtora de resinas termoplásticas nas Américas e a maior produtora de polipropileno nos Estados Unidos. Sua produção é focada nas resinas polietileno (PE), polipropileno (PP) e policloreto de vinila (PVC), além de insumos químicos básicos como eteno, propeno, butadieno, benzeno, tolueno, cloro, soda e solventes, entre outros. Juntos, compõe um dos portfólios mais completos do mercado, ao incluir também o polietileno verde, produzido a partir da cana-de-açúcar, de origem 100\% renovável (BRASKEM, 2017).

Fundada em 1945, a Porto Seguro Cia. de Seguros Gerais iniciou suas atividades operando em seguros e resseguros de ramos elementares. Atualmente, a empresa atua em todos os ramos de seguros patrimoniais e de pessoas, que são complementados por outros negócios, dentre eles consórcios, soluções financeiras e serviços como proteção e monitoramento, telefonia móvel, saúde ocupacional, entre outros (PORTO SEGURO, 2017). Já o Itaú Unibanco é o maior banco privado do Brasil e uma das maiores empresas do mundo, levando em conta atributos como negócios gerados, ativos e valor de mercado. O banco nasceu em Poços de Caldas, Minas Gerais em 1924 e em 2008 uniu-se ao Unibanco, numa operação que representou uma das maiores fusões da história brasileira (ITAÚ, 2017).

O Google LLC, com sede em Mountain View, Califórnia, Estados Unidos, é uma empresa multinacional de serviços online e software, que hospeda e desenvolve uma série de serviços e produtos baseados na internet, gerando lucro principalmente por meio da publicidade pelo AdWords. Foi fundada em 1998 e atualmente, a missão da empresa é organizar as informações do mundo todo e torná-las universalmente acessíveis e úteis (GOOGLE, 2017). A Telefônica começou a escrever sua história no Brasil em 1998 quando a Telesp, companhia estatal de

\footnotetext{
${ }^{5} \mathrm{O}$ estudo de Abreu e Campos (2016) mostra que no Brasil, 865 startups passaram por um processo de aceleração, dentro da amostra pesquisada. Considerando que a amostra cobriu cerca de $75 \%$ do mercado brasileiro de aceleradoras, os autores deduziram que 1.153 startups já foram aceleradas no país, levando em consideração 41 aceleradoras de startups em atividade.
} 
telecomunicações do Sistema Telebrás, foi privatizada e adquirida pela Telefónica, da Espanha, formando a Telefônica Brasil. Atualmente, a empresa conecta acessos à internet e telefonia móvel e fixa, além de TV por assinatura, sendo referência na telefonia móvel 4G e na banda larga fixa de ultra velocidade (TELEFÔNICA, 2017).

A Figura 10 ilustra o cenário delineado pelas primeiras etapas da pesquisa, de modo a evidenciar os relacionamentos interorganizacionais entre as startups e grandes empresas, em ambientes de empreendedorismo e inovação promovidos pelas aceleradoras. A natureza complementar de startups e grandes corporações sugere que ambas podem se beneficiar da colaboração e ao fazêla, as startups recebem ajuda para melhorar seu desempenho e as grandes empresas recebem suporte para buscar inovação. Entre grandes corporações e startups, as aceleradoras corporativas apresentam-se como possibilidade de tornar as colaborações mais eficientes e econômicas, fornecem uma plataforma única para crescimento a longo prazo e renovação corporativa (KOHLER, 2016).

Figura 10 - Ambiente de empreendedorismo e inovação

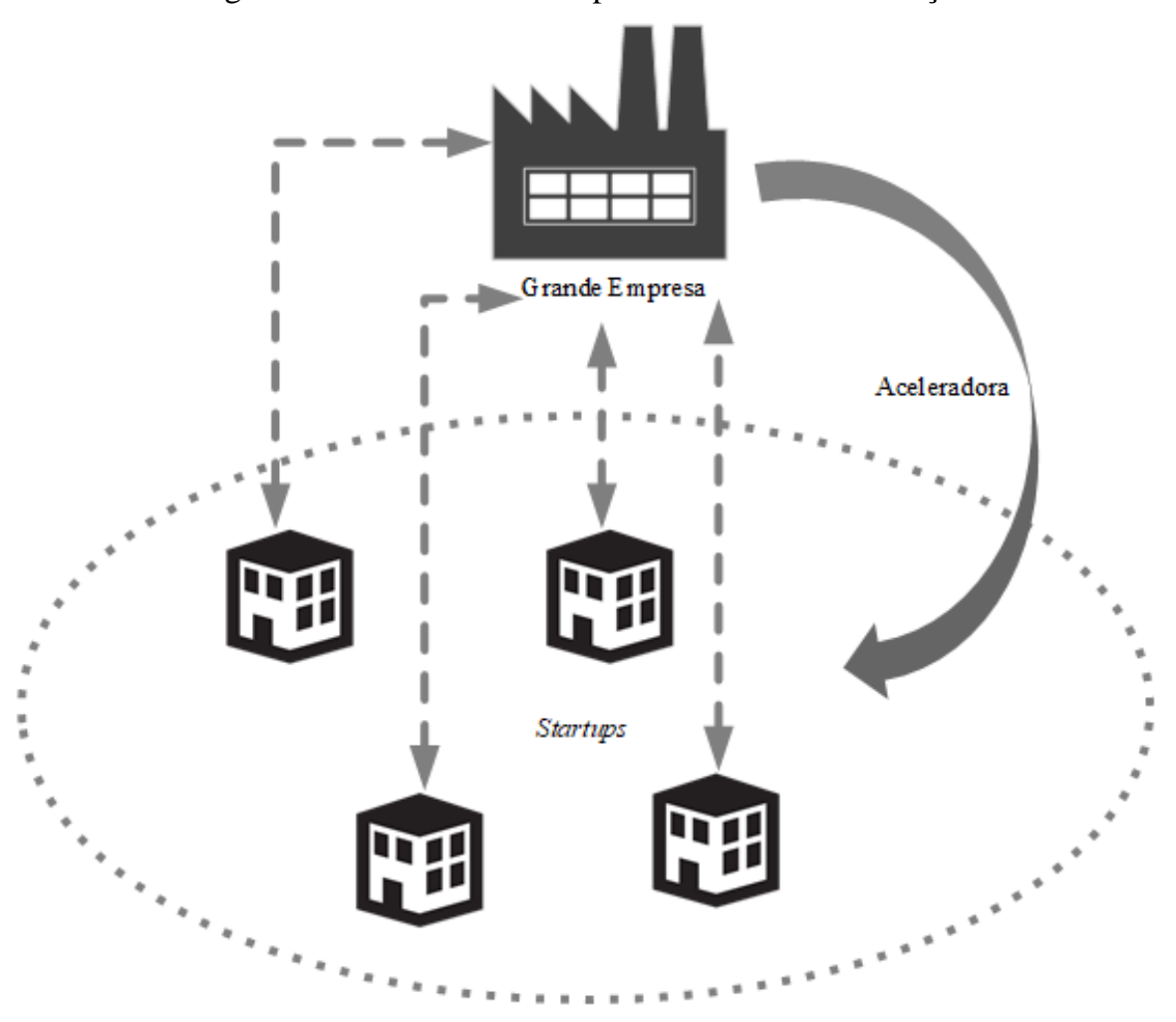

Fonte: Elaborado pelo autor.

De posse dos primeiros dados coletados, a próxima etapa da pesquisa consistiu em realizar um levantamento de contatos das 175 startups previamente selecionadas. Mais uma vez, recorreu- 
se à internet para realização de uma consulta ao website de cada startup, de onde foram extraídas informações que pudessem ser utilizadas para entrar em contato com a empresa. Os critérios e a definição das unidades de análise serão explicados em detalhes nas seções seguintes.

\subsection{Critérios para definição das unidades de análise}

Na primeira quinzena de outubro de 2017, o website das 175 startups foi consultado com o objetivo de buscar, primeiramente, o endereço eletrônico da empresa. Na falta dessa informação, buscou-se outras formas de contato em redes sociais, como o Facebook e LinkedIn. Essas ações resultaram em um banco de dados de 160 startups destacando que, em 15 startups, o website não estava funcionando ou não havia contato disponível, seja por e-mail ou redes sociais, onde essa falta de informação distribui-se em $46 \%$ para a Braskem, $40 \%$ para a Telefônica e 7\% para o Itaú Unibanco e Porto Seguro, respectivamente.

Com esse banco de dados disponível, foi enviado por e-mail às startups relacionadas uma pesquisa de levantamento (survey) utilizando um questionário online gerenciado pela ferramenta LimeSurvey (APÊNDICE B), com o objetivo de direcionar o mapeamento em busca de startups que indicassem um grau razoável de capacidade de absorção, além de informações relevantes para caracterizar o relacionamento interorganizacional com a grande empresa. Essa fase iniciou-se na segunda quinzena de outubro e encerrou-se na primeira quinzena de dezembro de 2017, totalizando oito semanas. O primeiro contato foi encaminhado via e-mail, sendo enviado um lembrete semanal aos que ainda não haviam respondido a pesquisa. De forma alternativa, a página do Facebook das startups foi acessada, sendo solicitado que o responsável pela empresa respondesse ao questionário, utilizando o recurso "Mensagem" para envio do link da pesquisa.

Ademais, a página da startup na rede social de negócios LinkedIn foi acessada, com o intuito de buscar os usuários intitulados "Diretor", "CEO", "Fundador", "Co-fundador", "Sócio", "Sócio-fundador" e "Proprietário" para que fossem convidados a fazerem parte da rede de conexões do pesquisador. Quando a solicitação era aceita, o responsável pela empresa era convidado a participar da pesquisa, por meio do link enviado via recurso "Enviar mensagem". Dado o tempo para recebimento das respostas, obteve-se um total de 34 registros no questionário. Considerando o conjunto de elementos pesquisados as 160 startups, atingiu-se uma taxa de retorno total de $21,3 \%$.

Para dar continuidade a análise das respostas do questionário, recorreu-se ao software IBM SPSS Statistics 17.0 com o qual puderam ser realizadas algumas inferências. Na Tabela 1, 
observa-se que $97,1 \%$ das startups respondentes mantém algum tipo de parceria ou relacionamento com uma grande empresa. Nas próximas análises, o valor atribuído ao "Não" (uma ocorrência) será tratado pelo software como um valor que falta ou que não foi obtido (missing value). Esse tratamento corrobora com o objetivo da pesquisa, pois pretende-se estudar startups que mantém ou já tiveram algum relacionamento interorganizacional com grandes empresas.

Tabela 1 - Startups que mantém parceria ou relacionamento com grandes empresas

\begin{tabular}{|c|c|c|c|c|c|}
\hline \multicolumn{6}{|c|}{$\begin{array}{c}\text { A startup mantém parceria ou relacionamento com alguma grande } \\
\text { empresa? }\end{array}$} \\
\hline & & Frequency & Percent & Valid Percent & $\begin{array}{l}\text { Cumulative } \\
\text { Percent }\end{array}$ \\
\hline \multirow[t]{3}{*}{ Valid } & Sim & 33 & 97,1 & 97,1 & 97,1 \\
\hline & Não & 1 & 2,9 & 2,9 & 100,0 \\
\hline & Total & 34 & 100,0 & 100,0 & \\
\hline
\end{tabular}

Fonte: Elaborado pelo autor. Tabela gerada pelo SPSS.

Para os fins desta pesquisa, é importante descobrir se as startups que representam a amostra reconhecem a grande empresa a qual estão ligadas, por intermédio da aceleradora, como um parceiro potencial. Para responder a essa pergunta, foi utilizado o teste qui-quadrado de Pearson (Tabela 2), uma estatística baseada na ideia de comparar frequências observadas em certas categorias com as frequências esperadas nessas categorias, sendo uma opção estatística para tabulações cruzadas (FIELD, 2009).

Tabela 2 - Teste qui-quadrado de Pearson

Chi-Square Tests
\begin{tabular}{|l|r|r|r|}
\hline \multicolumn{1}{|c|}{} & \multicolumn{1}{|c|}{ Value } & df & $\begin{array}{c}\text { Asymp. Sig. } \\
\text { (2-sided) }\end{array}$ \\
\hline Pearson Chi-Square & $16,816^{\text {a }}$ & 4 &, 002 \\
Likelihood Ratio & 19,737 & 4 &, 001 \\
Linear-by-Linear & 1,553 & 1 &, 213 \\
Association & & & \\
N of Valid Cases & 33 & & \\
\hline
\end{tabular}
a. 8 cells (80,0\%) have expected count less than 5. The
minimum expected count is 1,27.

Fonte: Elaborado pelo autor. Tabela gerada pelo SPSS.

Como parte do procedimento das tabulações cruzadas, a Tabela 2 inclui a estatística quiquadrado e sua significância. O valor da estatística qui-quadrado é 16,816 e esse valor é 
altamente significativo ( $\mathrm{p}<0,01$ ), indicando que existe uma associação entre cada uma das cinco grandes empresas e o reconhecimento da startup como parceira. O que se quer dizer por associação é que o padrão das respostas (isto é, a proporção de startups que reconhecem a parceria junto à grande empresa a qual estão ligadas a proporção de startups que não reconhecem essa parceria) para cada uma das cinco grandes empresas é significantemente diferente.

A tabela de tabulação cruzada (Tabela 3) apresenta o número de casos que se encaixam em cada combinação de categorias. Observa-se que de 33 startups, 14 reconhecem a parceria com a grande empresa (42,4\% do total) e, dessas, 27,3\% estão ligadas à Porto Seguro, 6,1\% à Braskem e Itaú Unibanco, respectivamente e $3 \%$ à Telefônica, somando essas três últimas startups $15,2 \%$.

Destacando a Porto Seguro, dentro da categoria grande empresa, 90\% das startups (ou seja, nove startups) reconhecem essa empresa como parceira, contrastando de forma significativa com as demais. A empresa Braskem apresenta dentro de sua categoria duas startups que reconhecem a parceria (66,7\%), Telefônica uma startup (25\%) e Itaú Unibanco duas startups $(18,2 \%)$. Dentro dos respondentes, a empresa Google não teve nenhuma startup que a reconheça como uma parceira potencial. Considerando o conjunto de 14 startups que reconhecem a grande empresa como parceira, 64,3\% estão vinculadas a Porto Seguro, 14,3\% estão vinculadas a Braskem e Itaú Unibanco, respectivamente e 7,1\% a Telefônica.

$\mathrm{O}$ achado significativo reflete no fato de que nem todas as grandes empresas são reconhecidas como parceiras pelas startups, mesmo fomentando ambientes de empreendedorismo e inovação. A Porto Seguro desponta-se como uma empresa promissora para estudo dos relacionamentos interorganizacionais junto às startups vinculadas ao programa da Oxigênio Aceleradora, pois dentro do conjunto de startups que reconhecem a parceria com a grande empresa representa $64,3 \%$ frente a $35,7 \%$ de todas as outras somadas. 
Tabela 3 - Tabulação cruzada do reconhecimento da parceria

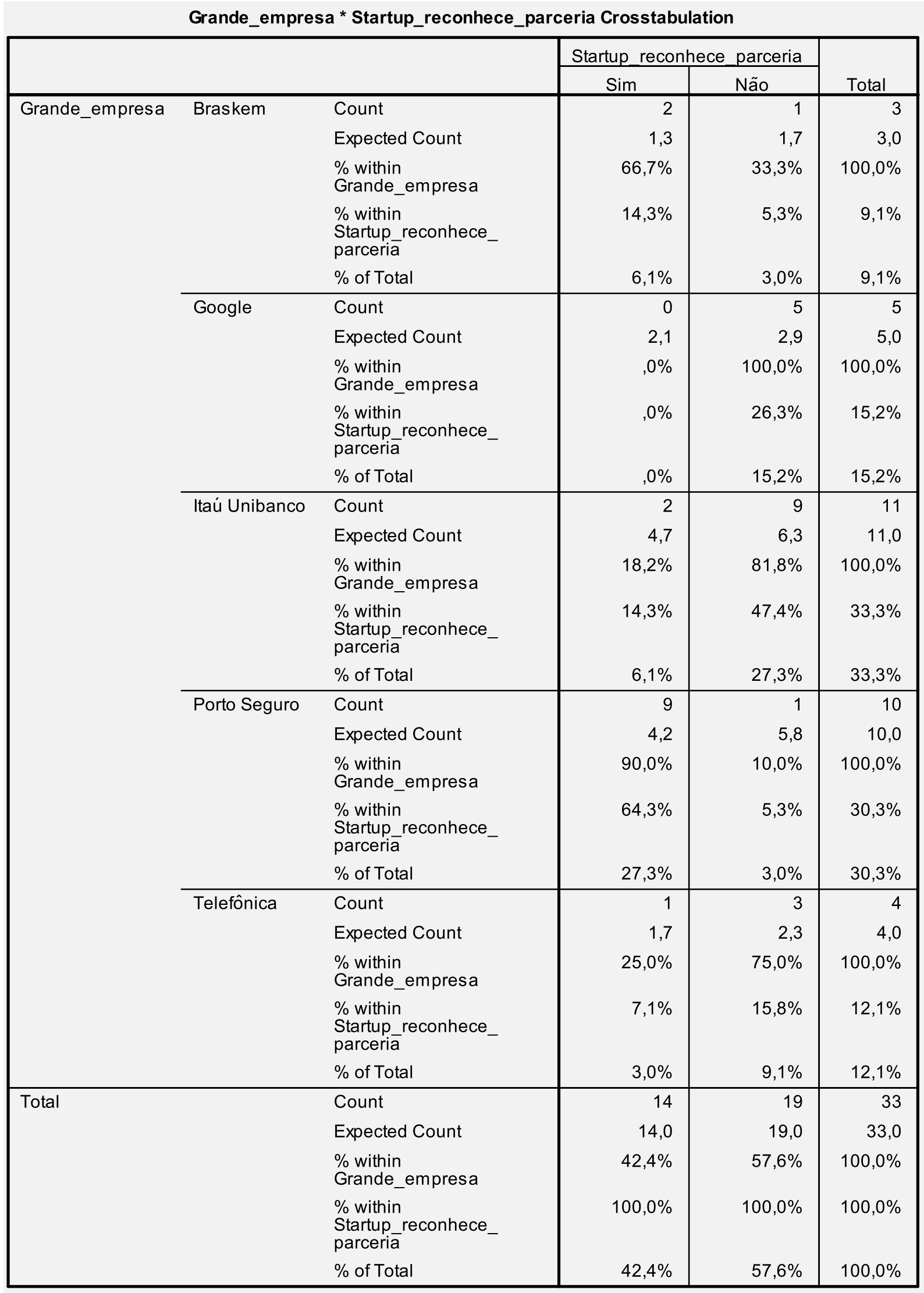

Fonte: Elaborado pelo autor. Tabela gerada pelo SPSS. 
Nas ciências sociais, geralmente busca-se medir coisas que não podem ser medidas diretamente, as chamadas variáveis latentes ou constructos (FIELD, 2009). O questionário online que as startups responderam continham um grupo de perguntas relacionadas ao constructo de capacidade de absorção, com o objetivo de descobrir startups que indicassem um grau razoável de aprendizagem organizacional junto ao relacionamento interorganizacional com a grande empresa.

As perguntas do questionário foram baseadas na escala de Pavlou e El Sawy (2006), sintetizadas em quatro perguntas-chave que buscavam evidenciar um grau razoável de capacidade de absorção potencial (aquisição e assimilação) e realizada (transformação e exploração) junto às startups. Cada pergunta era uma afirmação avaliada por uma escala de Likert de cinco pontos iniciando com "nunca" passando por "às vezes" e finalizando em "sempre", caracterizando a oposição semântica implícita na escala de Likert. O questionário foi projetado para avaliar se a parceria com a grande empresa produzia um grau razoável de aprendizado para a startup, contribuindo para a concepção de medidas qualitativas de análise (APÊNDICE B). Pereira (2001) reforça que a mensuração qualitativa é uma medida derivada, que não se realiza diretamente sobre o fenômeno de interesse e sim, em suas manifestações.

Para a interpretação qualitativa desse evento, ou seja, a capacidade de absorção das startups, foram calculadas as médias das categorias onde foram atribuídos pesos que representassem o diferencial semântico e a regularidade de intervalos, como: nunca $=(-) 1$; raramente $=(-) 0,5$; às vezes $=0$; frequentemente $=0,5$ e sempre $=1$. O cálculo da média foi feito tomando-se as frequências relativas como peso para os valores da medida, resultando que a média pode ser interpretada como uma frequência relativa ponderada. Nesse caso, a categoria de referência é "sempre" e todas as outras transformam-se em frações e/ou opostos de "sempre" (PEREIRA, 2001), como indica a fórmula:

Frequência relativa ponderada $=(p v \times-1)+(p v \times-0,5)+(p v \times 0)+(p v \times 0,5)+(p v \times 1)(1)$

A Tabela 4, Tabela 5, Tabela 6 e Tabela 7 apresentam as respostas das startups ligadas às 5 grandes empresas estudadas, agrupadas em quatro dimensões que representam aquisição, assimilação, transformação e exploração do conhecimento obtido junto à grande empresa. Já o Gráfico 3 mostra a frequência relativa ponderada, calculada sobre o percentual válido (pv) de respostas. 
Tabela 4 - Frequência e percentual de respostas para aquisição

\begin{tabular}{|c|c|c|c|c|c|c|}
\hline \multicolumn{7}{|c|}{ Aquisição de novos conhecimentos para a startup } \\
\hline \multicolumn{3}{|c|}{ Grande empresa } & Frequency & Percent & Valid Percent & $\begin{array}{l}\text { Cumulative } \\
\text { Percent }\end{array}$ \\
\hline \multirow[t]{3}{*}{ Braskem } & \multirow[t]{3}{*}{ Valid } & Frequentemente & 1 & 33,3 & 33,3 & \multirow{3}{*}{$\begin{array}{r}33,3 \\
100,0\end{array}$} \\
\hline & & Sempre & 2 & 66,7 & 66,7 & \\
\hline & & Total & 3 & 100,0 & 100,0 & \\
\hline \multirow[t]{4}{*}{ Google } & \multirow[t]{4}{*}{ Valid } & Raramente & 3 & 60,0 & 60,0 & \multirow{4}{*}{$\begin{array}{r}60,0 \\
80,0 \\
100,0\end{array}$} \\
\hline & & Às vezes & 1 & 20,0 & 20,0 & \\
\hline & & Sempre & 1 & 20,0 & 20,0 & \\
\hline & & Total & 5 & 100,0 & 100,0 & \\
\hline \multirow[t]{6}{*}{ Itaú Unibanco } & \multirow[t]{6}{*}{ Valid } & Nunca & 1 & 9,1 & 9,1 & 9,1 \\
\hline & & Raramente & 2 & 18,2 & 18,2 & 27,3 \\
\hline & & Às vezes & 2 & 18,2 & 18,2 & 45,5 \\
\hline & & Frequentemente & 3 & 27,3 & 27,3 & 72,7 \\
\hline & & Sempre & 3 & 27,3 & 27,3 & 100,0 \\
\hline & & Total & 11 & 100,0 & 100,0 & \\
\hline \multirow[t]{5}{*}{ Porto Seguro } & \multirow[t]{5}{*}{ Valid } & Nunca & 1 & 10,0 & 10,0 & 10,0 \\
\hline & & Às vezes & 3 & 30,0 & 30,0 & 40,0 \\
\hline & & Frequentemente & 3 & 30,0 & 30,0 & 70,0 \\
\hline & & Sempre & 3 & 30,0 & 30,0 & 100,0 \\
\hline & & Total & 10 & 100,0 & 100,0 & \\
\hline \multirow[t]{5}{*}{ Telefônica } & \multirow[t]{5}{*}{ Valid } & Nunca & 1 & 25,0 & 25,0 & 25,0 \\
\hline & & Às vezes & 1 & 25,0 & 25,0 & 50,0 \\
\hline & & Frequentemente & 1 & 25,0 & 25,0 & 75,0 \\
\hline & & Sempre & 1 & 25,0 & 25,0 & 100,0 \\
\hline & & Total & 4 & 100,0 & 100,0 & \\
\hline
\end{tabular}

Fonte: Elaborado pelo autor. Tabela gerada pelo SPSS.

Tabela 5 - Frequência e percentual de respostas para assimilação

\begin{tabular}{|c|c|c|c|c|c|c|}
\hline \multicolumn{7}{|c|}{ Realização de reuniões periódicas com a grande empresa } \\
\hline \multicolumn{3}{|c|}{ Grande empresa } & Frequency & Percent & Valid Percent & $\begin{array}{c}\text { Cumulative } \\
\text { Percent }\end{array}$ \\
\hline \multirow[t]{4}{*}{ Braskem } & \multirow[t]{4}{*}{ Valid } & Raramente & 1 & 33,3 & 33,3 & 33,3 \\
\hline & & Frequentemente & 1 & 33,3 & 33,3 & 66,7 \\
\hline & & Sempre & 1 & 33,3 & 33,3 & 100,0 \\
\hline & & Total & 3 & 100,0 & 100,0 & \\
\hline \multirow[t]{3}{*}{ Google } & \multirow[t]{3}{*}{ Valid } & Raramente & 1 & 20,0 & 20,0 & 20,0 \\
\hline & & Frequentemente & 4 & 80,0 & 80,0 & 100,0 \\
\hline & & Total & 5 & 100,0 & 100,0 & \\
\hline \multirow[t]{6}{*}{ Itaú Unibanco } & \multirow[t]{6}{*}{ Valid } & Nunca & 1 & 9,1 & 9,1 & 9,1 \\
\hline & & Raramente & 1 & 9,1 & 9,1 & 18,2 \\
\hline & & Às vezes & 1 & 9,1 & 9,1 & 27,3 \\
\hline & & Frequentemente & 7 & 63,6 & 63,6 & 90,9 \\
\hline & & Sempre & 1 & 9,1 & 9,1 & 100,0 \\
\hline & & Total & 11 & 100,0 & 100,0 & \\
\hline \multirow{5}{*}{ Porto Seguro } & \multirow[t]{5}{*}{ Valid } & Raramente & 1 & 10,0 & 10,0 & 10,0 \\
\hline & & Às vezes & 2 & 20,0 & 20,0 & 30,0 \\
\hline & & Frequentemente & 2 & 20,0 & 20,0 & 50,0 \\
\hline & & Sempre & 5 & 50,0 & 50,0 & 100,0 \\
\hline & & Total & 10 & 100,0 & 100,0 & \\
\hline \multirow[t]{3}{*}{ Telefônica } & \multirow[t]{3}{*}{ Valid } & Às vezes & 3 & 75,0 & 75,0 & 75,0 \\
\hline & & Sempre & 1 & 25,0 & 25,0 & 100,0 \\
\hline & & Total & 4 & 100,0 & 100,0 & \\
\hline
\end{tabular}

Fonte: Elaborado pelo autor. Tabela gerada pelo SPSS. 
Tabela 6 - Frequência e percentual de respostas para transformação

Aplicação dos novos conhecimentos adquiridos da grande empresa ao trabalho prático da startup

\begin{tabular}{|c|c|c|c|c|c|c|}
\hline \multicolumn{3}{|c|}{ Grande empresa } & Frequency & Percent & Valid Percent & $\begin{array}{c}\text { Cumulative } \\
\text { Percent }\end{array}$ \\
\hline \multirow[t]{3}{*}{ Braskem } & \multirow[t]{3}{*}{ Valid } & Às vezes & 1 & 33,3 & 33,3 & 33,3 \\
\hline & & Sempre & 2 & 66,7 & 66,7 & 100,0 \\
\hline & & Total & 3 & 100,0 & 100,0 & \\
\hline \multirow[t]{4}{*}{ Google } & \multirow[t]{4}{*}{ Valid } & Nunca & 1 & 20,0 & 20,0 & 20,0 \\
\hline & & Raramente & 3 & 60,0 & 60,0 & 80,0 \\
\hline & & Frequentemente & 1 & 20,0 & 20,0 & 100,0 \\
\hline & & Total & 5 & 100,0 & 100,0 & \\
\hline \multirow[t]{6}{*}{ Itaú Unibanco } & \multirow[t]{6}{*}{ Valid } & Nunca & 1 & 9,1 & 9,1 & 9,1 \\
\hline & & Raramente & 3 & 27,3 & 27,3 & 36,4 \\
\hline & & Às vezes & 2 & 18,2 & 18,2 & 54,5 \\
\hline & & Frequentemente & 3 & 27,3 & 27,3 & 81,8 \\
\hline & & Sempre & 2 & 18,2 & 18,2 & 100,0 \\
\hline & & Total & 11 & 100,0 & 100,0 & \\
\hline \multirow[t]{5}{*}{ Porto Seguro } & \multirow[t]{5}{*}{ Valid } & Nunca & 2 & 20,0 & 20,0 & 20,0 \\
\hline & & Às vezes & 3 & 30,0 & 30,0 & 50,0 \\
\hline & & Frequentemente & 2 & 20,0 & 20,0 & 70,0 \\
\hline & & Sempre & 3 & 30,0 & 30,0 & 100,0 \\
\hline & & Total & 10 & 100,0 & 100,0 & \\
\hline \multirow[t]{4}{*}{ Telefônica } & \multirow[t]{4}{*}{ Valid } & Nunca & 1 & 25,0 & 25,0 & 25,0 \\
\hline & & Raramente & 2 & 50,0 & 50,0 & 75,0 \\
\hline & & Sempre & 1 & 25,0 & 25,0 & 100,0 \\
\hline & & Total & 4 & 100,0 & 100,0 & \\
\hline
\end{tabular}

Fonte: Elaborado pelo autor. Tabela gerada pelo SPSS.

Tabela 7 - Frequência e percentual de respostas para exploração

Utilização das informações e conhecimentos obtidos da grande empresa no desenvolvimento de novos produtos e serviços ou na melhoria do desempenho da startup

\begin{tabular}{|c|c|c|c|c|c|c|}
\hline \multicolumn{3}{|c|}{ Grande empresa } & Frequency & Percent & Valid Percent & $\begin{array}{c}\text { Cumulative } \\
\text { Percent }\end{array}$ \\
\hline \multirow{3}{*}{ Braskem } & \multirow[t]{3}{*}{ Valid } & Frequentemente & 2 & 66,7 & 66,7 & 66,7 \\
\hline & & Sempre & 1 & 33,3 & 33,3 & 100,0 \\
\hline & & Total & 3 & 100,0 & 100,0 & \\
\hline \multirow[t]{5}{*}{ Google } & \multirow[t]{5}{*}{ Valid } & Nunca & 1 & 20,0 & 20,0 & 20,0 \\
\hline & & Raramente & 2 & 40,0 & 40,0 & 60,0 \\
\hline & & Frequentemente & 1 & 20,0 & 20,0 & 80,0 \\
\hline & & Sempre & 1 & 20,0 & 20,0 & 100,0 \\
\hline & & Total & 5 & 100,0 & 100,0 & \\
\hline \multirow[t]{6}{*}{ Itaú Unibanco } & \multirow[t]{6}{*}{ Valid } & Nunca & 1 & 9,1 & 9,1 & 9,1 \\
\hline & & Raramente & 1 & 9,1 & 9,1 & 18,2 \\
\hline & & Às vezes & 4 & 36,4 & 36,4 & 54,5 \\
\hline & & Frequentemente & 3 & 27,3 & 27,3 & 81,8 \\
\hline & & Sempre & 2 & 18,2 & 18,2 & 100,0 \\
\hline & & Total & 11 & 100,0 & 100,0 & \\
\hline \multirow[t]{5}{*}{ Porto Seguro } & \multirow[t]{5}{*}{ Valid } & Nunca & 1 & 10,0 & 10,0 & 10,0 \\
\hline & & Às vezes & 2 & 20,0 & 20,0 & 30,0 \\
\hline & & Frequentemente & 3 & 30,0 & 30,0 & 60,0 \\
\hline & & Sempre & 4 & 40,0 & 40,0 & 100,0 \\
\hline & & Total & 10 & 100,0 & 100,0 & \\
\hline \multirow[t]{5}{*}{ Telefônica } & \multirow[t]{5}{*}{ Valid } & Nunca & 1 & 25,0 & 25,0 & 25,0 \\
\hline & & Raramente & 1 & 25,0 & 25,0 & 50,0 \\
\hline & & Frequentemente & 1 & 25,0 & 25,0 & 75,0 \\
\hline & & Sempre & 1 & 25,0 & 25,0 & 100,0 \\
\hline & & Total & 4 & 100,0 & 100,0 & \\
\hline
\end{tabular}

Fonte: Elaborado pelo autor. Tabela gerada pelo SPSS. 
Gráfico 3 - Frequência relativa ponderada das dimensões da capacidade de absorção

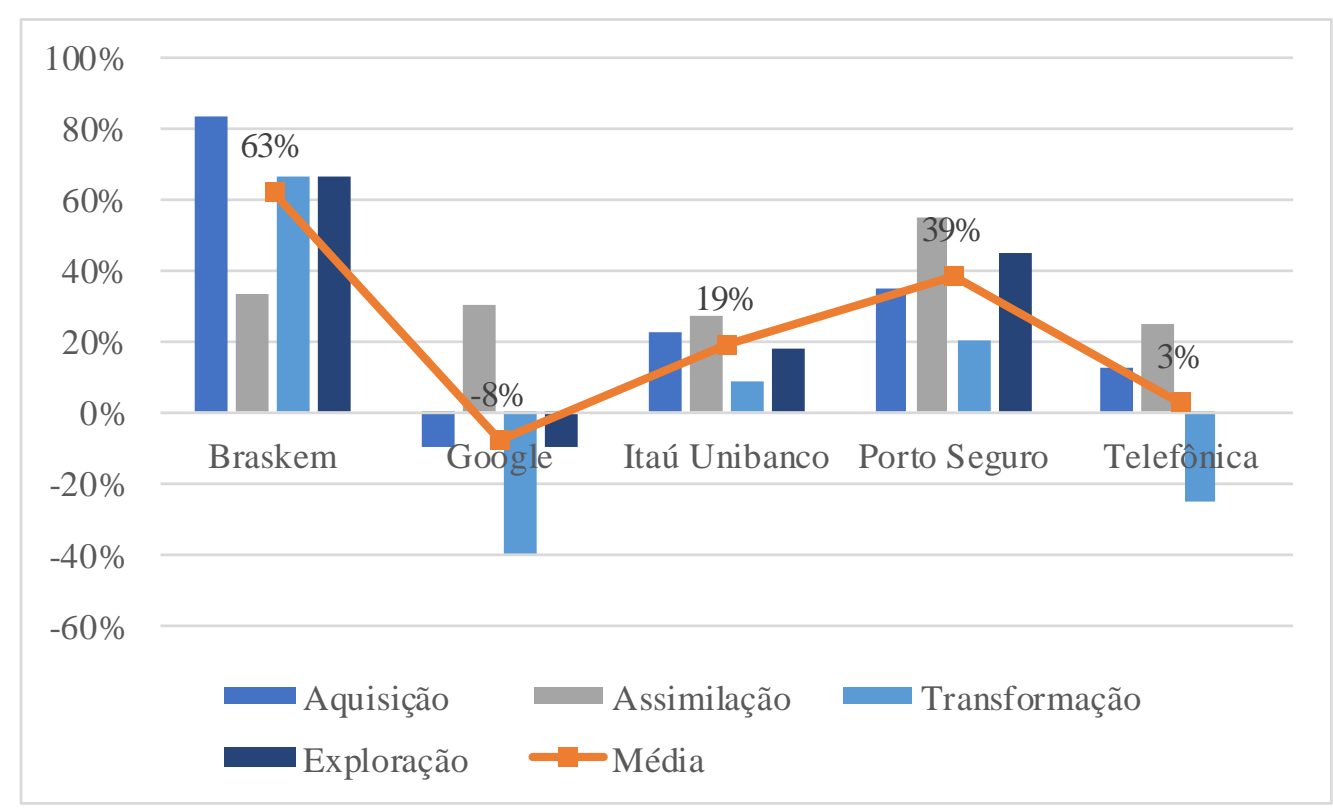

Fonte: Elaborado pelo autor.

Analisando o Gráfico 3, o sinal da média não deve ser interpretado como valor positivo ou negativo, mas apenas como indicador do sentido semântico da medida, ou seja, o valor da média indica a quantidade de atributo nesse sentido (PEREIRA, 2001). Neste estudo, limitando-se a amostra de startups respondentes, conclui-se que há uma tendência no sentido de não absorver conhecimento junto à grande empresa com uma intensidade de $8 \%$ para a amostra de startups ligadas ao Google. Em sentido oposto, há uma tendência de absorver conhecimento junto à grande empresa, com uma intensidade de $63 \%$ para a amostra de startups ligadas a Braskem, 39\% para a Porto Seguro, 19\% para o Itaú Unibanco e 3\% para a Telefônica.

Para que se estabeleça um valor de referência com relação às dimensões da capacidade de absorção, que será utilizado para definição das startups que serão investigadas em profundidade, primeiramente é necessário verificar se a distribuição como um todo se desvia de uma distribuição normal modelo. Os testes de Kolmogorov-Smirnov e de Shapiro-Wilk (Tabela 8) comparam escores de uma amostra a uma distribuição normal modelo de mesma média e variância dos valores encontrados na amostra. 
Tabela 8 - Teste de normalidade da média geral das dimensões da capacidade de absorção

\begin{tabular}{|c|c|c|c|c|c|c|}
\hline \multicolumn{1}{|c|}{ Tests of Normality } \\
\cline { 2 - 8 } & \multicolumn{2}{|c|}{ Kolmogorov-Smirnov } & \multicolumn{3}{c|}{ Shapiro-Wilk } \\
\cline { 2 - 7 } & Statistic & df & Sig. & Statistic & df & Sig. \\
\hline Média_Geral &, 161 & 5 &, $200^{*}$ &, 966 & 5 &, 848 \\
\hline
\end{tabular}

a. Lilliefors Significance Correction

*. This is a lower bound of the true significance.

Fonte: Elaborado pelo autor. Tabela gerada pelo SPSS.

Observa-se que o teste é não-significativo (os valores na coluna denominada Sig. são maiores do que 0,05), informando que os dados da amostra não diferem significativamente de uma distribuição normal, isto é, as distribuições são possivelmente normais (FIELD, 2009).

De posse dessa afirmação, pode-se utilizar a média da frequência relativa ponderada das dimensões da capacidade de absorção, neste caso 23,2\%, como mostra a Tabela 9, para estabelecer um valor de referência onde as startups que apresentaram uma intensidade de capacidade de absorção superior a média foram selecionadas para entrevista, observação nãoparticipante e análise documental, de acordo com o previsto no protocolo para o estudo de caso (APÊNDICE A).

Tabela 9 - Estatística descritiva da média geral das dimensões da capacidade de absorção

\section{Statistics}

Média Geral
\begin{tabular}{|l|r|}
\hline N $\quad$ Valid & Missing \\
Mean & 0 \\
Median & 23,20 \\
Mode & 19,00 \\
Std. Deviation & $-8^{\mathrm{a}}$ \\
Variance & 28,429 \\
\hline
\end{tabular}

a. Multiple modes exist. The smallest value is shown

Fonte: Elaborado pelo autor. Tabela gerada pelo SPSS.

Como critério de seleção, também foi utilizado o índice de reconhecimento da parceria entre as startups e as grandes empresas, já apresentado na Tabela 3 (Startup_reconhece_parceria vs. \% within Grande_empresa). Da mesma forma, foi aplicado o teste de normalidade para verificar se o índice de reconhecimento da parceria identifica-se com uma distribuição normal, como mostra a Tabela 10. 
Tabela 10 - Teste de normalidade do índice de reconhecimento da parceria

\begin{tabular}{|l|r|r|r|r|r|r|}
\hline \multicolumn{1}{|c|}{ Tests of Normality } \\
\cline { 2 - 8 } & \multicolumn{3}{|c|}{ Kolmogorov-Smirnov } & \multicolumn{3}{c|}{ Shapiro-Wilk } \\
\cline { 2 - 8 } & Statistic & df & Sig. & Statistic & df & Sig. \\
\hline $\begin{array}{l}\text { Startup reconhece_ } \\
\text { parceria }\end{array}$ &, 257 & 5 &, $200^{*}$ &, 927 & 5 &, 575 \\
\hline
\end{tabular}

a. Lilliefors Significance Correction

*. This is a lower bound of the true significance.

Fonte: Elaborado pelo autor. Tabela gerada pelo SPSS.

Observa-se que o teste é não-significativo ( $\mathrm{p}>0,05)$, informando que os índices apresentados por cada grande empresa não diferem significativamente de uma distribuição normal (isto é, eles podem ser normais), o que indica a utilização da média como uma medida de tendência central para se estabelecer um valor de referência e consequentemente, um critério de seleção das unidades de análise. O Gráfico 4, então, mostra o índice de startups que reconhecem a parceria com a grande empresa e o ponto médio, indicando que serão selecionadas para entrevista, observação não-participante e análise documental as startups cujo índice esteja acima da média.

Gráfico 4 - Índice de reconhecimento da parceria entre startups e grandes empresas

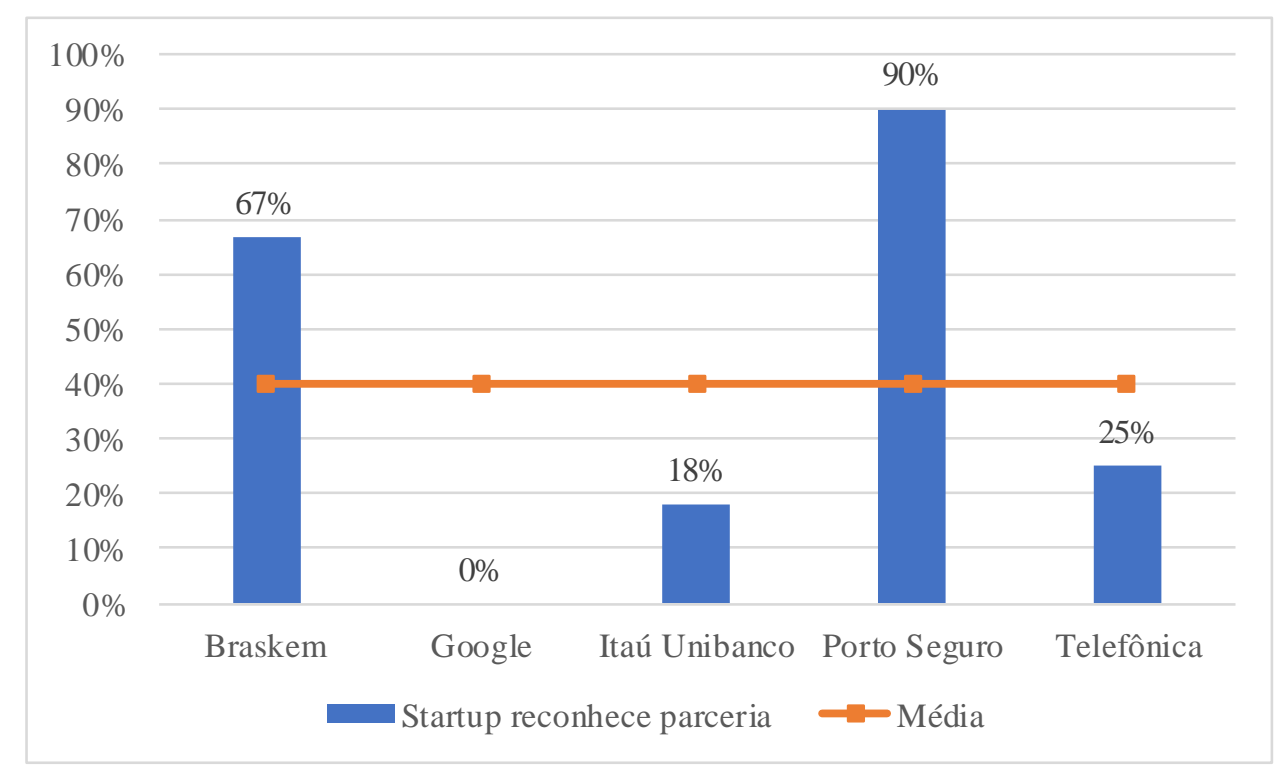

Fonte: Elaborado pelo autor.

\subsection{Definição das unidades de análise}


Sintetizando as informações apresentadas nas seções anteriores, a população examinada neste estudo são startups que mantém algum tipo de relacionamento interorganizacional para inovação com grandes empresas. É importante ressaltar que essa população foi intencionalmente selecionada, pois buscou-se startups inseridas em programas de aceleração corporativa no Brasil. Essa busca resultou em uma população de 175 startups, contudo, 160 estavam com os dados disponíveis para a coleta de informações. As startups estavam distribuídas em cinco programas de aceleração fomentados por grandes empresas.

A utilização de uma pesquisa de levantamento (survey) por meio de um questionário online foi decisiva para a definição da primeira amostra do estudo, buscando startups que indicassem um grau razoável de capacidade de absorção e informações relevantes para caracterizar o relacionamento interorganizacional com a grande empresa. Nessa etapa, obteve-se respostas de 34 startups convidadas a participarem da pesquisa, gerando uma amostra de 33 startups consideradas válidas para o estudo.

De posse dessa amostra, foram realizadas algumas inferências estatísticas envolvendo a formulação de certos julgamentos sobre as startups respondentes, de onde surgiram informações relevantes quanto ao desenvolvimento da capacidade de absorção, para a seleção das startups que foram investigadas em profundidade. Essa amostragem não é probabilística, pois foi realizada seguindo os critérios ou julgamentos descritos na seção anterior. Observando novamente o Gráfico 3 e Gráfico 4, conclui-se que houve uma convergência de características que indicassem um grau razoável de capacidade de absorção junto às startups ligadas a Braskem e Porto Seguro e, deste modo, o Quadro 11 apresenta as unidades de análise que foram selecionadas dentro do grupo de startups respondentes.

Quadro 11 - Startups pré-definidas como unidades de análise

\begin{tabular}{|l|l|}
\hline \multicolumn{1}{|c|}{ Grande Empresa } & \multicolumn{1}{c|}{ Unidades de Análise } \\
\hline \multirow{2}{*}{ Braskem } & BR Goods \\
& Vasos Raiz \\
\hline \multirow{3}{*}{ Porto Seguro } & Bynd \\
& Confere Cartões \\
& CreBit \\
& Evnts \\
& Klooks \\
& Mania de Passar \\
& Nexoos \\
& Psicologia Viva \\
& Reboque.me \\
\hline
\end{tabular}

Fonte: Elaborado pelo autor. 
$\mathrm{Na}$ segunda quinzena de dezembro de 2017, iniciou-se o contato com as 11 startups selecionadas, de acordo com as informações para contato disponibilizadas pelas mesmas no formulário de pesquisa online. $\mathrm{O}$ objetivo dessa etapa foi agendar uma entrevista com o proprietário, gestor ou responsável pela startup, para que os dados primários fossem coletados seguindo o método já descrito. Obteve-se uma resposta positiva de sete startups (quatro se recusaram a participar do estudo) e as entrevistas ocorreram entre a segunda quinzena de dezembro de 2017 e a primeira quinzena de janeiro de 2018.

Com base nas startups apresentadas na Figura 11, reconfigurou-se o conjunto de dados que foram estudados, formando a amostra deste estudo. Vale observar que a amostra conta com startups que indicaram um grau razoável de capacidade de absorção e que reconheceram a parceria junto às grandes empresas Braskem (BR Goods e Raiz) e Porto Seguro (Bynd, Confere Cartões, Evnts, Nexoos e Psicologia Viva).

Figura 11 - Startups participantes do estudo (unidades de análise)

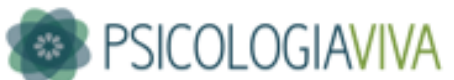

Marketplace para conectar paciente a psicólogos através da web conference em ambiente seguro, com sede em Belo Horizonte - MG

\section{NEXOS}

Plataforma de empréstimos peer-to-peer para pequenas e médias empresas, que conecta empresas em busca de crédito com pessoas dispostas a financiá-las, proporcionando taxas de juros mais baixas e retornos mais expressivos aos investidores, com sede em São Paulo - SP

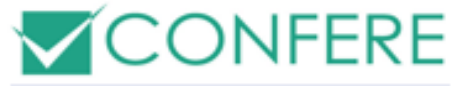

Plataforma SaaS para gerenciamento e conciliação automática de vendas em cartão de crédito e débito, focado em pequenas e médias empresas, com sede em São Paulo - SP

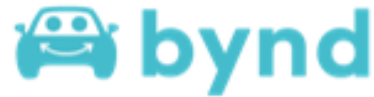

Solução de mobilidade urbana para grandes cidades, que busca melhorar a experiência das pessoas em seu tráfego entre casa e trabalho e oferecer eficiência no transporte para corporações através de caronas, com sede em São Paulo - SP

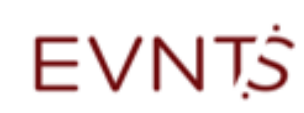

Ferramenta de reserva de hotéis para eventos e grupos, oferece descontos de até $40 \%$ em mais de 2500 hotéis além de beneficios para organizadores e participantes, com sede em São Paulo - SP

\section{br goods}

Especiallizada em cartines divisóries
e acabaimentos

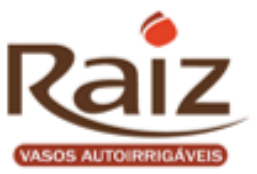

Sistema que facilita o cuidado com plantas na residência do usuário, onde a irrigação interna garante umidade para a terra por vários dias, sem a necessidade de regar e não permitindo a proliferação do mosquito Aedes aegypti, com sede em Novo Hamburgo - RS

Referência na fabricação de cortinas divisórias de leito hospitalar e box de chuveiro, que utilizam nanotecnologia retardante de chamas, antimicrobianas, manufaturadas com plástico verde, com sede em Indaiatuba - SP

Fonte: Elaborado pelo autor.

O Quadro 12 mostra as startups fontes de informação, o método de coleta de dados e as siglas para a devida identificação. Vale ressaltar que nas entrevistas realizadas por Skype, os 
empreendedores entrevistados estavam localizados na sede ou escritório da startup, de modo a manter o foco da conversa restrito aos temas de interesse da pesquisa e deixar o entrevistado confortável com a situação de investigação, no âmbito dos relacionamentos interorganizacionais com as grandes empresas.

Quadro 12 - Quadro de siglas de entrevistados

\begin{tabular}{|c|c|c|c|}
\hline Fonte da Informação & Sigla da Startup & Método de Coleta & Sigla do Entrevistado \\
\hline $\begin{array}{l}\text { Entrevistado Psicologia } \\
\text { Viva (BB) }\end{array}$ & \multirow{2}{*}{$\mathrm{S} 1$} & Entrevista por Skype & \multirow{2}{*}{ E1 } \\
\hline $\begin{array}{l}\text { Entrevistado Psicologia } \\
\text { Viva (ES) }\end{array}$ & & Entrevista pessoal & \\
\hline $\begin{array}{l}\text { Entrevistado Confere } \\
\text { Cartões (RC) }\end{array}$ & $\mathrm{S} 2$ & Entrevista pessoal & E2 \\
\hline $\begin{array}{l}\text { Entrevistado Bynd } \\
\text { (LL) }\end{array}$ & S3 & Entrevista pessoal & E3 \\
\hline $\begin{array}{l}\text { Entrevistado Nexoos } \\
\text { (JG \& MB) }\end{array}$ & S4 & Entrevista pessoal & E4 \\
\hline $\begin{array}{l}\text { Entrevistado Evnts } \\
\text { (MQ) }\end{array}$ & S5 & Entrevista pessoal & E5 \\
\hline $\begin{array}{l}\text { Entrevistado Vasos } \\
\text { Raiz (JM) }\end{array}$ & S6 & Entrevista por Skype & E6 \\
\hline $\begin{array}{l}\text { Entrevistado BR Goods } \\
\text { (BA) }\end{array}$ & S7 & Entrevista por Skype & E7 \\
\hline
\end{tabular}

Fonte: Elaborado pelo autor. 


\section{ORGANIZAÇÃO DA ANÁLISE DE DADOS}

De acordo com o que já foi descrito na seção "Método", as diferentes fases da análise de conteúdo organizam-se em torno de três polos cronológicos. O presente capítulo descreve com mais detalhes as fases de pré-análise e exploração do material, uma vez que as unidades de análise já foram definidas. O tratamento dos resultados obtidos e sua interpretação serão devidamente explorados na seção "Análise e discussão dos resultados".

\subsection{Pré-análise dos dados}

Esta fase constitui a organização propriamente dita do plano de análise de dados, com o objetivo de tornar operacionais e sistematizar as ideias e informações já levantadas pelos casos e unidades de análise. Destaca-se na pré-análise a escolha dos documentos a serem submetidos à análise, a formulação e elaboração de indicadores que irão fundamentar a interpretação final. Citando Bardin (2016) é necessário constituir um corpus textual, ou seja, um conjunto de documentos tidos em conta para serem submetidos aos procedimentos analíticos. Neste estudo, as entrevistas semiestruturadas realizadas com as sete startups foram registradas em áudio e integralmente transcritas. Ademais, foi realizada uma busca sistematizada pela internet de notícias, artigos e entrevistas envolvendo as startups estudadas, com o objetivo de se obter o máximo de informações pertinentes das unidades de análise. Integrando o conjunto de documentos analisados estão também as anotações do diário de campo, realizadas durantes as entrevistas. O material reunido no corpus foi preparado de modo a ser submetido a análise de dados assistidos por computador, destacando os softwares Iramuteq e NVivo.

Sendo a análise de conteúdo uma análise das comunicações que busca descrever o conteúdo das mensagens, considera-se o corpus textual uma manifestação que contém índices que a análise explicitará (BARDIN, 2016). Nesse contexto, o trabalho de análise consistiu-se em buscar no corpus textual os índices correspondentes ao constructo de capacidade de absorção tanto potencial quanto realizada, em suas quatro dimensões e gerenciamento de processos de negócio. Levando em conta os índices (também chamados de unidades de registro) definidos pela base teórica, procedeu-se a construção dos indicadores, que auxiliaram as operações de recorte dos textos e codificação.

A construção dos indicadores levou em consideração pesquisas empíricas que buscaram operacionalizar o constructo de capacidade de absorção (CAMISÓN; FORÉS, 2010; FLATTEN et al., 2011; JIMÉNEZ-BARRIONUEVO; GARCÍA-MORALES; MOLINA, 2011; 
PAVLOU; EL SAWY, 2006), de onde foram elaborados instrumentos de medida amplamente aceitos e que contemplam suas dimensões. Essas diversas medidas de capacidade de absorção empregadas em estudos anteriores serviram de base para a extração de palavras-chave, utilizadas como indicadores precisos e seguros para o tratamento do material reunido, ou seja, para sua codificação, em concordância com Bardin (2016, p. 133)

A codificação corresponde a uma transformação - efetuada segundo regras precisas dos dados brutos do texto, transformação esta que, por recorte, agregação e enumeração, permite atingir uma representação do conteúdo ou da sua expressão.

A síntese de palavras-chave decorrentes das medidas de capacidade de absorção apresentadas por estudos anteriores (CAMISÓN; FORÉS, 2010; FLATTEN et al., 2011; JIMÉNEZBARRIONUEVO; GARCÍA-MORALES; MOLINA, 2011; PAVLOU; EL SAWY, 2006) estão descritas no Quadro 13. As partes do tex to com as medidas de capacidade de absorção de cada autor foram traduzidas para o português, com as quais, posteriormente, foi realizada uma parametragem e extração de palavras, cuja lógica foi trabalhar com os elementos de linguagem plenos, ou seja, portadores de sentido: adjetivos, substantivos e verbos (BARDIN, 2016; CAMARGO; JUSTO, 2018).

Quadro 13 - Palavras-chave utilizadas como indicadores da capacidade de absorção

\begin{tabular}{|l|l|l|l|}
\hline \multicolumn{1}{|c|}{ Aquisição } & \multicolumn{1}{|c|}{ Assimilação } & Transformação & \multicolumn{1}{c|}{ Exploração } \\
\hline Adquirir (v.) & Analisar (v.) & Absorver (v.) & Adaptar (v.) \\
\hline Aprender (v.) & Apresentar (v.) & Adaptação (s.) & Adotar (v.) \\
\hline Aquisição (s.) & Assimilação (s.) & Alternativa (s.) & Aplicação (s.) \\
\hline Atualizado (adj.) & Assimilar (v.) & Compartilhar (v.) & Apoiar (v.) \\
\hline Busca (s.) & Assistir (v.) & Competência (s.) & Aplicar (v.) \\
\hline Buscar (v.) & Beneficiar (v.) & Coordenar (v.) & Colocar (v.) \\
\hline Captar (v.) & Compatibilidade (s.) & Desenvolver (v.) & Competitividade (s.) \\
\hline Confiança (s.) & Compatível (adj.) & Discutir (v.) & Concreto (adj.) \\
\hline Conhecimento (s.) & Complementaridade (s.) & Disponível (adj.) & Demanda (s.) \\
\hline Cooperação (s.) & Compreender (v.) & Eliminar (v.) & Eficaz (adj.) \\
\hline Criar (v.) & Comunicado (s.) & Estimular (v.) & Eficiente (adj.) \\
\hline Descobrir (v.) & Comunicar (v.) & Estruturar (v.) & Exigência (s.) \\
\hline Fonte (s.) & Conceito (s.) & Fluir (v.) & Exito (s.) \\
\hline Identificar (v.) & Departamento (s.) & Fomentar (v.) & Exploração (s.) \\
\hline Influenciar (v.) & Enfatizar (v.) & Integrar (v.) & Explorar (v.) \\
\hline Informação (s.) & Estilo (s.) & Melhorar (v.) & Explorado (adj.) \\
\hline Insight (s.) & Fluxo (s.) & Necessidade (s.) & Manter (v.) \\
\hline Interação (s.) & Ideia (s.) & Obsoleto (adj.) & Mudança (s.) \\
\hline
\end{tabular}


Conclusão

\begin{tabular}{|l|l|l|l|}
\hline \multicolumn{1}{|c|}{ Aquisição } & \multicolumn{1}{|c|}{ Assimilação } & \multicolumn{1}{c|}{ Transformação } & \multicolumn{1}{c|}{ Exploração } \\
\hline Lidar (v.) & Importar (v.) & Prático (adj.) & Patente (s.) \\
\hline Monitorar (v.) & Informado (adj.) & Preparar (v.) & Portfólio (s.) \\
\hline Nova (s.) & Intercambiar (v.) & Publicar (v.) & Pressão (s.) \\
\hline Oportunidade (s.) & Interpretação (s.) & Relacionar (v.) & Processo (s.) \\
\hline Orientação (s.) & Linguagem (s.) & Relação (s.) & Produto (s.) \\
\hline Preocupação (s.) & Participação (s.) & Sensibilização (s.) & Protótipo (s.) \\
\hline Programa (s.) & Partilhar (v.) & Tornar (v.) & Reconsiderar (v.) \\
\hline Reciprocidade (s.) & Periódico (adj.) & Transformação (s.) & Responder (v.) \\
\hline Relevante (adj.) & Realizar (v.) & Transformar (v.) & Responsabilidade (s.) \\
\hline Respeito (s.) & Resolver (v.) & Transmitir (v.) & Usar (v.) \\
\hline Tendência (s.) & Reunião (s.) & & Uso (s.) \\
\hline & Rotina (s.) & & Utilização (s.) \\
\hline & Semelhante (adj.) & & Utilizar (v.) \\
\hline & Similaridade (s.) & & Vanguarda (s.) \\
\hline & Suporte (s.) & & \\
\hline & Útil (adj.) & & \\
\hline & Valorizar (v.) & & \\
\hline
\end{tabular}

Fonte: Elaborado pelo autor.

Buscando elucidar as regras previamente formuladas que conduziram as operações de codificação do material, introduzidas na Figura 6, as palavras-chave utilizadas em um nível linguístico, devidamente categorizados em classes gramaticais, conduziram os recortes de texto a um nível semântico que por sua vez, levaram ao tema propriamente dito. Parafraseando Bardin (2016), o tema é utilizado como unidade de registro para estudar motivações de opiniões, de atitudes, de valores, de tendências, etc. e as respostas a questões abertas formuladas em uma entrevista podem ser analisadas tendo o tema por base.

O tema processos de negócio também é uma unidade de registro a ser buscada no corpus textual e como já foi mencionado anteriormente, não há uma classificação (taxonomia) única de processos. As palavras-chave constantes no Quadro 4 auxiliaram as operações de recorte dos textos e codificação, pois apresentam definições para termos distintos e que são usualmente relacionados com processos de negócio.

\subsection{Exploração do material}

Bardin (2016) esclarece que, se as diferentes operações da pré-análise forem convenientemente concluídas, a fase de exploração do material consiste na análise propriamente dita e compreende 
a aplicação sistemática das decisões tomadas. Esta fase resume-se essencialmente nas operações de codificação, decomposição ou enumeração do corpus textual, em função das regras previamente formuladas.

A exploração do material contou com o auxílio de operações efetuadas por computador, onde foram utilizados os softwares NVivo para tratamento do texto, que corresponde às funções de recorte, codificação e análise e Iramuteq, para as operações estatísticas sobre os resultados. O uso do computador sobre a prática da análise de conteúdo aumenta a rapidez e acrescenta rigor na organização da investigação, uma vez que o computador recusa a ambiguidade, desde que sejam definidas regras claras de inferência (BARDIN, 2016).

O NVivo é um software que apoia a pesquisa que utiliza métodos qualitativos e mistos, projetado para ajudar a organizar, analisar e encontrar insights em dados não estruturados ou qualitativos como entrevistas, respostas de pesquisa abertas, artigos, mídias sociais e conteúdo da web (NVIVO, 2018). O Iramuteq é uma interface para análise multidimensional de textos e questionários, que usa como base o Sistema $\mathrm{R}$ de estatística. O software viabiliza diferentes tipos de análise de dados textuais, desde a lexicografia básica, que abrange sobretudo a lematização e o cálculo de frequência de palavras até análises multivariadas como classificação hierárquica descendente, análise pós-fatorial de correspondências e análises de similitude. Por meio desse software, a distribuição do vocabulário pode ser organizada de forma facilmente compreensível e visualmente clara, com representações gráficas pautadas nas análises lexicográficas (CAMARGO; JUSTO, 2018).

O primeiro passo para realizar a análise utilizando o Iramuteq foi construir o corpus textual, composto pelas unidades de contexto provenientes das respostas dos questionários de entrevistas, devidamente transcritas. Todo o material foi colocado em um único arquivo de texto, separados por linhas de comando com asteriscos $(* * * *)$ ou seja, para que cada entrevista e documento seja reconhecido pelo software como um texto individual, eles devem começar por uma linha desse tipo. Após os 4 asteriscos, há um espaço em branco e um novo asterisco (*), que isoladamente representa uma variável descritiva categorial. Tais variáveis possuem categorias ou modalidades, indicadas logo após o traço underline ( _ ). Neste estudo, o corpus textual foi organizado de acordo com o exemplo: ***** *rande_empresa_01 *startup_01 *entrevistado_01. A construção do corpus também envolveu tratamentos específicos ao texto, como supressão do material verbal produzido pelo pesquisador (intervenções e anotações) na transcrição das entrevistas, as palavras compostas ou hifenizadas foram unidas por um traço underline, para não serem entendidas pelo software como duas palavras distintas, os verbos que utilizavam pronomes ficaram na forma de próclise, pois o dicionário do software não prevê as 
flexões verbo-pronominais e foram retirados dos textos os caracteres aspas ("), apóstrofo ('), hífen (-), cifrão (\$), percentagem (\%), reticências (...) e asterisco $\left(^{*}\right)$, sendo este último utilizado somente nas linhas que antecedem cada texto, nas linhas de comando (CAMARGO; JUSTO, 2018).

Também nessa fase, o corpus textual composto pelos parágrafos de cada entrevista, assim como os textos de documentos e as anotações de diários de campo foi recortado em unidades de registro, com o auxílio do software NVivo. Essa operação de recorte e codificação consistiu em identificar as palavras-chave já definidas, gerando uma primeira categorização. Essas primeiras categorias foram agrupadas de acordo com temas correlatos, dando origem às categorias iniciais (aquisição, assimilação, transformação, exploração e processos de negócio), que no software são chamadas de "nós". As categorias iniciais foram agrupadas tematicamente, originando as categorias intermediárias (capacidade de absorção potencial e realizada) e por fim as categorias finais, aglutinadas em função da ocorrência dos temas (capacidade de absorção e gerenciamento de processos de negócio). Em suma, o texto das entrevistas e todo material coletado foi recortado em unidades de registro (palavras, frases e parágrafos), agrupadas tematicamente em categorias iniciais, intermediárias e finais, as quais possibilitaram as inferências. Por este processo indutivo ou inferencial, procura-se não apenas compreender o sentido da fala dos entrevistados, mas também as significações que a mensagem do corpus textual como um todo fornece, confrontando sistematicamente com os conceitos teóricos referenciados no trabalho (SILVA; FOSSÁ, 2015). 


\section{ANÁLISE E DISCUSSÃO DOS RESULTADOS}

Nesta seção, são apresentadas as análises realizadas na pesquisa empírica e o significado dos resultados encontrados, com o propósito de responder aos objetivos específicos do trabalho e sustentar a condução das discussões. A utilização do software Iramuteq e NVivo permitiu a realização de análises preliminares que auxiliaram a condução da análise de conteúdo, funcionando como uma primeira visão exploratória do conteúdo analisado.

Primeiramente, o corpus textual foi submetido a análise do Iramuteq, que divide todo o corpus em segmentos de texto, normalmente com três linhas, formando um contexto léxico. $\mathrm{O}$ agrupamento desse contexto léxico forma as classes, que por sua vez são partições que expressam os sentidos comuns do pensamento dos produtores dos textos, ou seja, os entrevistados (CAMARGO; JUSTO, 2018). No caso da análise das entrevistas, os segmentos de textos formados e as consequentes classes definidas agruparam as ideias comuns presentes nas sete startups da amostra, utilizando a classificação hierárquica descendente (CHD), onde as classes são apresentadas por meio de dendogramas.

Por meio do dendograma apresentado na Figura 12, percebe-se que as classes 1 e 3 estão mais próximas, da mesma forma que existe uma proximidade maior entre as classes 2 e 4 . Essas aproximações serão melhor percebidas na etapa seguinte, ao analisar o dendograma da CHD, onde encontram-se os resultados que identificam o conteúdo lexical das classes. 
Figura 12 - Dendograma preliminar do corpus textual

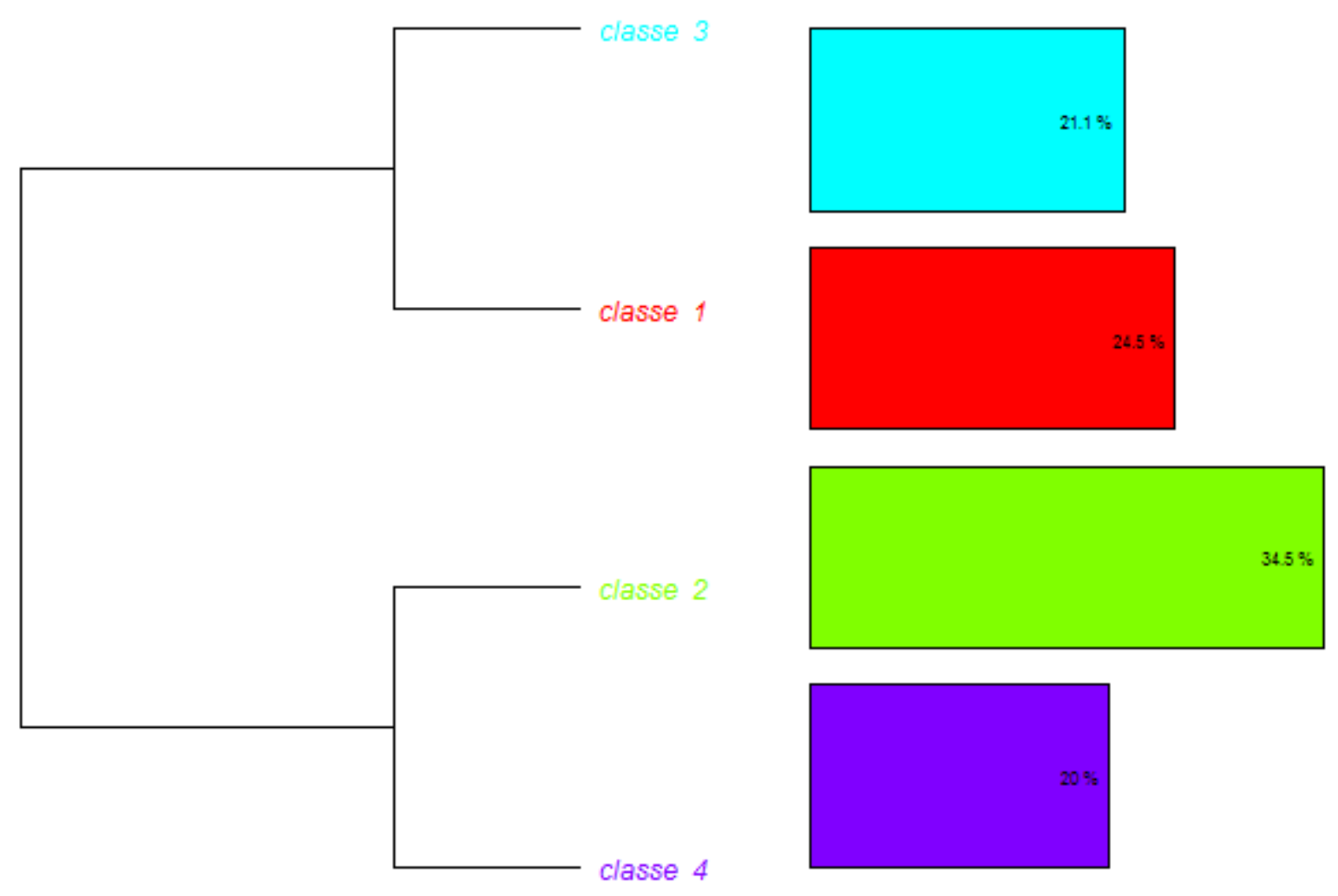

Fonte: Elaborado pelo autor. Figura gerada pelo Iramuteq.

Evidencia-se no dendograma da Figura 12 que nas sete startups pesquisadas, há quatro conceitos centrais envolvidos no discurso dos entrevistados ao responderem as perguntas da entrevista. A classe 1 representa 24,5\% dos segmentos de texto do corpus, a classe 2 representa $34,5 \%$ do conteúdo do corpus, a classe 3 representa $21,1 \%$ e a classe 4 representa $20 \%$ do corpus. O dendograma que ilustra a Figura 13 permite examinar todas as palavras que compõe o vocabulário de cada conceito central envolvido (classes) resultantes das entrevistas. 
Figura 13 - Dendograma do corpus textual com palavras-chave
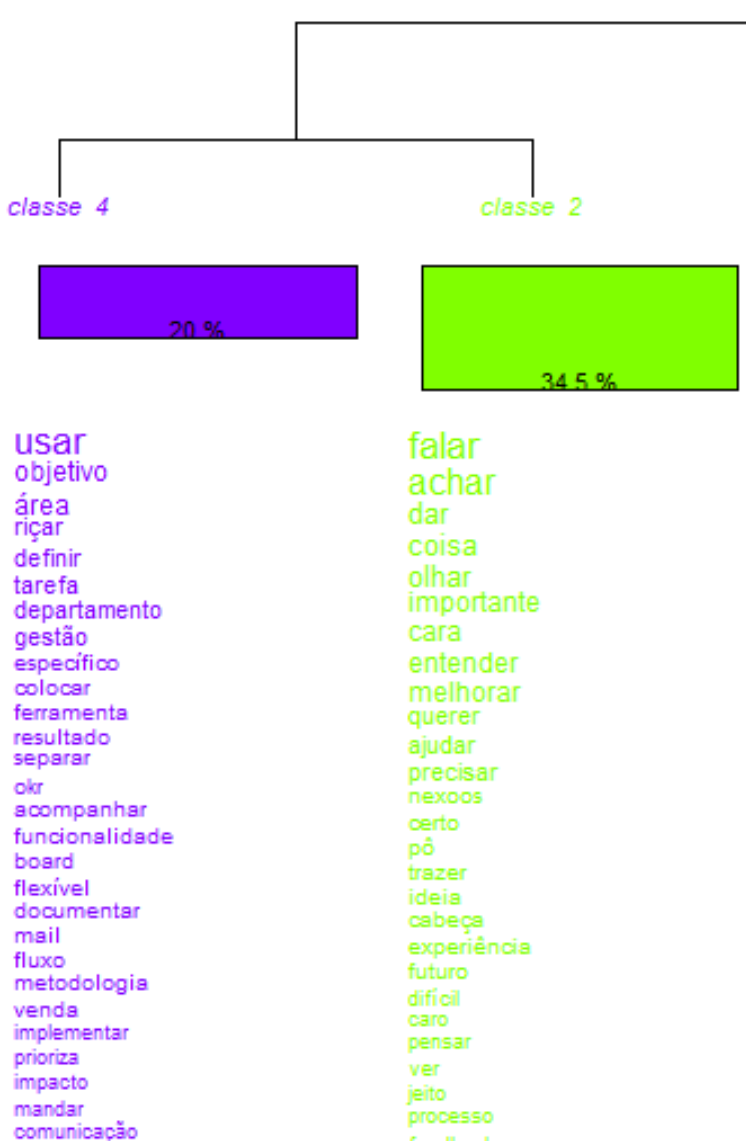
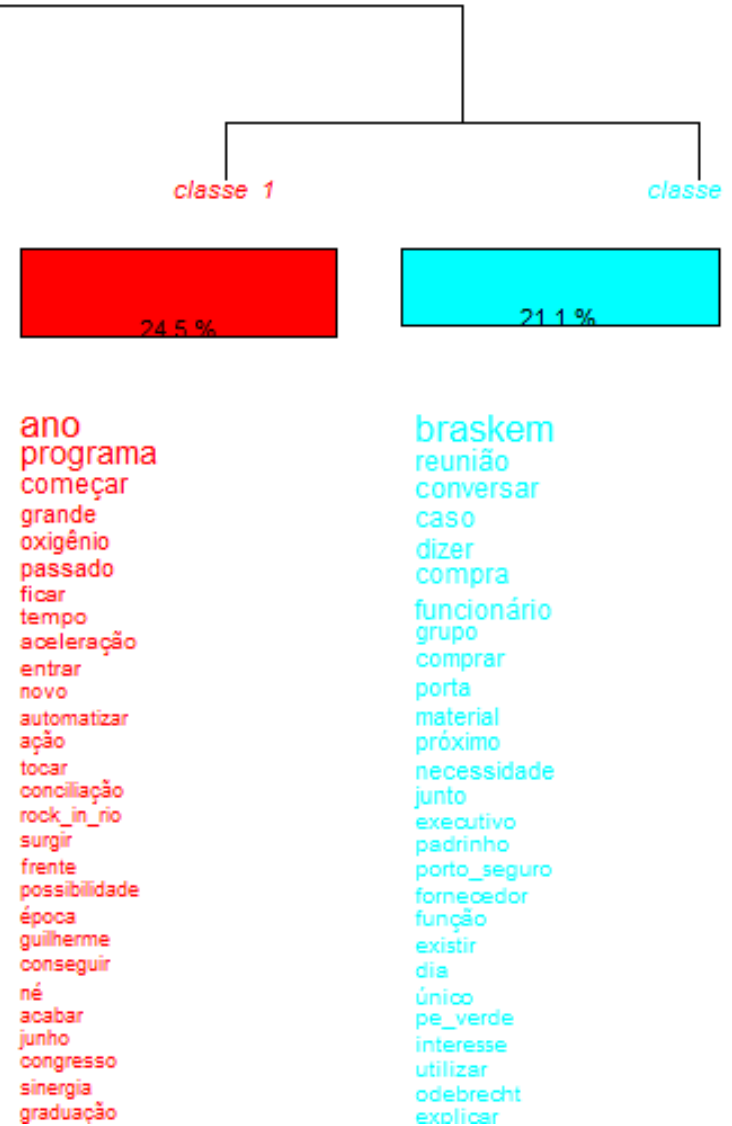

Fonte: Elaborado pelo autor. Figura gerada pelo Iramuteq.

É possível perceber que a classe 3 apresenta as principais palavras relacionadas às grandes empresas que se relacionam com as startups pesquisadas, neste caso, Braskem e Porto Seguro. Nessa classe também se nota algumas características das grandes empresas que corroboram com as informações coletadas pessoalmente nas entrevistas, como a exigência de reuniões periódicas junto às startups participantes dos programas de aceleração e a disponibilização de um executivo ou "padrinho" para acompanhar o processo, que atuava como um mentor. As startups relataram que tinham acesso facilitado aos executivos de diversas áreas e especialidades dentro da grande empresa, podendo solicitar mentorias e treinamentos específicos de acordo com suas necessidades. Uma característica presente na Braskem é servir de fornecedor de matérias-primas para algumas startups.

Analisando a classe 1, fica claro que o conceito central é o programa de aceleração promovido pelas grandes empresas e a proximidade de contexto com a classe 3 é evidente. Algumas palavras presentes nessa classe indicam que os programas de aceleração são temporais, ou seja, tem um início, meio e fim. Contudo, observou-se nas entrevistas que mesmo após o término formal do programa de aceleração, as startups continuaram mantendo contato com as grandes 
empresas e tendo acesso aos mentores. Percebe-se também na classe 1 a presença de verbos que indicam as novas possibilidades que surgiram para as startups inseridas nos programas, desde a mudança expressiva na gestão e desempenho organizacional até a abertura de mercado para novos clientes.

Já as classes 2 e 4 concentram um conjunto de palavras que expressam o discurso dos entrevistados relacionados à capacidade de absorção e processos de negócio. Analisando novamente as palavras-chave do Quadro 13, utilizadas como indicadores da capacidade de absorção, encontrou-se na classe 4 palavras como "comunicar", "departamento" e "fluxo", relacionadas a assimilação de conhecimento e "colocar" e "usar", evidentes na fase de exploração do conhecimento.

É importante destacar que a classe 2 representa 34,5\% do conteúdo do corpus textual, apresentando um número expressivo de palavras relacionadas aos temas centrais do estudo, considerando as palavras-chave já definidas e seus sinônimos, como "melhorar, "ideia", "processo", "falar" relacionada a "comunicar", "achar" relacionada a "resolver", "dar" relacionada a "informado" e "comunicar", "coisa" relacionada a "realizar", "olhar" relacionada a "assistir" e "analisar", "entender" relacionada a "compreender", "importante" relacionada a "relevante", dentre outras. A análise das palavras da classe 2 permitiu identificar que a capacidade de aquisição e assimilação do conhecimento, ou seja, a capacidade de absorção potencial, é muito mais desenvolvida nas startups que a capacidade de absorção realizada, pois as palavras concentram-se nessas duas dimensões. De fato, o foco dos programas de aceleração corporativa é disponibilizar os conhecimentos da grande empresa para compartilhar experiências com os empreendedores em fase inicial, ajudando a startup a definir estratégias e utilizar ferramentas para alavancar o negócio.

Essa análise preliminar do discurso dos entrevistados, utilizando o suporte estatístico do software Iramuteq, permitiu validar o material textual coletado nas entrevistas semiestruturadas, no sentido de alinhar o conteúdo a ser analisado aos objetivos específicos do trabalho.

O uso do software NVivo como auxílio às operações de recorte e codificação do material textual proveniente das entrevistas foi de grande valia, pois deu suporte estatístico às análises realizadas no presente estudo. Para exemplificar, observa-se na Figura 14 o agrupamento de palavras por similaridade de codificação, representado por um dendograma. Nessa análise de agrupamento (cluster), as distâncias euclidianas entre os segmentos de texto do material codificado foram calculadas e agrupadas, conforme a proximidade geométrica entre elas. Primeiramente, constitui-se um grupo inicial com os dois segmentos de texto mais próximos e em seguida, 
verifica-se qual segmento se localiza mais próximo desse primeiro grupo, formando assim um novo grupo. Esses cálculos ocorrem sucessivamente até que todos os segmentos de texto sejam reunidos no grupo total (PEREIRA, 2001).

Figura 14 - Nós em cluster por similaridade de codificação

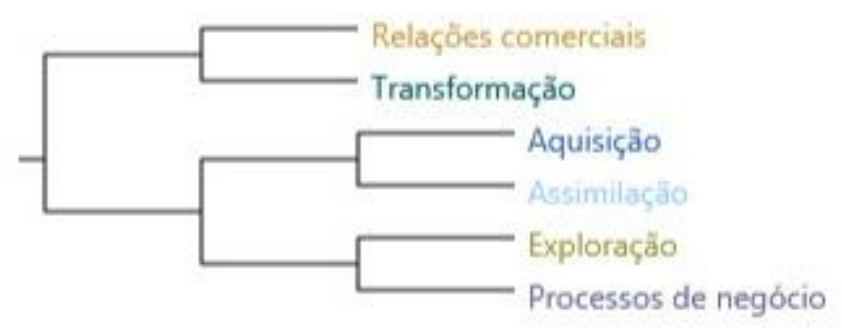

Fonte: Elaborado pelo autor. Figura gerada pelo NVivo.

Nota-se na Figura 14 o agrupamento dos "nós" Aquisição e Assimilação, evidenciando uma proximidade que corrobora com a base teórica em estudo, pois são as duas dimensões da capacidade de absorção potencial. A análise mostra que as startups investigadas apresentam um desempenho coerente quanto a capacidade de adquirir e assimilar conhecimento, pois o próprio movimento de entrar em um programa de aceleração corporativa demonstra a habilidade da startup em identificar e obter conhecimentos a partir de fontes externas. Da mesma forma, evidencia-se no estudo a habilidade das startups em analisar, interpretar e compreender os conhecimentos adquiridos externamente, criando rotinas que promovem a disseminação do conhecimento adquirido da grande empresa, por meio de reuniões, ferramentas de informática e processos administrativos.

No mesmo nível da primeira aglomeração surge o agrupamento Exploração e Processos de negócio. Porém, antes da interpretação dessa descoberta, faz-se necessário observar o último e mais distante agrupamento: Relações comerciais e Transformação. Sabe-se que além da busca por conhecimento, as startups veem nos programas de aceleração corporativa uma oportunidade para iniciar e manter relações comerciais com as grandes empresas. Nesse contexto, a capacidade das startups em combinar os conhecimentos existentes com os conhecimentos adquiridos da grande empresa sustentam a parceria comercial entre as duas organizações. O agrupamento Relações comerciais e Transformação, que se apresentam distantes, porém ligados a toda aglomeração, distinguem-se dos outros por apresentarem uma forte representatividade para as startups. Retornando ao agrupamento Exploração e Processos de negócio, o conhecimento transformado é utilizado pelas startups para melhorar seu 
desempenho organizacional. É nesse estágio que os processos de negócio são estruturados nas startups, onde criam-se rotinas, procedimentos e controle para as atividades críticas. De fato, a pesquisa evidenciou que as capacidades de transformação e exploração, decorrentes da capacidade de absorção realizada, são susceptíveis de influenciar o desempenho das startups por meio da inovação de processos e organizacional.

As descobertas apresentadas preliminarmente nesses agrupamentos indicam que as startups desenvolvem a capacidade de absorção potencial, em suas dimensões de aquisição e assimilação de conhecimento, de forma mais efetiva frente à capacidade de absorção realizada, pois nessa última os esforços ficam diluídos entre manter as relações comerciais com a grande empresa e desenvolver processos para melhoria de desempenho. O desenvolvimento de capacidades será analisado com maiores detalhes no decorrer deste trabalho, nas seções seguintes.

\subsection{Capacidade de absorção potencial}

Retomando alguns conceitos, capacidade de absorção potencial refere-se à habilidade da empresa em identificar e obter conhecimentos a partir de fontes externas e a partir da aquisição desse conhecimento, desenvolver processos e rotinas úteis na análise, interpretação e compreensão dos conhecimentos adquiridos externamente. Sabe-se que a capacidade de absorção potencial torna a empresa receptiva à aquisição e assimilação de conhecimento externo, entretanto, não garante a exploração desse conhecimento (ZAHRA; GEORGE, 2002).

\subsubsection{Processo de aquisição de conhecimento}

Uma característica comum às startups analisadas neste estudo é a busca por conhecimento externo, por meio dos programas de aceleração corporativa. Esses programas geralmente são abertos em determinados períodos e seguem uma metodologia própria para seleção dos projetos. O processo de seleção da Oxigênio é composto por três fases: a) inscrição da startup, onde o time da grande empresa avalia todas as inscrições e define até 50 empresas para participarem da segunda fase; b) as startups selecionadas participam de uma entrevista remota com o time da aceleradora, onde cerca de 20 empresas são selecionadas para avançarem para a terceira fase; c) realização do Pitch Day, composto por uma banca de diretores da Porto Seguro, Plug And Play e especialistas da Liga Ventures, que avaliam presencialmente o pitch de cinco minutos das startups selecionadas para essa fase. Já no programa Braskem Labs, os projetos 
inscritos são avaliados por uma equipe composta por pessoas da Braskem e da ACE aceleradora. Essa banca avaliadora define quais projetos irão apresentar suas empresas para executivos e clientes da Braskem, rede de mentores da ACE, investidores e outros players do mercado.

Todos os entrevistados disseram que os processos seletivos são bastante rigorosos e, por esse motivo, precisaram se preparar muito bem para serem selecionados e isso significa que tiveram algum aprendizado pela participação no processo seletivo. O entrevistado E6, por exemplo, relatou que não teve sucesso na primeira vez que se inscreveu no programa, pois a startup ainda era muito embrionária e não tinha uma estrutura melhor definida e processos de negócio sistematizados. A partir dessa negativa, houve um movimento na empresa para reestruturação e realinhamento de objetivos, a fim de se adequarem às exigências do processo seletivo. Tratando ainda do processo de seleção de startups para os programas de aceleração, a iniciativa de se inscrever no programa e o atendimento a um fluxo de atividades exigidas pelas aceleradoras, levou as startups a desenvolverem novas competências para se adequarem ao processo e como consequência, serem selecionadas. Nesse contexto, o processo de aquisição de conhecimento ficou evidenciado no discurso dos empreendedores, destacando a narrativa do entrevistado E2 "Foi com a Oxigênio, a gente estava chegando em um estágio que a gente estava começando a crescer e pegar alguns clientes e aí a gente buscou por uma aceleradora para passar expertise, para passar conhecimento, teve um processo de seleção e tal...” e E3 “A Porto Seguro assim, a gente estava buscando opções de aceleradores e a gente viu nessa possibilidade da Oxigênio um caminho bom para seguir, a gente gostou muito da proposta sabe, a gente achou que tinha sinergia com a própria Porto Seguro né, com o negócio que a gente tem, então a gente achou interessante, aplicou e acabou dando certo".

Além da busca por conhecimento externo, os motivos que levaram as startups procurarem uma parceria com a grande empresa ficaram divididos entre:

a) qualificação dos gestores e da equipe da startup e assessoria especializada;

b) adentrar ao mundo corporativo das grandes empresas, para ampliar a rede de contatos;

c) possibilidade de realizar negócios com a grande empresa, seus clientes e parceiros;

d) desenvolver novos produtos ou serviços em conjunto com a grande empresa.

O material coletado nas entrevistas e na pesquisa survey pode evidenciar os interesses das startups em entrar nos programas de aceleração. A pesquisa online coletou informações quanto ao envolvimento das startups em realizar negócios com a grande empresa, no sentido de 
descobrir o grau de interesse em realizar vendas potenciais para o parceiro ou acesso aos mercados já estabelecidos. Observando o Gráfico 5, nota-se que a grande maioria se relaciona comercialmente com a grande empresa frequentemente ou sempre, com exceção da startup S6. Essa última, mesmo depois de finalizado o processo de aceleração, mantém um trabalho de pesquisa e desenvolvimento de PE Verde ${ }^{6}$ junto a Braskem, mostrando que a absorção de conhecimento junto à grande empresa sobrepõe às relações comerciais.

Gráfico 5 - Envolvimento das startups em relações comerciais com a grande empresa

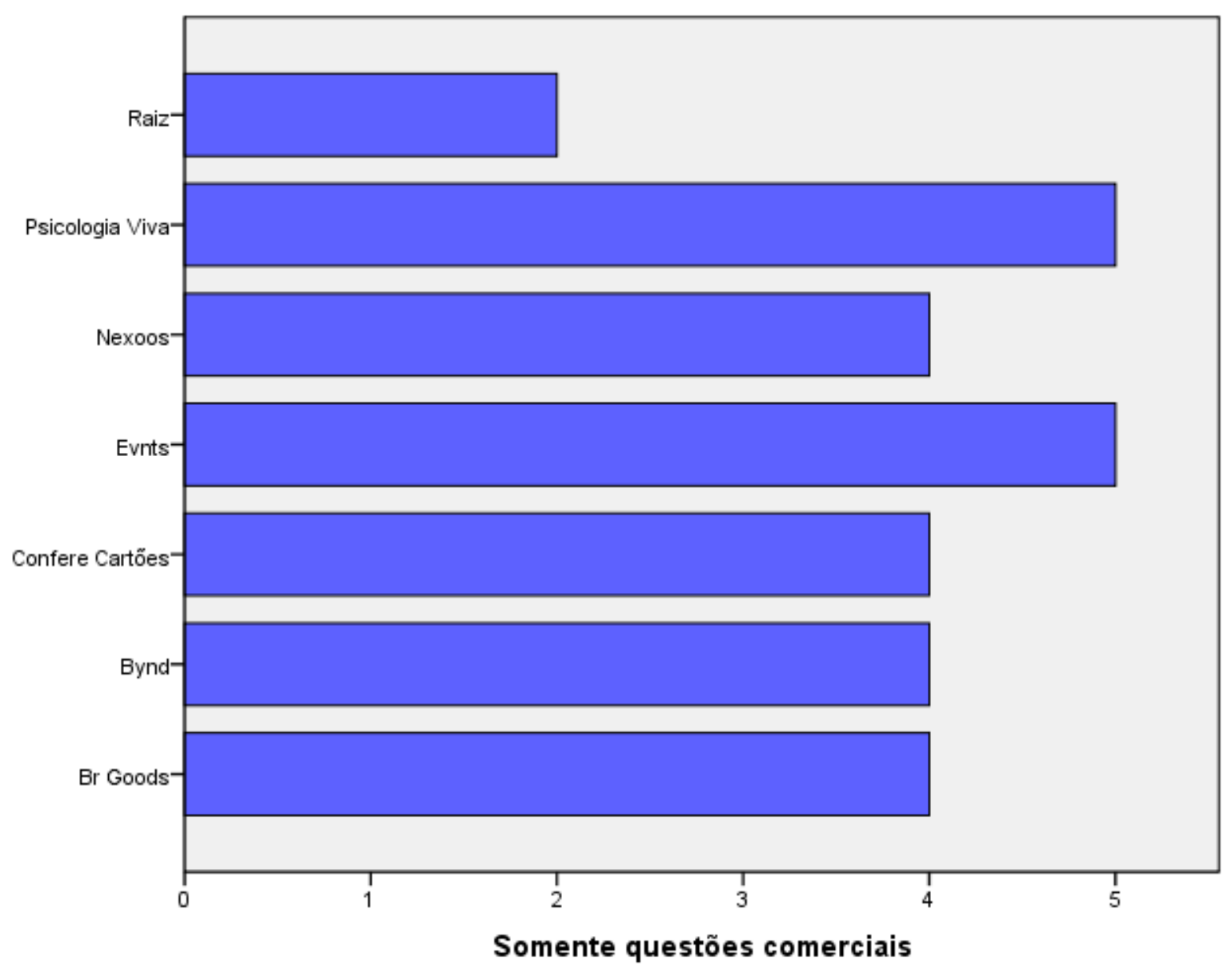

Fonte: Elaborado pelo autor. Gráfico gerado pelo SPSS.

Analisando o Gráfico 6 produzido pela codificação do material textual, confirma-se as startups que mantém um grau mais elevado de relacionamentos comerciais junto a grande empresa. A Psicologia Viva tem a Porto Seguro como um dos principais clientes, fornecendo serviços de saúde mental para os colaboradores e soluções para a área de gestão de pessoas, identificando

\footnotetext{
${ }^{6}$ O polietileno verde, também chamado Plástico Verde ou PE Verde, é um plástico feito a partir de matéria-prima renovável, o etanol produzido a partir de da cana-de-açúcar (BRASKEM, 2018).
} 
e desenvolvendo as competências comportamentais dos colaboradores, bem como talentos internos e externos à organização. A startup Bynd, plataforma de caronas para organizações, tem a Porto Seguro como um de seus maiores clientes, de acordo com E3 “.... Porto Seguro se tornou um dos nossos clientes lá. Então assim, a gente presta serviço para eles, hoje é o nosso maior cliente na verdade, em termos de números de pessoas é muito maior que os outros, só naquela região dos Campos Elíseos são 10 mil pessoas, para a gente faz muito sentido atender eles com essa solução".

Gráfico 6 - Percentual de texto codificado como "relações comerciais"

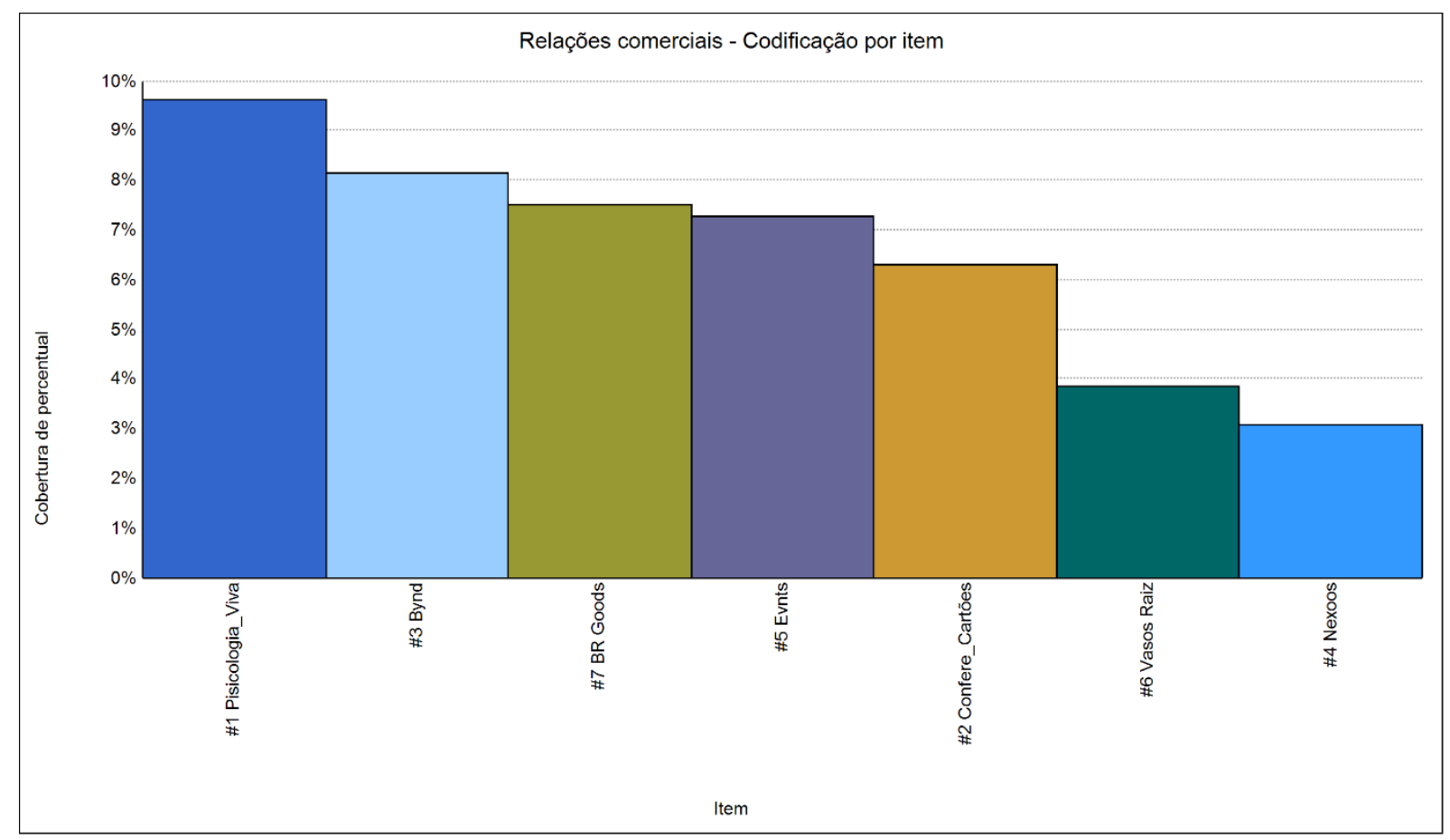

Fonte: Elaborado pelo autor. Gráfico gerado pelo NVivo.

Tal discussão sobre o interesse das startups em aproximar-se das grandes empresas para realizar negócios tem como propósito mostrar que busca por conhecimento externo não é o fator determinante. Outros fatores permeiam o interesse das startups em entrar nos programas de aceleração, contudo, ficou evidente na pesquisa que a aprendizagem organizacional decorrente da capacidade de absorção está presente em diversos momentos, quando não em todos, do processo de aceleração. O desenvolvimento de capacidades para sustentar a parceria comercial é quase uma exigência da grande empresa e o fluxo de ações da startup para atender ao parceiro acaba trazendo o desenvolvimento de vantagem competitiva, principalmente na melhoria do desempenho organizacional da startup. 
Dentro do processo de aquisição de conhecimento, a qualificação dos gestores e equipes das startups, bem como o apoio de profissionais que são referência no mercado em que atuam fazem parte do pacote de benefícios e vantagens dos programas de aceleração. As duas aceleradoras investigadas neste estudo possuem programas semelhantes, que incluem a capacitação de pessoas-chave da startup, eventos presenciais e mentorias coletivas e individuais. E2 relatou que semanalmente havia uma seção de mentoria sobre algum assunto específico e se precisassem, poderiam solicitar mentorias específicas. Já E3 destacou que uma das propostas mais fortes do programa era justamente a conexão com a grande empresa, onde os gestores da startup conseguiam falar diretamente com os executivos e especialistas da Porto Seguro, enfatizando que “...um dos grandes trunfos do programa corporativo é ter o acesso à empresa”. O processo de mentoria foi enfatizado por E4, destacando que os mentores eram muito experientes e auxiliaram a startup a identificar os diferenciais competitivos, além de orientarem em processo básicos de melhoria de gestão. Os gestores em uma startup tendem a ser muito generalistas ou muito especializados em somente um determinado assunto e nas palavras de E4 “...quando a gente entrava em contato para tentar desenvolver um projeto é que eles sempre traziam alguém muito especialista de algum tópico que tinha que ser discutido sobre aquela reunião". Outro exemplo foi o contato com um executivo do alto escalão da área de tecnologia da Porto Seguro, que, a pedido da startup, orientou a equipe técnica a preparar o software para atender ao crescimento e escalada da empresa, tratando de funcionalidades e segurança do programa.

No programa da Braskem, E6 informou que conseguiam ter reuniões separadas com os mentores, onde eles ajudavam nas principais dores ou necessidades da startup. Apontou também que era muito mais da startup buscar o auxílio do mentor, por exemplo, quando precisaram de ajuda para desenvolver uma planilha financeira ou gestão de vendas. A startup apontava para o mentor sua necessidade e este procurava pessoas com a expertise necessária para ajudar com o tema específico. E6 disse “...eu tinha oportunidade falar com pessoas de alto nível do mercado e a gente iria atrás do que realmente necessitava...”. Ainda no Braskem Labs, E7 relatou que o programa de aceleração permitiu que a equipe e os gestores da startup tivessem contato com profissionais altamente capacitados da Braskem e em suas palavras, "...se envolvendo com os meus profissionais e mostrando, passando conhecimento".

Analisando o material codificado, por meio do Gráfico 7, observa-se a porcentagem de recortes de texto que apresentaram a capacidade de aquisição de conhecimento. Em especial, as duas primeiras startups (S6 e S7) estão ligadas à empresa Braskem, indicando que o programa Braskem Labs realmente existe para incentivar o ecossistema empreendedor, promovendo 
acesso a uma rede de mentores e executivos experientes, dispostos a levar para as startups novas visões e soluções.

Gráfico 7 - Percentual de texto codificado como "aquisição"

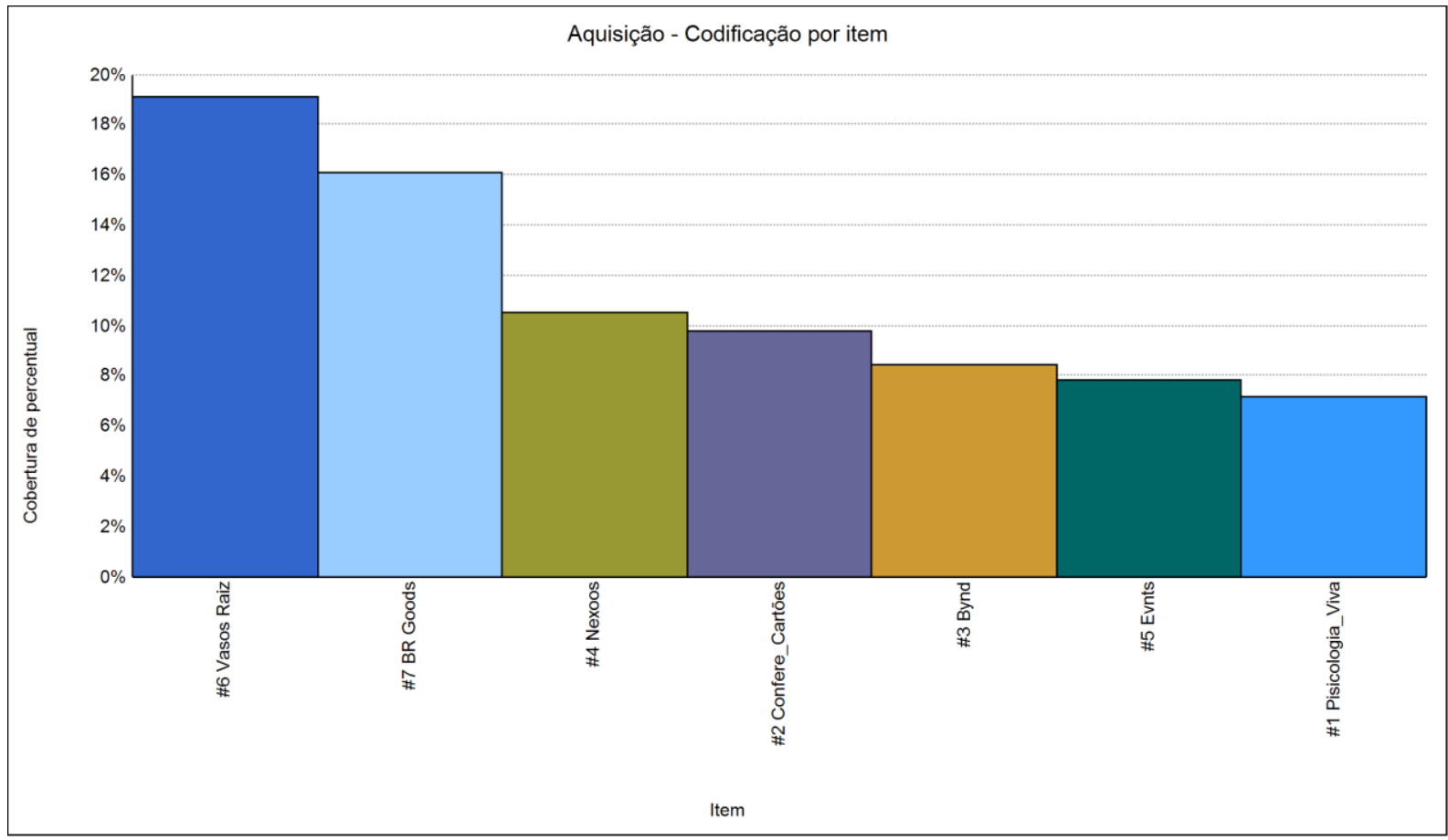

Fonte: Elaborado pelo autor. Gráfico gerado pelo NVivo.

Observando novamente o Gráfico 6, verifica-se que a startup Psicologia Viva aparece com a maior porcentagem de informações relacionadas à parceria para fins comerciais, contrapondose às iniciativas de aquisição de conhecimento.

\subsubsection{Processo de assimilação de conhecimento}

Quanto à assimilação de conhecimento, essa dimensão da capacidade de absorção foca na interpretação do conhecimento adquirido externamente, de modo a compartilha-lo em toda a organização, destacando o componente da comunicação do conhecimento dentro do ambiente organizacional (FLATTEN et al., 2011).

Um procedimento comum aos programas de aceleração investigados foram as reuniões estruturadas entre os executivos da grande empresa e os gestores das startups. No programa da Porto Seguro, essas reuniões aconteciam quinzenalmente e na Braskem, mensalmente. Os empreendedores dos negócios instalados na aceleradora Oxigênio relataram que as reuniões eram registradas em ata e que havia um procedimento de follow-up, ou seja, uma continuação 
e acompanhamento das ações e decisões tomadas na reunião. Complementando o que já mencionado anteriormente, existia um procedimento bem definido pelas grandes empresas quanto a agenda de reuniões periódicas junto às startups participantes dos programas de aceleração. Faz parte do processo de assimilação de conhecimento o fluxo de informações entre a grande empresa e a startup, além da comunicação efetiva entre a equipe de gestores e colaboradores da startup. Ademais, o relacionamento com os executivos da grande empresa nessas reuniões ou em mentorias específicas também faz parte do fluxo de informações supracitado. Em destaque, a fala do entrevistado E4 sobre as reuniões e mentorias: “...eu peguei tudo aquilo, algumas coisas não faziam sentido para a gente nesse momento, a gente sabe que a gente vai chegar lá. Algumas outras coisas a gente já implementou, a gente já trouxe como implementação de fato".

Ainda tratando da comunicação do conhecimento adquirido externamente, dentro do ambiente organizacional, o processo de assimilação dessas informações passou a fazer parte da rotina das startups de modo muito efetivo, por meio do uso de ferramentas para registro e compartilhamento de informações. Foi evidenciado nas entrevista e observação direta o uso da ferramenta Trello ${ }^{\circledR}$ para a gestão das informações entre os membros da equipe e projetos da startup. Segundo os entrevistados, a ferramenta se adapta aos projetos, equipes e fluxos de trabalhos, operando com quadros que deixam à vista todas as informações disponibilizadas, atualizadas em tempo real. Todos da equipe recebem as informações instantaneamente, podendo fazer comentários para receber feedback imediato. O uso dessa ferramenta estava presente na maioria das startups ligadas a Oxigênio, tanto que a ferramenta foi apresentada aos gestores durante o processo de mentoria. Na sede da aceleradora Oxigênio, existem vários dashboards ou painéis que mostram informações, métricas, indicadores e metas traçadas pelas startups, de forma visual, facilitando a compreensão e disseminação das informações geradas. Nas palavras do entrevistado E2 "Startup whiteboard é muito mais produtivo que 50 mil folhas de um documento de Word, que ninguém vê... Documentado por exemplo o processo e tal, coloca ali quadro branco, beleza, quer discutir alguma coisa, vai apaga, já faz, muda”.

A aprendizagem organizacional é um processo de internalização de informações internas e externas e ficou claro, nesta investigação, que as startups estão buscando desenvolver sistemas formais de internalização de informações, registrando ocorrências importantes que podem ser utilizadas para desenvolvimento de vantagens competitivas. E as startups não estariam buscando desenvolver esses sistemas, possivelmente, se não tivessem em contato com a grande empresa, muito mais profissionalizada e formalizada nesses sistemas. Portanto o que houve foi, 
pela relação com a grande, a assimilação de informações e conhecimentos por intermédio das reuniões periódicas e comunicação efetiva.

Dentro do material coletado nas entrevistas, o Gráfico 8 apresenta o percentual de codificação relacionada a capacidade de assimilação de conhecimento. Pode-se observar que as três startups com maior percentual estavam ligadas a aceleradora Oxigênio, corroborando com os fatos observados durante as visitas à startup.

Gráfico 8 - Percentual de texto codificado como "assimilação"

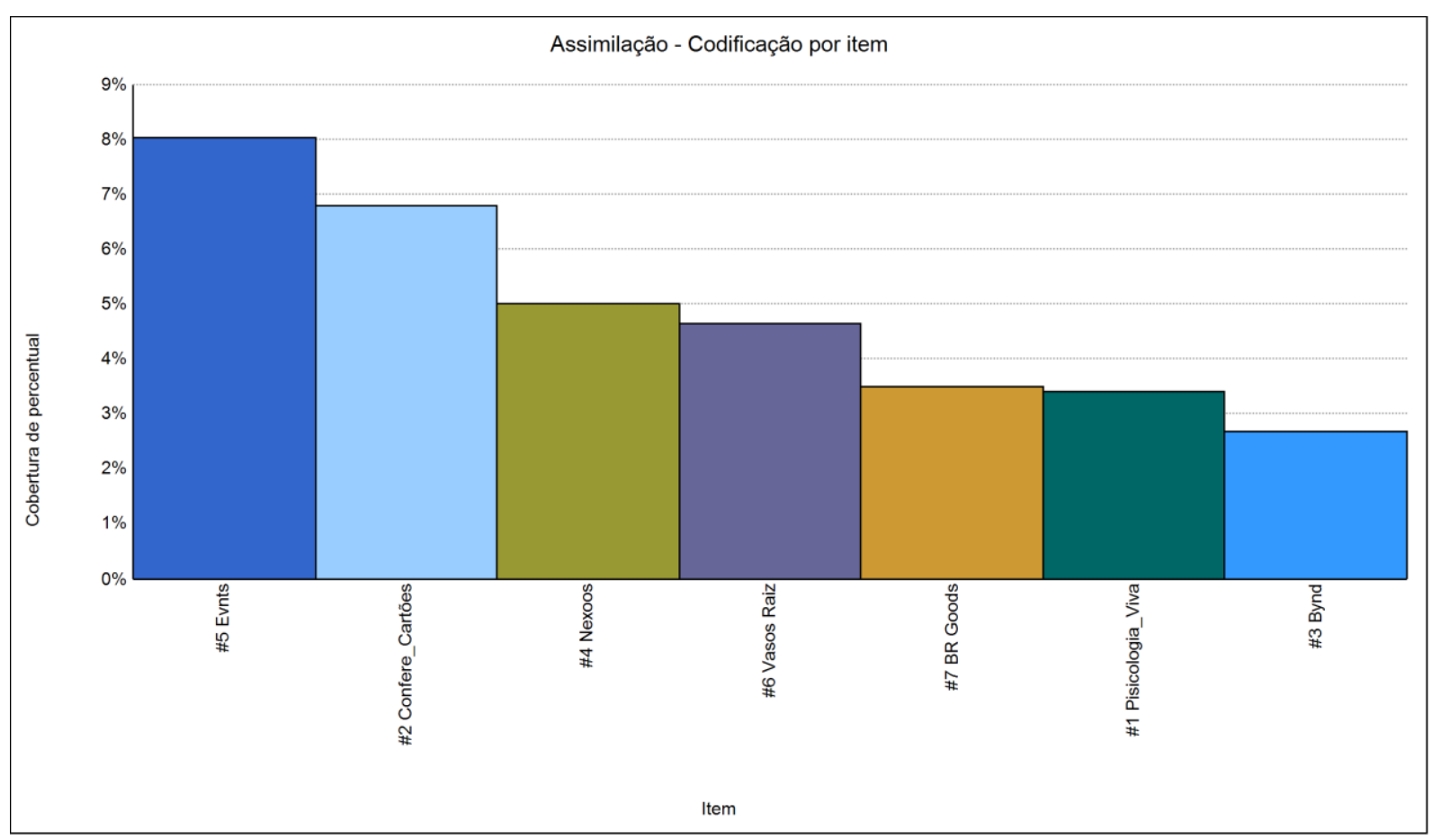

Fonte: Elaborado pelo autor. Gráfico gerado pelo NVivo.

Pode-se inferir neste estudo que a capacidade de absorção potencial reflete os esforços realizados pelas startups para buscar inovação e desenvolver capacidades para suportar esse processo.

\subsection{Capacidade de absorção realizada}

Capacidade de absorção realizada é uma função dos recursos de transformação e exploração, que refletem a capacidade da empresa em alavancar e utilizar o conhecimento que foi absorvido. A capacidade de transformação ajuda a empresa a desenvolver novos esquemas perceptivos ou mudanças nos processos existentes. Já a capacidade de exploração leva um passo adiante, convertendo o conhecimento em novos produtos ou serviços, da mesma forma que melhora o 
desempenho e produz uma vantagem competitiva para a organização (ZAHRA; GEORGE, 2002).

\subsubsection{Processo de transformação de conhecimento}

Uma das mais importantes descobertas deste estudo foi a relação entre o processo de transformação do conhecimento absorvido da grande empresa e sua aplicação para sustentar o relacionamento comercial entre as duas organizações. Ficou evidente nesta pesquisa a capacidade das startups em combinar o conhecimento anterior e já existente com o novo conhecimento adquirido e assimilado no programa de aceleração corporativa, de acordo com os processos descritos nas seções anteriores, de modo a adaptar-se às necessidades da grande empresa. O entrevistado E1 relatou que após a entrada no programa de aceleração, a busca por melhorias tornou-se constante na startup, principalmente pelo fato de estarem integrados a serviços oferecidos pela Porto Seguro. O mesmo entrevistado disse "...estamos fazendo um piloto agora, tem coisas que não estão saindo bem, eles vão dando um feedback, olha isso aqui precisa melhorar e aí a gente corre atrás para melhorar”.

Já o entrevistado E2 destacou a sinergia que havia entre a Porto Seguro e a startup, com relação aos produtos e serviços que estavam sendo desenvolvidos em conjunto. Esse trabalho associado trouxe uma melhoria significativa para a startup, principalmente porque contavam com a ajuda dos mentores para auxiliá-los em assuntos bem específicos e que muitas vezes estavam além do conhecimento ou experiência dos gestores. Em contrapartida, o entrevistado E3 explicou que na linha de negócios com a Porto Seguro, a startup tentou desenvolver novos serviços associados aos produtos da grande empresa, porém, essas iniciativas acabaram não evoluindo e manteve-se somente o relacionamento comercial empresa-cliente.

O processo de transformação do conhecimento também envolveu mudanças de atitudes e, de uma forma implícita, mudanças na cultura organizacional. Tanto nas entrevistas quanto na observação direta e análise de documentos das startups, ficou evidente o respeito e o reconhecimento da importância de se ter uma grande empresa, com vasta experiência de mercado e disposta a dividir conhecimentos, como parceira. Nas palavras de E4 “...eles ajudaram bastante a evoluir a nossa cabeça como empreendedor, enfim, a cabeça de todo mundo da Nexoos". Segundo o entrevistado E7, o relacionamento com a Braskem levou a startup a rever conceitos e procedimentos relacionados à sustentabilidade, onde a grande empresa auxiliou na busca por matérias-primas mais sustentáveis e a encontrar parcerias que pudessem desenvolver junto com a startup programas de descarte do produto final. 


\subsubsection{Processo de exploração de conhecimento}

Com relação a capacidade da startup em incorporar o conhecimento adquirido, assimilado e transformado, em suas operações e rotinas úteis, descobriu-se na pesquisa que a aplicação e uso organizacional desse conhecimento concentra-se em boa parte na criação ou melhoria dos processos de negócio.

Em média, as startups da amostra foram fundadas há dois anos e no decorrer de sua atuação no mercado, ingressaram nos programas de aceleração. Um fato relatado por todos os empreendedores foi que no início das operações das startups o conjunto de atividades realizadas para produzir uma saída de valor para a organização não seguia uma estrutura previamente definida e estava muito na "cabeça" de seus idealizadores. Enquanto a equipe de trabalho da startup restringia-se ao grupo de sócios e fundadores, a comunicação interna e gestão da empresa ocorria de forma satisfatória. Com a entrada nos programas de aceleração, os modelos de negócio das startups ganharam escalabilidade, ou seja, cresceram aceleradamente. Contudo, o aumento do volume de trabalho e a necessidade de atender aos interesses das grandes empresas fizeram surgir a necessidade de ampliação da equipe e até mesmo da estrutura física da organização. Mesmo prezando pela autonomia e a flexibilidade que a falta de processos estruturados proporciona, os empreendedores foram levados a repensarem os processos de negócio, dentro do setor de atuação e particularidades de cada startup da amostra.

Os entrevistados relataram a importância de estruturar processos e utilizarem metodologias para melhorar o desempenho das rotinas de trabalho e, em uma visão mais ampla, dar suporte a tomada de decisões e planejamento estratégico da organização. Nesse contexto, a incorporação do conhecimento obtido da grande empresa devidamente compreendido, fez com que as operações organizacionais das startups se modificassem por meio da junção entre as novas informações e as experiências já existentes, evidenciado pela estruturação de processos de negócio nas startups.

Levando em consideração a capacidade das startups em utilizar o conhecimento transformado para desenvolvimento de novos produtos ou serviços, a pesquisa revelou que isso ocorre muito pouco ou quase nunca nas startups ligadas a Porto Seguro e de forma bem marcante às ligadas a Braskem.

Os entrevistados do programa de aceleração da Porto Seguro relataram que os modelos de negócio de entrada no programa de aceleração sofreram algumas modificações, customização ou personalização, mais uma vez, para atender aos interesses da grande empresa. Não houve um produto ou serviço totalmente novo ou com grandes modificações, fruto do relacionamento 
interorganizacional. Essas descobertas podem ser evidenciadas segundo E1, que disse “...provavelmente vai exigir uma customização, não é desenvolver um produto específico para eles, mas é customização", E4 destacando que seguiu a risca uma orientação do mentor relacionada a criar um diferencial de mercado para a startup, sendo nesse ponto surge o conhecimento sendo explorado "Ao invés de tentar massificar a coisa, a gente personalizou e deixou mais detalhado e claro". Sob o ponto de vista de E6, a parceria com a Porto Seguro teve um papel fundamental para validar algo que os fundadores da startup mantinham como estratégia, que era encontrar o modelo de negócio correto e focar nesse modelo, para que pudessem escalar. Interessante registrar que essa última startup recebeu ofertas de parceria com outras grandes empresas, como Fiat e Ambev, para gerenciar o sistema de viagens corporativo e, contudo, recusaram as propostas para manter-se focada no modelo de negócio original.

Esse cenário modifica-se ao estudar as startups ligadas à Braskem, pois alguns produtos específicos sofreram grande influência da parceria com a grande empresa. No caso da startup Raiz, a grande empresa auxiliou no processo de requerimento de patente de modelo de utilidade $^{7}$ de um produto que utiliza o PE Verde, plástico biodegradável desenvolvido pela Braskem. Nas palavras de E6, “...estando próximo da Braskem, toda a equipe técnica deles nos explicando a melhorias que poderíamos ter juntos aquele produto, a gente desenvolveu alguns testes...". O entrevistado reforçou que a ajuda técnica, disponibilidade de uso de laboratórios e transferência de conhecimento feita pela Braskem permitiram o desenvolvimento do produto que será lançado em breve no mercado com a certificação "I'm green TM", que é um selo que identifica as resinas da Braskem feitas a partir de fontes renováveis. A startup BR Goods se beneficiou dos conhecimentos absorvidos da Braskem para desenvolvimento de cortinas descartáveis que também contam com a certificação "I'm green"M". O entrevistado E7 afirmou que outros produtos estão em desenvolvimento, mantendo-se a parceria e o auxílio da Braskem mesmo depois de finalizado o programa de aceleração. O Gráfico 9 deixa claro que as startups ligadas à Braskem demonstraram uma maior capacidade de exploração do conhecimento, evidenciado pelas empresas S6 e S7.

\footnotetext{
${ }^{7}$ Objeto de uso prático, ou parte deste, suscetível de aplicação industrial, que apresente nova forma ou disposição, envolvendo ato inventivo, que resulte em melhoria funcional no seu uso ou em sua fabricação (INPI, 2018).
} 
Gráfico 9 - Percentual de texto codificado como "exploração"

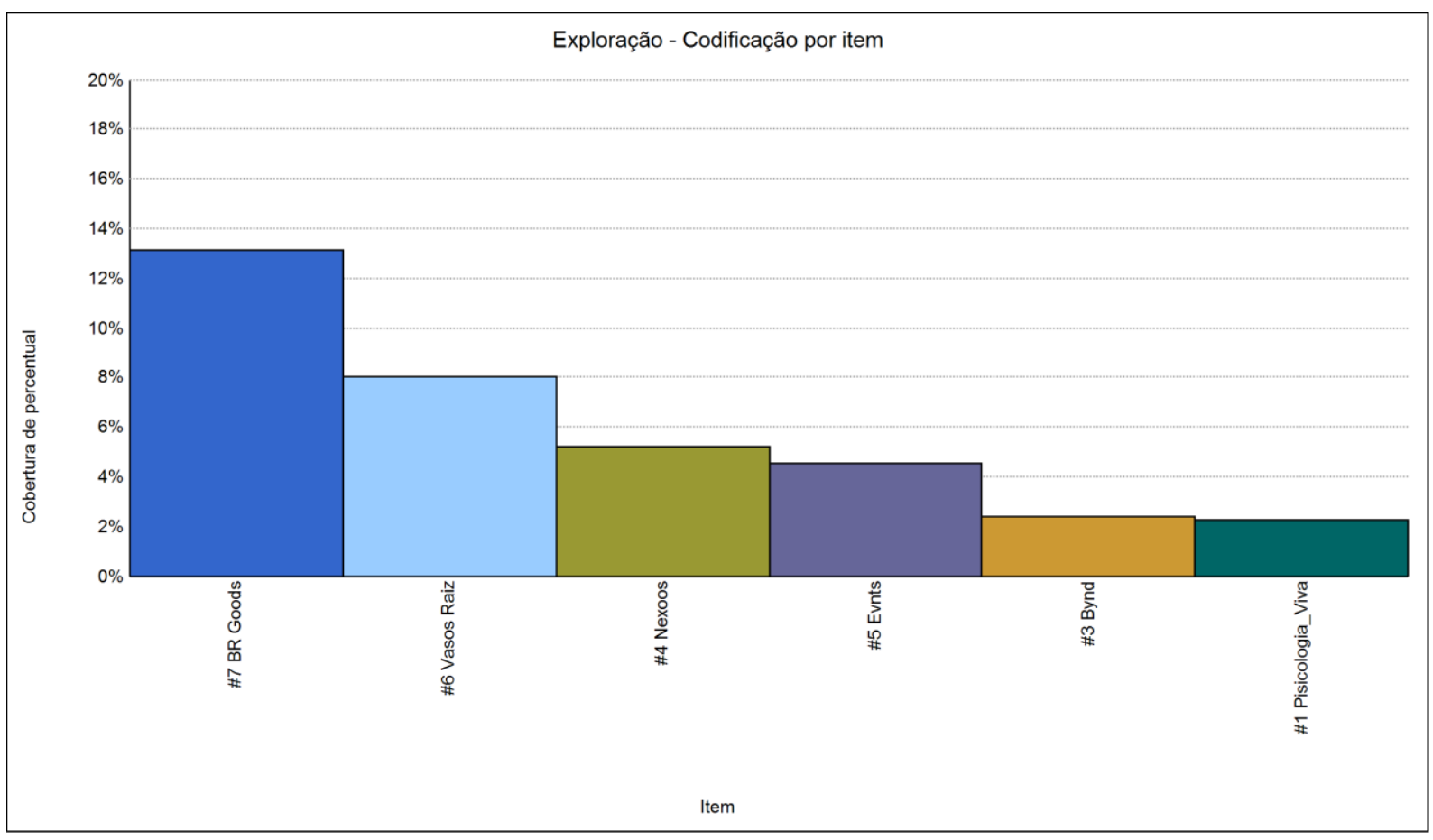

Fonte: Elaborado pelo autor. Gráfico gerado pelo NVivo.

Se observado novamente o Gráfico 3, verifica-se que as startups que compõem a amostra deste estudo apresentam uma tendência de absorver conhecimento junto à grande empresa, com uma intensidade de 63\% para a amostra de startups ligadas a Braskem e 39\% para a Porto Seguro, indicando que as startups são receptivas a aquisição e assimilação de conhecimento externo, da mesma forma que são capazes de explorar esse conhecimento em benefício próprio. No tocante, a premissa de selecionar para o estudo startups com elevada capacidade de absorção está diretamente relacionada ao problema de pesquisa, uma vez que há uma falta de observação direta ou análise das rotinas e processos que compõem efetivamente a capacidade de absorção. Na sequência, será apresentada uma síntese das descobertas discutidas nessa seção, explicando como o gerenciamento de processos de negócio é utilizado pelas startups para efetiva implementação e realização da capacidade de absorção, e como efeito, as vantagens competitivas obtidas.

\subsection{Processos de negócio relacionados à capacidade de absorção das startups}

Com o propósito de sumarizar as análises dos processos de negócio que constituem a capacidade de absorção das startups, bem como sua implementação e realização, a atual seção apresenta uma síntese das descobertas deste estudo, utilizando como base o diagrama de 
fornecedores, entradas, processos, saídas e clientes (SIPOC). O diagrama SIPOC permitiu definir, de forma simplificada, as macroatividades que compõem os processos relacionados à capacidade de absorção potencial e realizada, identificando os gatilhos que iniciam e terminam o processo. O Quadro 14 e o Quadro 15 demonstram o mapeamento simplificado dos processos, levando em consideração as ações do programa de aceleração corporativa conduzido pelas grandes empresas (fornecedores) e as startups como beneficiárias (clientes), proporcionando, de modo estruturado, as bases para a discussão dos processos que compõem a capacidade de absorção nas startups. 
Quadro 14 - Processo de aquisição e assimilação de conhecimento

\begin{tabular}{|c|c|c|c|c|c|}
\hline & $\begin{array}{c}\text { Supplier (Fornecedor) } \\
\text { Ações Promovidas pela } \\
\text { Aceleradora Corporativa } \\
\end{array}$ & $\begin{array}{c}\text { Input (Entradas) } \\
\text { Processos Iniciados } \\
\text { pela Startup } \\
\end{array}$ & $\begin{array}{c}\text { Process (Processos) } \\
\text { Macroprocessos Realizados } \\
\text { pela Startup } \\
\end{array}$ & $\begin{array}{c}\text { Output (Saídas) } \\
\text { Capacidades Desenvolvidas } \\
\text { pela Startup } \\
\end{array}$ & $\begin{array}{c}\text { Customer (Cliente) } \\
\text { Vantagem Competitiva } \\
\text { para a Startup } \\
\end{array}$ \\
\hline \multirow{2}{*}{ 导 } & Capacitações & $\begin{array}{l}\text { - Acompanhamento da } \\
\text { programação previamente } \\
\text { agendada pela aceleradora; } \\
\text { - Solicitação, por parte dos } \\
\text { gestores da startup, de } \\
\text { capacitações específicas e de } \\
\text { acordo com as necessidades. }\end{array}$ & $\begin{array}{l}\text { - Participar dos workshops e } \\
\text { palestras programadas pela } \\
\text { aceleradora; } \\
\text { - Participar das capacitações } \\
\text { personalizadas e específicas. }\end{array}$ & $\begin{array}{l}\text { - Aquisição de conhecimentos } \\
\text { por parte dos gestores e } \\
\text { equipes; } \\
\text { - Descobrimento de } \\
\text { ferramentas úteis a gestão } \\
\text { empresarial; } \\
\text { - Busca por aprimoramento } \\
\text { do planejamento estratégico. }\end{array}$ & $\begin{array}{l}\text { - Flexibilidade estratégica; } \\
\text { - Inovação organizacional. }\end{array}$ \\
\hline & Rede de mentores & $\begin{array}{l}\text { - Alinhar-se ao programa de } \\
\text { mentoria empreendedora } \\
\text { estabelecido pela aceleradora; } \\
\text { - Solicitação, por parte dos } \\
\text { gestores da startup, de apoio } \\
\text { do mentor. }\end{array}$ & $\begin{array}{l}\text { - Acessar a rede de mentores } \\
\text { disponibilizada; } \\
\text { - Participar das seções de } \\
\text { mentoria. }\end{array}$ & $\begin{array}{l}\text { - Aquisição de novas } \\
\text { perspectivas e expertise; } \\
\text { - Conhecimento de } \\
\text { informações relevantes sobre } \\
\text { o mercado; } \\
\text { - Formação e manutenção de } \\
\text { uma rede de contatos; }\end{array}$ & - Flexibilidade estratégica. \\
\hline : & $\begin{array}{l}\text { Reuniões periódicas e } \\
\text { comunicação efetiva }\end{array}$ & $\begin{array}{l}\text { - Atender às reuniões } \\
\text { semanais programadas pela } \\
\text { aceleradora; } \\
\text { - Reuniões agendadas, de } \\
\text { acordo com as necessidades e } \\
\text { solicitações da startup; } \\
\text { - Utilização de software para } \\
\text { a gestão das informações. }\end{array}$ & $\begin{array}{l}\text { - Participar das reuniões; } \\
\text { - Registrar as reuniões em } \\
\text { atas; } \\
\text { - Realizar o follow-up das } \\
\text { reuniões; } \\
\text { - Intercambiar as informações } \\
\text { entre as equipes. }\end{array}$ & $\begin{array}{l}\text { - Criação de um repositório de } \\
\text { informações; } \\
\text { - Comunicação efetiva entre } \\
\text { startup e grande empresa; } \\
\text { - Interação entre } \\
\text { departamentos; } \\
\text { - Análise e compartilhamento } \\
\text { de informações. }\end{array}$ & - Inovação organizacional. \\
\hline
\end{tabular}

Fonte: Elaborado pelo autor. 
Quadro 15 - Processo de transformação e exploração do conhecimento

\begin{tabular}{|c|c|c|c|c|c|}
\hline & $\begin{array}{c}\text { Supplier (Fornecedor) } \\
\text { Ações Promovidas pela } \\
\text { Aceleradora Corporativa } \\
\end{array}$ & $\begin{array}{c}\text { Input (Entradas) } \\
\text { Processos Iniciados } \\
\text { pela Startup } \\
\end{array}$ & $\begin{array}{c}\text { Process (Processos) } \\
\text { Macroprocessos Realizados } \\
\text { pela Startup } \\
\end{array}$ & $\begin{array}{c}\text { Output (Saídas) } \\
\text { Capacidades Desenvolvidas } \\
\text { pela Startup } \\
\end{array}$ & $\begin{array}{c}\text { Customer (Cliente) } \\
\text { Vantagem Competitiva } \\
\text { para a Startup } \\
\end{array}$ \\
\hline \multirow[t]{2}{*}{ 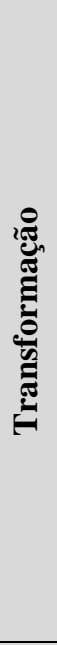 } & Relações comerciais & $\begin{array}{l}\text { - Produto ou serviço já } \\
\text { existente (MVP) na startup; } \\
\text { - Sinergia de negócio com a } \\
\text { grande empresa e/ou seus } \\
\text { clientes e parceiros. }\end{array}$ & $\begin{array}{l}\text { - Adaptar-se às necessidades } \\
\text { da grande empresa e/ou seus } \\
\text { clientes e parceiros; } \\
\text { - Desenvolver produtos e/ou } \\
\text { serviços em conjunto com a } \\
\text { grande empresa. }\end{array}$ & $\begin{array}{l}\text { - Adaptação de produtos e/ou } \\
\text { serviços; } \\
\text { - Melhorias na gestão } \\
\text { empresarial e no } \\
\text { desenvolvimento de produtos } \\
\text { e/ou serviços; } \\
\text { - Estruturação de áreas } \\
\text { funcionais; } \\
\text { - Aceitação de mudanças e } \\
\text { novas regras de negócio. }\end{array}$ & $\begin{array}{l}\text { - Inovação organizacional; } \\
\text { - Desempenho organizacional. }\end{array}$ \\
\hline & $\begin{array}{l}\text { Transformação organizacional } \\
\text { e mudança estratégica }\end{array}$ & $\begin{array}{l}\text { - Mentalidade e ação } \\
\text { empreendedora. }\end{array}$ & $\begin{array}{l}\text { - Alinhar estratégias, } \\
\text { estruturas e processos; } \\
\text { - Apropriar-se de informações } \\
\text { para se adaptar ao ambiente; } \\
\text { - Realizar mudanças } \\
\text { organizacionais. }\end{array}$ & $\begin{array}{l}\text { - Novos insights; } \\
\text { - Reconhecimento de } \\
\text { oportunidades; } \\
\text { - Posicionamento competitivo. }\end{array}$ & $\begin{array}{l}\text { - Inovação organizacional; } \\
\text { - Desempenho organizacional. }\end{array}$ \\
\hline \multirow{2}{*}{ 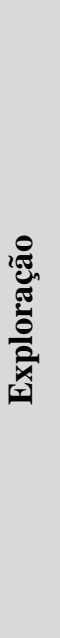 } & $\begin{array}{l}\text { Estruturação de processos de } \\
\text { negócio }\end{array}$ & $\begin{array}{l}\text { - Escalabilidade do modelo de } \\
\text { negócio; } \\
\text { - Necessidade de atender aos } \\
\text { interesses da grande empresa; } \\
\text { - Necessidade de compartilhar } \\
\text { informações entre as equipes. }\end{array}$ & $\begin{array}{l}\text { - Criar rotinas e fluxos de } \\
\text { trabalho estruturados; } \\
\text { - Utilizar metodologias e } \\
\text { ferramentas para melhorar o } \\
\text { desempenho das rotinas de } \\
\text { trabalho; } \\
\text { - Criar uma estrutura } \\
\text { funcional para dar suporte aos } \\
\text { processos. }\end{array}$ & $\begin{array}{l}\text { - Colaboradores atuando como } \\
\text { força de trabalho organizada e } \\
\text { eficiente; } \\
\text { - Produção de valor para os } \\
\text { clientes e stakeholders; } \\
\text { - Adoção de procedimentos } \\
\text { estruturados e sistematizados; } \\
\text { - Expansão das áreas } \\
\text { funcionais. }\end{array}$ & $\begin{array}{l}\text { - Inovação organizacional; } \\
\text { - Desempenho organizacional. }\end{array}$ \\
\hline & $\begin{array}{l}\text { Desenvolvimento de novos } \\
\text { produtos ou serviços }\end{array}$ & $\begin{array}{l}\text { - Plano de pesquisa e } \\
\text { desenvolvimento; } \\
\text { - Contato com as equipes de } \\
\text { inovação e técnica das grandes } \\
\text { empresas. }\end{array}$ & $\begin{array}{l}\text { - Utilizar os canais e } \\
\text { infraestrutura da aceleradora. }\end{array}$ & $\begin{array}{l}\text { - Modificações, customização } \\
\text { ou personalização dos } \\
\text { produtos ou serviços; } \\
\text { - Desenvolvimento de novos } \\
\text { produtos específicos; } \\
\text { - Transferência de } \\
\text { conhecimentos; }\end{array}$ & $\begin{array}{l}\text { - Inovação incremental de } \\
\text { produtos. }\end{array}$ \\
\hline
\end{tabular}

Fonte: Elaborado pelo autor. 
O mapeamento dos macroprocessos que compõem a capacidade de absorção, sob a perspectiva do gerenciamento de processos de negócio, permitiu identificar os componentes que surgem nos programas de aceleração, apresentados nos Quadro 14 e Quadro 15, dando entendimento à capacidade de absorver conhecimento por meio do comportamento dos processos. Os quadros sintetizam as discussões realizadas nas seções anteriores sobre os processos que compõem a capacidade de absorção, em suas quatro dimensões, bem como indicam as vantagens competitivas obtidas pela startup.

Segundo Zahra e George (2002), os esforços gastos em rotinas de aquisição de conhecimento possuem três atributos que podem influenciar o desenvolvimento da capacidade de absorção: intensidade, velocidade e direção. A intensidade dos esforços das startups para identificar e reunir conhecimento, dentro dos programas de aceleração corporativa, são potencializados pela oferta de capacitações especializadas e rede de mentores disponibilizadas pelas grandes empresas. Os autores supracitados afirmam que quanto maior o esforço, mais rapidamente a empresa construirá as capacidades necessárias e de fato, essa afirmação pode ser confirmada nesta pesquisa, pois ambos os programas de aceleração têm duração de apenas 4 meses e dentro desse período, determinaram a qualidade da capacidade de aquisição das startups. A direção de acumular conhecimento, ou seja, as capacitações e mentorias, também atenderam à necessidade de se ter diferentes áreas de especialização dentro da startup, para importar com sucesso tecnologias externas (ZAHRA; GEORGE, 2002).

O processo de aquisição de conhecimento gera novas ideias e descobertas que, muitas vezes, estão além da zona de busca de uma empresa e são negligenciadas, porque a empresa não pode facilmente compreendê-las. O conhecimento externo também é específico, o que muitas vezes impede que pessoas de fora compreendam ou reproduzam esse conhecimento (ZAHRA; GEORGE, 2002). Com base nessas premissas, a realização de reuniões periódicas e sistematizadas, bem como a comunicação efetiva entre as startups e as grandes empresas promove a assimilação do conhecimento, permitindo que as startups processem e internalizem o conhecimento gerado externamente.

Seguindo a base teórica proposta por Zahra e George (2002), a transformação muda o caráter do conhecimento por meio da biassociação ${ }^{8}$, que ocorre quando a empresa possui a capacidade de reconhecer dois conjuntos de informações aparentemente incongruentes e depois combinálas para chegar a um novo esquema. Essa capacidade, que surge do processo de biassociação, fica evidente nas startups que se relacionam com grandes empresas, principalmente pela

\footnotetext{
${ }^{8}$ Biassociação significa juntar informações não relacionadas, muitas vezes conflitantes, de uma nova maneira (KOESTLER, 1966 apud ZAHRA; GEORGE, 2002).
} 
diferença entre as formas empresariais e de realização do trabalho, que se tornam verdadeiros desafios para a obtenção de resultados quando ambos os lados trabalham juntos. São nas relações comerciais entre as grandes empresas e as startups que a origem de novas competências pode ser encontrada. Da mesma forma, os novos conhecimentos geram nas startups transformação organizacional e reformulação da estratégia competitiva, uma vez que os programas de aceleração oferecem a possibilidade de conexão e networking com os maiores e mais estratégicos players do mercado.

A ênfase principal da dimensão de exploração está nas rotinas que proporcionam às empresas explorar o conhecimento, fornecendo mecanismos estruturais, sistêmicos e processuais que permitem às empresas sustentar a exploração desse conhecimento por longos períodos (ZAHRA; GEORGE, 2002). Verificou-se nesta pesquisa que a escalabilidade do modelo de negócio das startups, juntamente com a necessidade de atender aos interesses da grande empresa levou as startups a estruturarem seus processos, desenvolvendo um conjunto profissional, disciplinado e repetível de práticas sobre processos de negócio. Para Zahra e George (2002), os resultados das rotinas de exploração sistemática são a criação persistente de novos bens, sistemas, processos, conhecimento ou novas formas organizacionais. Nesse contexto, observou-se o desenvolvimento de novos produtos e/ou serviços nas startups, mesmo que de forma modesta e incremental. 


\section{CONSIDERAÇÕES FINAIS}

Este capítulo apresenta as conclusões provenientes dos resultados da pesquisa de campo, a respeito dos relacionamentos interorganizacionais entre grandes empresas e startups, trazendo reflexões e discussões acerca dessa temática. Além disso, são apresentadas as implicações teóricas e gerenciais, as limitações da pesquisa e sugestões para futuros estudos, de acordo com as lacunas identificadas neste trabalho.

No Brasil, 27\% das aceleradoras de empresas são corporativas, ou seja, foram criadas por grandes empresas que buscam startups alinhadas aos interesses e estratégias da organização. A região Sudeste concentra $84 \%$ das aceleradoras corporativas, destacando a cidade de São Paulo com oito aceleradoras. Não por acaso, as aceleradoras selecionadas para a pesquisa concentramse na capital paulista, município com alto poder econômico, infraestrutura de boa qualidade e mercado desenvolvido. Nesta pesquisa, pode-se apurar um total de 175 startups inseridas em programas de aceleração corporativa, representando $15 \%$ do total de startups que passaram por um processo de aceleração. Os ambientes de empreendedorismo e inovação promovidos pelas aceleradoras corporativas possibilitam que as grandes empresas e startups mantenham uma relação de parceria e complementaridade, onde ambas se beneficiam desse relacionamento. Sob o ponto de vista da vantagem competitiva para as startups, alguns programas como o Oxigênio Aceleradora da Porto Seguro oferecem aporte financeiro para as empresas nascentes, além de outros benefícios comuns aos outros programas, como acesso facilitado a rede de executivos da grande empresa, capacitações especializadas e oportunidades para realizar negócios com a organização e seus parceiros.

O mapeamento da rede de colaboração constituída pelo relacionamento entre startups e grandes empresas possibilitou a definição das unidades de análise do estudo, compondo uma amostra de startups que mantém relacionamentos interorganizacionais com grandes empresas, por meio das aceleradoras corporativas. Ademais, esse tipo de relacionamento prevalece mesmo após o término do programa de aceleração, onde a rede de mentores continua à disposição das startups, além de outros tipos de contatos como as relações comerciais entre as organizações e a participação das startups em eventos promovidos pelas aceleradoras. Tais afirmações permitem reconfigurar o modelo de ambientes de empreendedorismo e inovação promovidos pelas grandes empresas, como apresentado na Figura 15. 
Figura 15 - Reconfiguração do modelo de ambientes de empreendedorismo e inovação

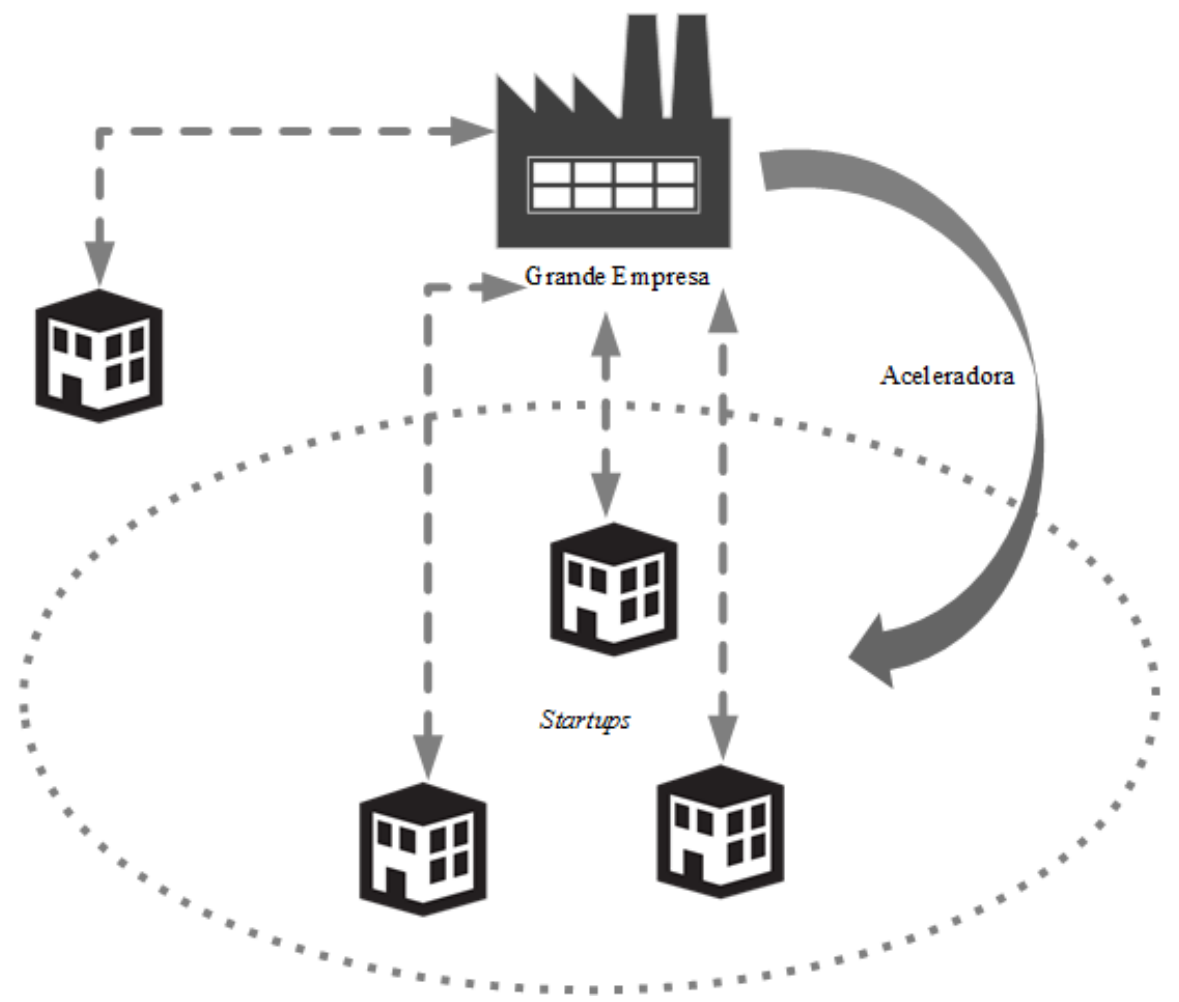

Fonte: Elaborado pelo autor.

As startups apresentam uma elevada capacidade de absorção de conhecimento da grande empresa, especialmente a capacidade de adquirir e assimilar conhecimento. A própria estrutura dos programas de aceleração favorece a aquisição do conhecimento externo, visto que está voltada a disponibilizar uma rede de mentores e fornecer capacitações personalizadas às startups, da mesma forma que estimula a internalização e disseminação desse conhecimento. A transformação do conhecimento para uso efetivo nas startups está diretamente relacionada a sustentabilidade das relações comerciais mantidas com a grande empresa, seus clientes e/ou parceiros. A transição da capacidade de absorção potencial para realizada materializa-se nas mudanças significativas que as startups apresentam em sua cultura e gestão empresarial, refletindo na exploração desse conhecimento transformado para criação de estruturas de gerenciamento de processos de negócio. Sob esse último aspecto, as startups envolvidas nos programas de aceleração corporativa apresentam uma forte tendência para inovação organizacional, uma vez que o gerenciamento de processos de negócio é incorporado às práticas de negócio das startups, implementando um novo método organizacional para lidar com a produção de valor para os clientes e stakeholders envolvidos.

A análise dos processos de negócio que constituem a capacidade de absorção das startups confirma a estrutura recursiva e não linear de ambos os conceitos, corroborando com a base 
teórica do estudo. A proposição de que existe uma relação entre o constructo capacidade de absorção e a área gerenciamento de processos de negócio, nos relacionamentos interorganizacionais entre grandes empresas e startups foi confirmada, pois as empresas inseridas nos programas de aceleração corporativa são levadas a desenvolverem rotinas organizacionais específicas e processos que operacionalizam e potencializam a aprendizagem organizacional, da mesma forma que a utilização do conhecimento adquirido externamente, assimilado e transformado proporciona às startups condições para melhoria contínua dos processos de negócio considerados críticos.

Nos programas de aceleração corporativa, as startups pouco desenvolvem a habilidade de criar processos para identificar e obter conhecimentos a partir de fontes externas ao programa de aceleração, ou seja, em outras empresas, uma vez que os programas e as grandes empresas fornecem e conduzem esses processos em sua totalidade. No entanto, são habilidosas em desenvolver processos e rotinas úteis para análise, interpretação e compreensão dos conhecimentos adquiridos da grande empresa. Em decorrência dessa habilidade, as startups são capazes de transformar esses conhecimentos e aplica-los na melhoria do seu desempenho. De fato, as startups conseguem desenvolver novos processos ou alterar os já existentes para atender às necessidades das grandes empresas ou sustentar as relações comerciais existentes, apropriando-se do conhecimento absorvido para manter uma vantagem competitiva frente ao mercado.

Os processos de negócio que surgem nos relacionamentos interorganizacionais entre as grandes empresas e startups estão relacionados aos fluxos de informações que são processados pelas empresas nos programas de aceleração. $\mathrm{O}$ gerenciamento desses processos, de forma efetiva e sistematizada, emerge nas startups enquanto estão sendo aceleradas e tem um efeito positivo e significativo na implementação e realização da capacidade de absorção. A aprendizagem organizacional gera nas startups modificações na forma como realizam suas atividades, provocando mudanças nas rotinas e comportamentos que já estavam estabelecidos. Nesse contexto, as vantagens competitivas decorrentes da capacidade de absorção concretizam-se nas startups por meio da flexibilidade estratégica, inovação do tipo organizacional e no desempenho organizacional, avaliado na perspectiva de seus processos internos.

Dessa forma, com base nos resultados encontrados, a Figura 16 apresenta um modelo de processo que responde à pergunta de pesquisa e sintetiza as contribuições do estudo. Vale ressaltar que o modelo de processo teve como base o estudo de Aribi e Dupouët (2016). 
Figura 16 - Capacidade de absorção em startups sob a perspectiva do gerenciamento de processos de negócio

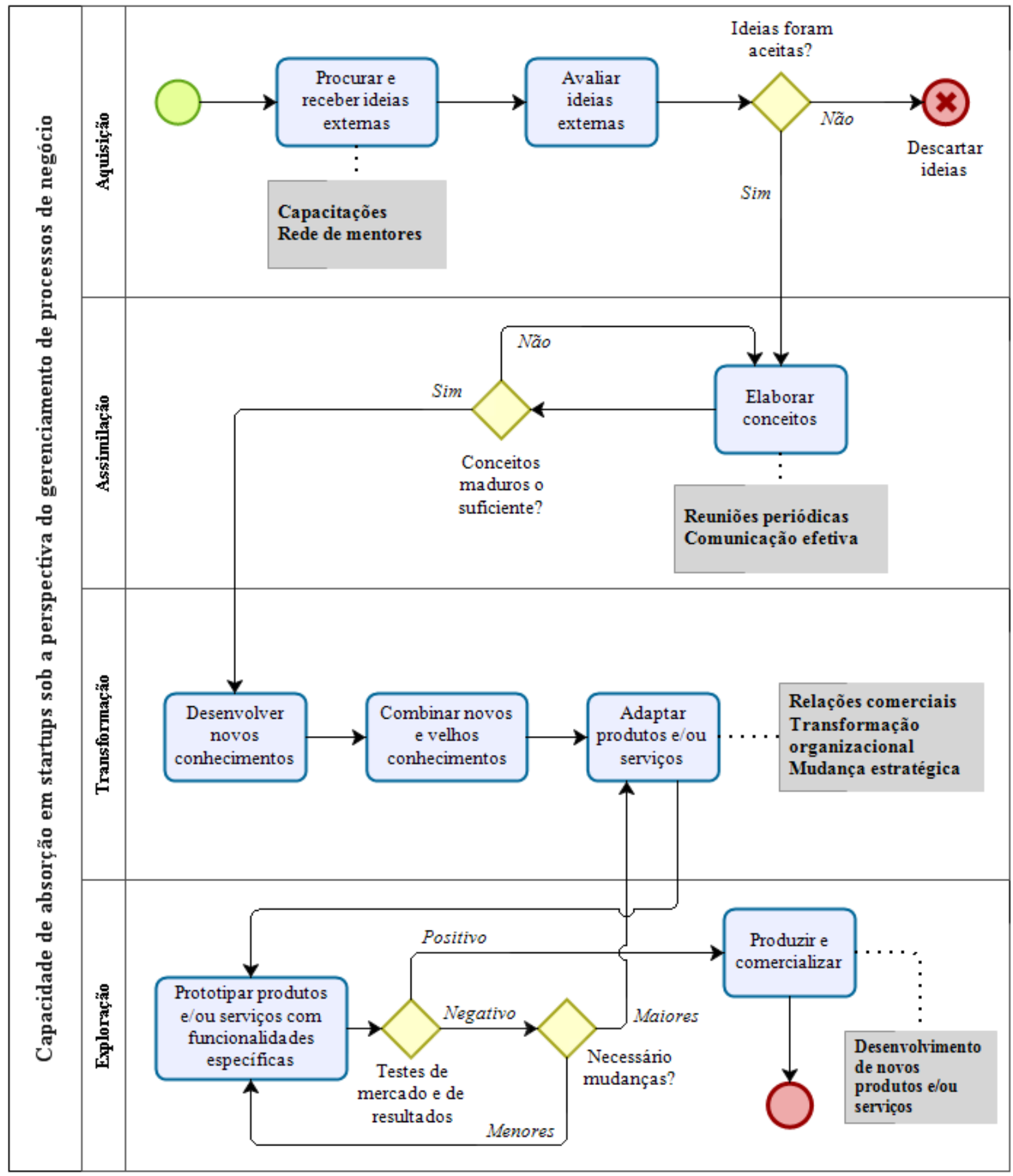

Fonte: Elaborado pelo autor.

O objetivo da Figura 16 é fornecer uma compreensão mais detalhada de como a capacidade de absorção realmente ocorre nas startups, descrevendo o processo de absorção de conhecimento junto às grandes empresas. As capacitações promovidas pelas aceleradoras corporativas e a rede de mentores disponibilizada pelas grandes empresas correspondem à introdução de novas ideias, onde posteriormente ocorre a avaliação e possível retenção dessas ideias, fazendo parte 
da dimensão de aquisição de conhecimento. Já a assimilação de conhecimento engloba o desenvolvimento de conceitos que, possivelmente, serão transformados em novos conhecimentos. Essa etapa é operacionalizada pela realização de reuniões periódicas e uma comunicação efetiva entre os membros da startup e grande empresa. A dimensão de transformação é a modificação da base de conhecimento existente na startup, gerando produtos e/ou serviços adaptados às necessidades da grande empresa para sustentar as relações comerciais existentes, bem como promovendo transformação organizacional e mudança estratégica. Finalmente, a exploração da base de conhecimento transformado converte-se em novos produtos e/ou serviços que são introduzidos no mercado.

É válido ressaltar que a estruturação de processos de negócio, mais evidente na dimensão de exploração do conhecimento como foi descrito no Quadro 15, não está destacado na Figura 16 por também fazer parte das outras dimensões da capacidade de absorção, uma vez que as startups criam rotinas e processos para explorar o conhecimento desde a sua aquisição. A estruturação de processos de negócio permite às startups sustentar todo o ciclo de absorção de conhecimento.

\subsection{Implicações teóricas e gerenciais}

Estudos anteriores abordaram e testaram empiricamente o funcionamento da capacidade de absorção em grandes empresas, principalmente em indústrias, fornecendo a base teórica do constructo. O presente trabalho contribui para o avanço no estado da arte ao descrever os processos de negócio relacionados à operacionalização do conceito de capacidade de absorção em startups, por meio dos relacionamentos interorganizacionais com as grandes empresas. Ademais, apresenta evidências sobre a influência do gerenciamento de processos de negócio no desenvolvimento da capacidade de absorção em startups, além de contribuir para o entendimento dos processos de inovação organizacional, uma vez que esse tipo de inovação é fundamental para a criação e sustentabilidade de vantagem competitiva para as empresas.

$\mathrm{O}$ trabalho atende às diretrizes para pesquisas futuras de estudos anteriores, em especial Zahra e George (2002), ao abordar empiricamente a operacionalização específica das capacidades da firma, que a capacidade de absorção compreende, além de se concentrar nas rotinas e processos que as startups usam para adquirir, assimilar, transformar e explorar o conhecimento.

Quanto às implicações gerenciais, as descobertas da pesquisa podem ser úteis aos gestores que buscam criar e sustentar vantagens competitivas. Os resultados mostram que o gerenciamento de processos de negócio é uma prática inevitável quando a startup começa a ganhar 
escalabilidade e mercado e o quanto antes os gestores conseguirem entender e tirar proveito dos processos de negócio que estão sendo estruturados, por meio de uma gestão estratégica, maior será a produtividade e qualidade dos produtos e serviços oferecidos pela startup. É importante ressaltar que existe uma certa resistência dos gestores em criar uma estrutura funcional nas startups, sempre com a preocupação de burocratizar demais ou perder a flexibilidade que a falta de uma hierarquia formal proporciona. Entretanto, os resultados mostram evidências de que a constituição de uma estrutura funcional, juntamente com a gestão de processos de forma estruturada e sistematizada, possibilita a melhoria do desempenho organizacional.

\subsection{Limitações da pesquisa}

As limitações relacionadas ao presente estudo envolvem, num primeiro momento, a adoção do estudo de caso como método qualitativo para a pesquisa de campo, uma vez que os resultados obtidos, mesmo contando com uma combinação de múltiplas fontes de evidências, não podem ser generalizados para outras empresas, restringindo-se às unidades de análise escolhidas devido às especificidades do contexto.

Outra limitação da pesquisa é a possibilidade de existência de um viés de interpretação, uma vez que as análises contêm a percepção do pesquisador sobre as informações obtidas. Além disso, os resultados refletem a visão dos entrevistados em cada organização, considerando-se uma limitação o número de entrevistas realizadas.

\subsection{Sugestões para estudos futuros}

O tema abordado na presente dissertação possui poucos trabalhos na literatura sobre gestão da estratégia acerca do funcionamento da capacidade de absorção, representando uma oportunidade de pesquisas futuras, a saber:

a) estudos em maior profundidade sobre os efeitos do gerenciamento de processos de negócio nas diferentes fases de absorção do conhecimento (capacidade de absorção potencial e realizada);

b) estudos sobre a evolução do gerenciamento de processos de negócio, especialmente o BPM explorador, que segue uma abordagem de fora para dentro da empresa em termos de capacidade para inovar processos organizacionais; 
c) estudos que avaliem quais novas capacidades estão emergindo das novas tecnologias, levantando quais processos se beneficiam mais delas. 


\section{REFERÊNCIAS}

ABREU, P. R. M.; CAMPOS, N. M. O panorama das aceleradoras de startups no Brasil. North Charleston: CreateSpace Independent Publishing Platform, 2016. Disponível em: $<$ https://bibliotecadigital.fgv.br/dspace/bitstream/handle/10438/18853/Abreu\%3B\%20Campo s\%20Neto_Panorama\%20das\%20aceleradoras\%20de\%20startups\%20no\%20Brasil.pdf?seque nce $=1 \&$ isAllowed $=y>$. Acesso em: 24 nov. 2017.

ARIBI, A.; DUPOUËT, O. Absorptive capacity: a non-linear process. Knowledge Management Research and Practice, v. 14, n. 1, p. 15-26, 2016.

ASQ SERVICE QUALITY DIVISON. Glossary. Disponível em: $<$ http://asqservicequality.org/glossary/sipoc-suppliers-inputs-process-outputs-customersdiagram/>. Acesso em: 23 mar. 2018.

ASSOCIATION OF BUSINESS PROCESS MANAGEMENT PROFESSIONALS (ABPMP). Guia para o gerenciamento de processos de negócio: corpo comum de conhecimento (ABPMP BPM CBOK V3.0). São Paulo, 2013.

BARDIN, L. Análise de conteúdo. São Paulo: Edições 70, 2016.

BARNEY, J. Firm resources and sustained competitive advantage. Journal of Management, v. 17, n. 1, p. 99-120, 1991.

BARRINGER, B. R.; HARRISON, J. S. Walking a tightrope: creating value through interorganizational relationships. Journal of Management, v. 26, n. 3, p. 367-403, 2000.

BIGARELLI, B. Os desafios de trazer as inovações de startups para grandes empresas. Época Negócios. 2017.2 Disponível em: $<$ http://epocanegocios.globo.com/Empresa/noticia/2017/09/os-desafios-de-trazer-inovacoesde-startups-para-grandes-empresas.html>. Acesso em: 18 nov. 2017.

BPTRENDS. Glossary. Disponível em: <http://www.bptrends.com/resources/glossary/business-process/>. Acesso em: 5 fev. 2017.

BRASKEM. Dúvidas frequentes. Disponível em: <http://www.braskem.com/site.aspx/FAQ_PeVerde>. Acesso em: 24 fev. 2018.

BRASKEM. Perfil. Disponível em: <https://www.braskem.com.br/perfil>. Acesso em: 25 nov. 2017.

BRINK, T. SME routes for innovation collaboration with larger enterprises. Industrial Marketing Management, v. 64, p. 122-134, 2017.

BURLTON, R. Delivering business strategy through process management. In: VOM BROCKE, J.; ROSEMANN, M. (Eds.). Handbook on business process management: strategic alignment, governance, people and culture. Berlin: Springer, 2010. v. 2, part 1, p. 537. 
CAMARGO B. V.; JUSTO A. M. Tutorial para uso do software de análise textual Iramuteq. Disponível em: http://www.iramuteq.org/documentation/fichiers/Tutorial\%20IRaMuTeQ\%20em\%20portugu es_17.03.2016.pdf>. Acesso em: 12 jan. 2018.

CAMISÓN, C.; FORÉS, B. Knowledge absorptive capacity: new insights for its conceptualization and measurement. Journal of Business Research, v. 63, n. 7, p. 707-715, 2010.

CATALINA, D.; MARIN, B. Orchestrating innovation ecosystems: a case study of a telco wholesaler growing into a global hub for cross-innovation. 2012. Tese KTH, Skolan för Industriell Teknik och Management (ITM), Industriell Ekonomi och Organisation (Inst.), Industriell Ekonomi och Organisation (Avd.), 2012.

CECCAGNOLI, M. et al. Cocreation of valueina platform ecosystem : the case of enterprise software. MIS Quarterly: Management Information Systems, v. 36, n. 1, p. 263-290, 2012.

COHEN, W. M.; LEVINTHAL, D. A. Absorptive capacity: a new perspective on learning and innovation. Administrative Science Quarterly, v. 35, n. 1, p. 128, 1990.

COOPER, D. R.; SCHINDLER, P. S. Métodos de pesquisa em administração. 7. ed. Porto Alegre: Bookman, 2003.

CORAL, E; CAMPAGNOLO, J. M.; CARIONI, L. Estratégias de inovação como vetor de desenvolvimento do Brasil: políticas públicas para parques tecnológicos e incubadoras de empresas. Curitiba: CRV, 2016.

DAGNINO, G. B. et al. Interorganizational network and innovation: a bibliometric study and proposed research agenda. Journal of Business \& Industrial Marketing, v. 30, n. 3-4, SI, p. 354-377, 2015.

DATT, F.; MEIRELLES, G. Empresas investem em inovação, com perspectiva de sair da crise. Valor Econômico. 2017.2 Disponível em:<http://www.valor.com.br/empresas/5025334/empresas-investem-em-inovacao-comperspectiva-de-sair-da-crise>. Acesso em: 16 ago. 2017.

DAVIS, J. P. The group dynamics of interorganizational relationships: collaborating with multiple partners in innovation ecosystems. Administrative Science Quarterly, v. 61, n. 4, p. 621-661, 2016.

DOBELIN, S. Os efeitos da adoção de práticas de inovação gerencial sobre a flexibilidade organizacional. 2016. Tese (Doutorado em Administração de Organizações) - Faculdade de Economia, Administração e Contabilidade de Ribeirão Preto, Universidade de São Paulo, Ribeirão Preto, 2016. doi:10.11606/T.96.2016.tde-11072016-144421. Acesso em: 22 abr. 2018.

DOOLEY, L.; KENNY, B.; CRONIN, M. Interorganizational innovation across geographic and cognitive boundaries: does firm size matter? R \& D Management, v. 46, n. 1, SI, p. 227 $243,2015$. 
EASTERBY-SMITH, M.; BURGOYNE, J.; ARAUJO, L. Aprendizagem organizacional e organização de aprendizagem: desenvolvimento na teoria e na prática. São Paulo: Atlas, 2001.

EISENMANN, T. R.; PARKER, G.; VAN ALSTYNE, M. Opening platforms: how, when and why? Platforms, Markets and Innovation, p. 131-162, 2009.

FERNANDES, B. H. R. Competências e desempenho organizacional: o que há além do balanced scorecard. São Paulo: Saraiva, 2006.

FIELD, A. Descobrindo a estatística usando o SPSS [recurso eletrônico]. 2. ed. Porto Alegre: Artmed, 2009.

FLATTEN, T. C. et al. A measure of absorptive capacity: scale development and validation. European Management Journal, v. 29, n. 2, p. 98-116, 2011.

FLATTEN, T. C.; GREVE, G. I.; BRETTEL, M. Absorptive capacity and firm performance in SMEs: the mediating influence of strategic alliances. European Management Review, v. 8, n. 3, p. 137-152, 2011.

FLICK, U. Desenho da pesquisa qualititiva. Porto Alegre: Artmed, 2009.

FLICK, U. Introdução à metodologia de pesquisa: um guia para iniciantes. Porto Alegre: Penso, 2013.

FREEMAN, C. Networks of innovators: a synthesis of research issues. Research Policy, v. 20, n. 5, p. 499-514, 1991.

FREEMAN, C. The national system of innovation in historical perspective. Cambridge Journal of Economics, v. 19, p. 5-24, 1995.

GEREFFI, G.; HUMPHREY, J.; STURGEON, T. The governance of global value chains. Review of International Political Economy, v. 12, n. 1, p. 78-104, 2005.

GHOSHAL, S.; TANURE, B. Estratégias e gestão empresarial: construindo empresas brasileiras de sucesso: estudos de casos. Rio de Janeiro: Elsevier, 2004.

GOOGLE. Sobre. Disponível em: <https://www.google.com.br/intl/ptBR_br/about/?utm_source=google.com\&utm_medium=referral\&utm_campaign=hpfooter\&fg=1>. Acesso em: 25 nov. 2017.

HAIR Jr., J. F. et al. Fundamentos e métodos de pesquisa em administração. Porto Alegre: Bookman, 2005.

HINDLE, T. Tudo sobre administração. São Paulo: Nobel, 2002.

INGIZZA, C. Contratos entre grandes empresas e startups crescem 194\% no Brasil. O Estado de S. Paulo. 2017. Disponível em: < http://link.estadao.com.br/noticias/inovacao,contratosentre-grandes-empresas-e-startups-crescem-194-em-2017,70002018249>. Acesso em: 18 nov. 2017. 
INSTITUTO NACIONAL DA PROPRIEDADE INDUSTRIAL (INPI). Perguntas frequentes - Patente. Disponível em: <http://www.inpi.gov.br/servicos/perguntas-frequentes-paginasinternas/perguntas-frequentes-patente\#tipos>. Acesso em: 19 mar. 2018.

IRITANI, D. R. et al. Análise sobre os conceitos e práticas de gestão por processos: revisão sistemática e bibliometria. Gestão \& Produção, v. 22, n. 1, p. 164-180, 2015.

ITAÚ. Sobre o Itaú. Disponível em: < https://www.itau.com.br/sobre/>. Acesso em: 25 nov. 2017.

JACK, E. P.; RATURI, A. S. Lessons learned from methodological triangulation in management research. Management Research News, v. 29, n. 6, p. 345-357, 2006.

JANG, H.; LEE, K.; YOON, B. Development of an open innovation model for R\&D collaboration between large firms and small-medium enterprises (SMEs) in manufacturing industries. International Journal of Innovation Management, v. 21, n. 1, p. 29, 2017.

JIMÉNEZ-BARRIONUEVO, M. M.; GARCÍA-MORALES, V. J.; MOLINA, L. M. Validation of an instrument to measure absorptive capacity. Technovation, v. 31, n. 5-6, p. 190-202, 2011.

KAPLAN, R. S.; NORTON, D. The balanced scorecard: measures that drive performance. Harvard Business Review, v. 70, n. 1, p. 71-79, 1992.

KNAPIK, J. Gestão de pessoas e talentos. 2. ed. Curitiba: Ibpex, 2008.

KOHLBORN, T. et al. Interview with Michael Rosemann on ambidextrous business process management. Business Process Management Journal, v. 20, n. 4, p. 634-638, 2014.

KOHLER, T. Corporate accelerators: building bridges between corporations and startups. Business Horizons, v. 59, n. 3, p. 347-357, 2016.

LAKATOS, E. M.; MARCONI, M. A. Fundamentos de metodologia científica. 6. ed. São Paulo: Atlas, 2007.

LANE, P. J.; KOKA, B. R.; PATHAK, S. The reification of absorptive capacity: a critical review and rejuvenation of the construct. Academy of Management Review, v. 31, n. 4, p. 833-863, 2006.

LAWTON SMITH, H.; DICKSON, K.; SMITH, S. L. "There are two sides to every story": innovation and collaboration within networks of large and small firms. Research Policy, v. 20, p. 457-468, 1991.

LEWIN, A. Y.; MASSINI, S.; PEETERS, C. Microfoundations of internal and external absorptive capacity routines. Organization Science, v. 22, n. 1, p. 81-98, 2011.

MEIRELleS, D. S.; CAMARGO, Á. A. B. Capacidades dinâmicas: o que são e como identificá-las? Revista de Administração Contemporânea, v. 18, n. spe, p. 41-64, 2014. 
NAMBISAN, S.; BARON, R. A. Entrepreneurship in innovation ecosystems: entrepreneurs' self-regulatory processes and their implications for new venture success. Entrepreneurship: Theory and Practice, v. 37, n. 5, p. 1071-1097, 2013.

NAMBISAN, S.; SAWHNEY, M. Orchestration processes in network-centric innovation: evidence from the field. Academy of Management Perspectives, v. 25, p. 40-57, 2011.

NEVES, M. F.; CONEJERO, M. A. Uma contribuição empírica para geração de métodos de planejamento e gestão. Revista de Administração, v. 47, n. 4, p. 699-714, 2012.

NVIVO. What is NVivo? Disponível em: < http://www.qsrinternational.com/nvivo/what-isnvivo>. Acesso em: 14 jan. 2018.

OBJECT MANAGEMENT GROUP (OMG). BPMN 2.0 examples non-normative document. Disponível em: < http://www.omg.org/cgi-bin/doc?dtc/10-06-02>. Acesso em: 3 nov. 2016.

ORGANISATION FOR ECONOMIC CO-OPERATION AND DEVELOPMENT (OECD). Manual de Oslo: diretrizes para coleta e interpretação de dados sobre inovação. OECD, 2005.

PAUWELS, C. et al. Understanding a new generation incubation model: the accelerator. Technovation, v. 50-51, p. 13-24, 2016.

PAVLOU, P. A.; EL SAWY, O. A. From IT leveraging competence to competitive advantage in turbulent environments: the case of new product development. Information Systems Research, v. 17, n. 3, p. 198-227, 2006.

PEREIRA, J. C. R. Análise de dados qualitativos: estratégias metodológicas para as ciências da saúde, humanas e sociais. 3. ed. São Paulo: Editora da Universidade de São Paulo, 2001.

PICOLI, F. R.; TAKAHASHI, A. Capacidade de absorção, aprendizagem organizacional e mecanismos de integração social. RAC - Revista de Administração Contemporânea - Anpad, v. 20, n. 1, p. 1-20, 2016.

PORTO, G. (Org.). Gestão da inovação e empreendedorismo. Rio de Janeiro: Elsevier, 2013.

PORTO SEGURO. Conheça a Porto Seguro. Disponível em: $<$ https://www.portoseguro.com.br/a-porto-seguro/conheca-a-porto-seguro/sobre-a-portoseguro>. Acesso em: 25 nov. 2017.

RICHARDSON, R. J. Pesquisa social: métodos e técnicas. 3. ed. São Paulo: Atlas, 2011.

ROCHA, D. Ninhos de startups. Exame, São Paulo, ano 50, n. 4, p. 32-37, 2 mar. 2016.

ROESER, T.; KERN, E. M. Surveys in business process management: a literature review. Business Process Management Journal, Emerald Group Publishing Limited, 28 maio 2015. Disponível em: <http://dx.doi.org/10.1108/BPMJ-07-2014-0065>. Acesso em: 30 out. 2016. 
ROSEMANN, M. Proposals for future BPM research directions. Lecture notes in business information processing, v. 181, LNBIP, p. 1-15, 2014.

SCHERER, A. Grandes empresas querem se parecer mais com startups. Exame. 2017. Disponível em: < https://exame.abril.com.br/revista-exame/grandes-empresas-querem-separecer-mais-com-startups/>. Acesso em: 18 nov. 2017.

SCHUMPETER, J. A. Capitalismo, socialismo e democracia. Rio de Janeiro: Fundo de Cultura, 1961.

SILVA, A. H.; FOSSÁ, M. I. T. Análise de conteúdo: exemplo de aplicação da técnica para análise de dados qualitativos. Qualitas Revista Eletrônica, v. 16, n. 1, p. 1-14, 2015.

SRIVARDHANA, T.; PAWLOWSKI, S. D. ERP systems as an enabler of sustained business process innovation: a knowledge-based view. Journal of Strategic Information Systems, v. 16, n. 1, p. 51-69, 2007.

TEECE, D. J. Explicating dynamic capabilities: the nature and microfoundations of (sustainable) enterprise performance. Strategic Management Journal, v. 28, n. 13, p. 1319$1350,2007$.

TEECE, D. J. Dynamic capabilities: routines versus entrepreneurial action. Journal of Management Studies, v. 49, n. 8, p. 1395-1401, 2012.

TEECE, D. J.; PISANO, G.; SHUEN, A. Dynamic capabilities and strategic management. Strategic Management Journal, v. 18, n. 7, p. 509-533, 1997.

TELEFÔNICA. Quem somos. Disponível em: $<$ http://www.telefonica.com.br/servlet/Satellite?c=Page\&cid=1386094888844\&pagename=In stitucionalVivo\%2FPage\%2FTemplateTextoDocumento>. Acesso em: 25 nov. 2017.

TIDD, J.; BESSANT, J.; PAVITT, K. Gestão da inovação. 3. ed. Porto Alegre: Bookman, 2008.

VALLE, R.; OLIVEIRA, S. B. (Orgs.). Análise e modelagem de processos de negócio: foco na notação BPMN (Business Process Modeling Notation). São Paulo: Atlas, 2016.

VAN LANCKER, J. et al. The organizational innovation system: a systemic framework for radical innovation at the organizational level. Technovation, v. 52-53, p. 40-50, 2016.

WANG, C. L.; AHMED, P. K. Dynamic capabilities: a review and research agenda. International Journal of Management Reviews, v. 9, n. 1, p. 31-51, 2007.

WEIBLEN, T.; CHESBROUGH, H. W. Engaging with startups to enhance corporate innovation. California Management Review, v. 57, n. 2, p. 66-90, 2015.

WEST, J.; BOGERS, M. Leveraging external sources of innovation: a review of research on open innovation. Journal of Product Innovation Management, v. 31, n. 4, p. 814-831, 2014. 
WINTER, S. G. Understanding dynamic capabilities. Strategic Management Journal, v. 24, n. 10, SPEC. ISS., p. 991-995, 2003.

YIN, R. K. Estudo de caso: planejamento e métodos. 5. ed. Porto Alegre: Bookman, 2015.

ZAHRA, S. A.; GEORGE, G. Absorptive capacity: a review, reconceptualization, and extension. Academy of Management Review, v. 27, n. 2, p. 185-203, 2002.

ZHOU, K. Z.; WU, F. Technological capability, strategic flexibility, and product innovation. Strategic Management Journal, v. 31, n. 5, p. 547-561, 2010. 


\section{APÊNDICE A - PROTOCOLO PARA O ESTUDO DE CASO}

\section{A) VISÃO GERAL DO ESTUDO DE CASO}

1. O presente protocolo apresenta os procedimentos e regras gerais a serem seguidas no estudo de caso proposto;

2. O caso a ser estudado neste projeto são os relacionamentos interorganizacionais entre grandes empresas e startups, com foco nos processos de negócio relacionados ao desenvolvimento da capacidade de absorção para obtenção de vantagem competitiva nas startups;

3. Dentro da problemática de investigação dos processos de negócio que compõem efetivamente a capacidade de absorção, surge a pergunta motivadora deste estudo: nos relacionamentos interorganizacionais entre grandes empresas e startups, como os processos de negócio são utilizados pelas startups para desenvolvimento da capacidade de absorção, com o objetivo de criar vantagem competitiva?

4. De forma a responder à pergunta problema proposta, este estudo tem como objetivo principal analisar como os processos de negócio são utilizados pelas startups, no âmbito dos relacionamentos interorganizacionais junto às grandes empresas, para desenvolvimento da capacidade de absorção e obtenção de vantagem competitiva;

5. Para atingir esse objetivo, os seguintes objetivos específicos foram estabelecidos: a) mapear a rede de colaboração constituída pelos relacionamentos interorganizacionais entre as startups e grandes empresas; b) descrever como os processos de negócio são utilizados pelas startups para adquirir, assimilar, transformar e utilizar os conhecimentos adquiridos da grande empresa; c) analisar os processos de negócio que constituem a capacidade de absorção das startups, bem como sua implementação e realização, a fim de promover vantagens competitivas;

6. Este estudo segue a reconceituação teórica de capacidade de absorção oferecida por Zahra e George (2002), que definem o constructo como um conjunto de rotinas organizacionais e processos pelos quais as empresas adquirem, assimilam, transformam e utilizam os conhecimentos externos para produzir uma capacidade organizacional dinâmica, influenciando os resultados empresariais;

7. O conjunto de rotinas organizacionais e processos pelos quais as empresas adquirem, assimilam, transformam e utilizam os conhecimentos externos serão analisados na perspectiva de processos de negócio, conceituado como um conjunto definido de atividades 
de negócios que representam as etapas necessárias para atingir um objetivo de negócios, incluindo o fluxo e o uso de informações e recursos (ABPMP, 2013; VALLE; OLIVEIRA, 2016; OMG, 2016);

8. Para identificar o conjunto de rotinas organizacionais e processos relacionados à capacidade de absorção das unidades de análise, será utilizado o questionário de pesquisa adaptado da escala de Pavlou e El Sawy (2006), para orientar o pesquisador no desenvolvimento das questões de protocolo, indicando as informações que necessitam ser coletadas nas entrevistas semiestruturadas (vide seção C).

\section{B) PROCEDIMENTOS DE COLETA DE DADOS}

1. As unidades de análise serão definidas como startups que mantém algum tipo de relacionamento interorganizacional para inovação com grandes empresas;

2. Será realizado um levantamento exploratório via internet de startups inseridas em programas corporativos de aceleração promovidos por grandes empresas, com o objetivo de mapear a rede de colaboração constituída pelos relacionamentos interorganizacionais entre as startups e grandes empresas que investem nesse modelo;

3. Após o levantamento inicial, será utilizada uma pesquisa de levantamento (survey) utilizando um questionário online, que será enviado por e-mail às startups relacionadas. Nessa fase, a pesquisa survey será utilizada para direcionar o mapeamento em busca de startups que indiquem um grau razoável de capacidade de absorção. Os dados quantitativos serão tratados estatisticamente, fornecendo ao pesquisador informaçõe relevantes para a seleção de startups que serão entrevistadas;

4. Serão realizadas entrevistas semiestruturadas com os gestores das startups, na fase da pesquisa de campo. As entrevistas serão gravadas de modo a permitir uma análise aprofundada;

5. A observação direta não-participante irá ocorrer com o pesquisador fisicamente presente na sede da startup e em contato direto com o gestor da organização, permitindo o monitoramento e registro de reuniões e conversas, atividades de trabalho e rede de contados dos gestores e empreendedores envolvidos, com anotações em um diário de campo;

6. A análise de documentos consiste ao acesso e observação de diferentes tipos de documentos administrativos pertencentes a startup, como atas de reuniões, contratos, estudos formais, notícias e artigos disponíveis em mídias e relatórios escritos de eventos, sites corporativos, artigos de notícias e panfletos do negócio, como exemplos; 
7. Os dados coletados na pesquisa survey irão apoiar a avaliação dos resultados, reforçando a triangulação das fontes de evidências pela combinação entre métodos qualitativos e quantitativos;

8. A Figura 1 esquematiza a sequência de procedimentos para a coleta de dados.

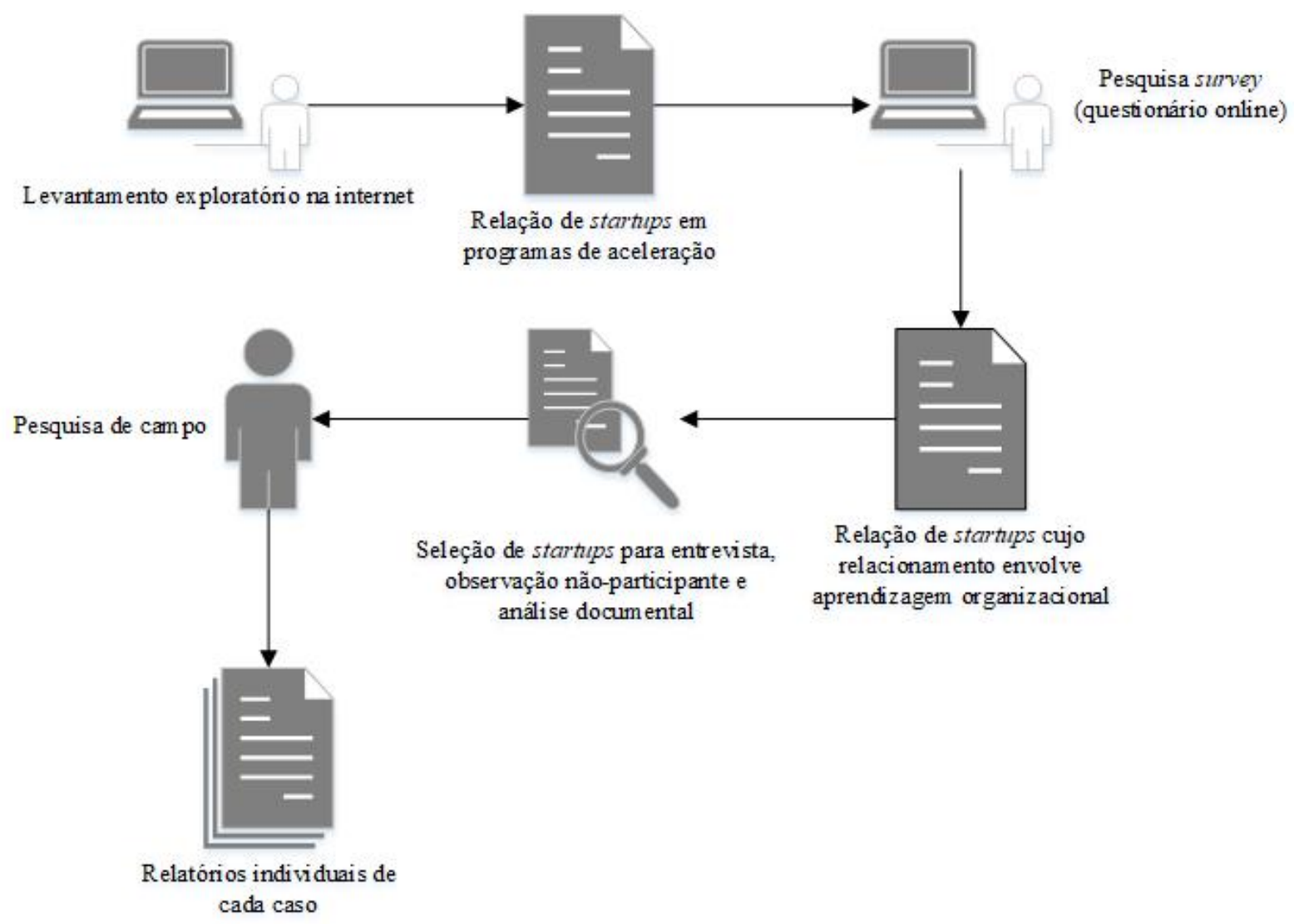

FIGURA 1 - Procedimentos de coleta de dados. Fonte: Elaborado pelo autor.

\section{C) QUESTÕES E PROCEDIMENTOS PARA A ENTREVISTA}

1. O conjunto de questões de protocolo, demonstradas nesta seção, refletem a verdadeira linha de investigação da pesquisa. As questões foram elaboradas para dirigir o pesquisador e deverão ser feitas sobre os casos individuais, com o objetivo de conduzir às informações que necessitam ser coletadas das organizações, formando a estrutura da investigação (YIN, 2015);

2. Observar uma organização a partir de seus processos significa focar mais nas ações, ou seja, nas atividades de trabalho do que em sua estrutura propriamente dita (funções, departamentos, etc.). Os gestores e empreendedores entrevistados devem ser vistos como aqueles que agem em um processo (VALLE; OLIVEIRA, 2016); 
3. O pesquisador deve manter o foco da entrevista nas ações relacionadas às parcerias realizadas entre o grupo classificado como grandes empresas e startups, dentro do ambiente onde se relacionam, ou seja, as aceleradoras de empresas;

4. As questões foram adaptadas para conduzir o pesquisador a descobrir quais são os processos de negócio, formalizados ou não, utilizados para operacionalizar a capacidade de absorção dentro das organizações;

5. As questões da coleta de dados, apresentadas no Quadro 1, abordam as quatro dimensões da capacidade de absorção em uma visão voltada para processos de negócio, constituindo o roteiro da entrevista semiestruturada. As questões foram baseadas nos itens de medição para o constructo capacidade de absorção proposto por Pavlou e El Sawy (2006);

\section{ROTEIRO PARA ENTREVISTA}

1. Identificação e breve histórico da startup;

2. Como surgiu a parceria/relacionamento com a grande empresa?

3. Como é a relação da startup com a grande empresa?

4. Há reuniões periódicas? Como são registradas? Há um histórico das novas ideias que surgem nesses encontros?

5. Há algum produto/serviço sendo desenvolvido especificamente em relação à parceria/relacionamento?

6. Os processos da startup foram de alguma forma alterados após essa parceria/relacionamento?

7. Há contribuição da grande empresa na qualificação do pessoal da startup?

QUADRO 1 - Questões da coleta de dados primários. Fonte: Elaborado pelo autor.

6. Ao conduzir a entrevista, o pesquisador deve preocupar-se com a documentação e registro das informações que está coletando, tendo como objetivo descrever os processos quando identificados. O Quadro 2 apresenta um guia de descrição de escopo dos processos.

\section{DESCRIÇÃO GERAL DO PROCESSO}

Nome do processo, subprocesso, responsável, objetivo e condição de início;

Fornecedores, entradas, saídas e clientes;

Atividades e tarefas (etapas: começo, meio e fim).

QUADRO 2 - Guia de descrição de escopo dos processos. Fonte: Valle e Oliveira (2016, p. 32).

\section{D) GUIA PARA O RELATÓRIO DOS CASOS}

1. O público-alvo do relatório final deste estudo de caso será a comissão julgadora da sessão de defesa final de mestrado, apresentado na forma de dissertação junto ao Programa de PósGraduação em Administração de Organizações da Faculdade de Economia, Administração e Contabilidade de Ribeirão Preto - FEA-RP/USP;

2. A estrutura composicional do relatório final deste estudo de caso classifica-se como 
analítica linear, pois seguirá uma sequência de capítulos, seções e subtópicos iniciando com o problema sendo estudado e uma revisão de literatura. Os subtópicos que seguirão o relatório irão cobrir os métodos utilizados, os dados coletados, a análise de dados e as descobertas, sendo finalizado com as conclusões e suas implicações para o problema original estudado (YIN, 2015);

3. Sendo este trabalho um estudo de casos múltiplos, o relatório final será composto da análise descritiva entre os casos, onde cada capítulo ou seção será destinado a um aspecto distinto entre os casos. O referido relatório irá sintetizar as lições aprendidas e descobertas de todos os casos e será organizado em torno dos tópicos capacidade de absorção potencial e realizada, enquanto a informação dos casos individuais ficará dispersa ao longo de cada capítulo ou seção (YIN, 2015);

4. Cada estudo de caso individual consiste em um estudo completo, no qual o pesquisador deve redigir relatórios individuais resumidos, buscando a indicação de como e por que uma determinada proposição foi demonstrada ou não, além da indicação da extensão da lógica da replicação (YIN, 2015);

5. Para a redação dos relatórios individuais, a análise de conteúdo será utilizada para análise e interpretação dos dados coletados nas entrevistas semiestruturadas, auxiliando na categorização e busca de significados para a construção de cadeias lógicas de evidências (BARDIN, 2016), seguindo em direção a resultados generalizáveis e lições aprendidas, ou seja, generalizações analíticas (YIN, 2015);

6. A análise estatística será utilizada como uma técnica complementar, para produzir descrições quantitativas dos dados coletados na pesquisa survey;

7. Para assegurar a validade de constructo, as minutas dos relatórios individuais serão revisadas pelos participantes e informantes do caso, ou seja, os sujeitos do estudo (YIN, 2015).

E) REFERÊNCIAS

ASSOCIATION OF BUSINESS PROCESS MANAGEMENT PROFESSIONALS (ABPMP). Guia para o gerenciamento de processos de negócio: corpo comum de conhecimento (ABPMP BPM CBOK V3.0). São Paulo, 2013.

BARDIN, L. Análise de conteúdo. São Paulo: Edições 70, 2016.

OBJECT MANAGEMENT GROUP (OMG). BPMN Quick Guide. Disponível em: <http://www.bpmnquickguide.com/view-bpmn-quick-guide/>. Acesso em: 26 jan. 2016. 
PAVLOU, P. A.; EL SAWY, O. A. From IT leveraging competence to competitive advantage in turbulent environments: the case of new product development. Information Systems Research, v. 17, n. 3, p. 198-227, 2006.

VALLE, R.; OLIVEIRA, S. B. (Orgs.). Análise e modelagem de processos de negócio: foco na notação BPMN (Business Process Modeling Notation). São Paulo: Atlas, 2016.

YIN, R. K. Estudo de caso: planejamento e métodos. 5. ed. Porto Alegre: Bookman, 2015.

ZAHRA, S. A.; GEORGE, G. Absorptive capacity: a review, reconceptualization, and extension. Academy of Management Review, v. 27, n. 2, p. 185-203, 2002. 
APÊNDICE B - QUESTIONÁRIO ONLINE UTILIZADO NA PESQUISA SURVEY

\title{
RELACIONAMENTOS INTERORGANIZACIONAIS ENTRE GRANDES EMPRESAS E STARTUPS
}

\$ app.fearp.usp.br/questionarios/index.php/admin/printablesurvey/sa/index/surveyid/688249

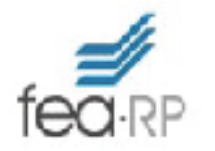

\author{
Faculdade de Economia, Administração \\ e Contabilidade de Ribeirão Preto \\ Universidade de São Paulo
}

\begin{abstract}
O presente questionário integra uma pesquisa acadêmica na área de Administraçăo, desenvolvida na Faculdade de Economia, Administraçăo e Contabilidade de Ribeirăo Preto da Universidade de Săo Paulo (FEARP/USP). O público alvo do estudo são as startups que mantém algum tipo de parceria ou relacionamento com grandes empresas. O objetivo dessa etapa da pesquisa é mapear a rede de colaboraçăo constituida pelos relacionamentos interorganizacionals entre as startups e grandes empresas.
\end{abstract}

O questionário é bem simples e o tempo estimado para a realizaçăo é de 5 minutos. Todas as informaçбes e dados obtidos nesta pesquisa serăo tratados como confidenclais, assim como todos os seus resultados. O nome das empresas envolvidas somente poderăo ser dlvulgados, na eventualidade do trabalho vir a ser publicado, mediante autorizaçăo por escrito das mesmas.

Desde já, agradecemos a sua participaçăo e contribuiçăo.

Pesquisador: Alexandre Rodrigues Cajuela (alexandrecajuela@usp.br)

Orientadora: Prof." Dr." Simone Vasconcelos Ribeiro Galina (svgalina@usp.br)

\section{IDENTIFICAÇÃo}

1 []Nome da startup. *

Por favor, coloque sua resposta aqui:

2 []Setor de atuação da startup. *

Favor escolher apenas uma das opфoles a seguir:

3 []Mês e ano de fundaçăo da startup (o dia pode ser aproximado).*

Favor informar uma data:

4 []Em qual estado se localiza a sede da startup? *

Favor escolher apenas uma das opழobes a seguir:

5 []Número de funcionários da startup, incluindo o(s) fundador(es). *

Apenas números podem ser usados nesse campo. 
Por favor, coloque sua resposta aqui:

\section{6 [E-mail para contato. *}

Por favor, coloque sua resposta aqui:

\section{RELACIONAMENTOS INTERORGANIZACIONAIS}

7 [A startup mantém parceria ou relacionamento com alguma grande empresa? Considere a situação atual ou relacionamentos e parcerias já realizadas. *

Favor escolher apenas uma das opçø̋es a seguir:

- $\mathrm{Sim}$

- Q não

Se houver mais de uma grande empresa envolvida em parcerias ou relacionamentos junto à startup, considere a grande empresa que mais contribuiu com o aprendizado e desenvolvimento da startup.

\section{8 [Qual o nome da grande empresa?*}

Só responder essa pergunta sob as seguintes condiçő́es:

A resposta foi 'Sim' na questăo '7 [RI7]' (A startup mantém parceria ou relacionamento com alguma grande empresa? Considere a situaçăo atual ou relacionamentos e parcerias já realizadas.)

Por favor, coloque sua resposta aqui:

\section{9 [Setor de atuação da grande empresa.*}

Só responder essa pergunta sob as seguintes condiçőes:

A resposta foi 'Sim' na questăo '7 [RI7]' (A startup mantém parceria ou relacionamento com alguma grande empresa? Considere a situaçăo atual ou relacionamentos e parcerias já realizadas.)

Favor escolher apenas uma das opçбes a seguir:

10 [

A parceria ou relacionamento com a grande empresa envolve:

1 = Nunca, 2 = Raramente, 3 = Às vezes, 4 = Frequentemente e 5 = Sempre*

Só responder essa pergunta sob as seguintes condiçø̋es:

A resposta foi 'Sim' na questăo '7 [RI7]' (A startup mantém parceria ou relacionamento com alguma grande empresa? Considere a situaçăo atual ou relacionamentos e parcerias já realizadas.)

Por favor, escolha a resposta adequada para cada item: 


\begin{tabular}{|c|c|c|c|c|}
\hline & 1 & 3 & 4 & 5 \\
\hline Realizaçăo de reuniōes periódicas com a grande empresa & 0 & 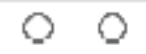 & $Q$ & o \\
\hline $\begin{array}{l}\text { Aplicaçăo dos novos conhecimentos adquiridos da grande empresa ao } \\
\text { trabalho prático da startup }\end{array}$ & $\mathrm{O}$ & $\mathrm{O} O$ & $Q$ & 0 \\
\hline $\begin{array}{c}\text { Utilização das informaçōes e conhecimentos obtidos da grande empresa no } \\
\text { desenvolvimento de novos produtos e serviços ou na melhoria do } \\
\text { desempenho da startup }\end{array}$ & 0 & 00 & $Q$ & 0 \\
\hline $\begin{array}{l}\text { Somente questőes comerciais, como exemplo, vendas potenciais para o } \\
\text { parceiro ou acesso aos mercados já estabelecidos }\end{array}$ & 0 & 00 & 0 & $\diamond$ \\
\hline
\end{tabular}

\section{1 [}

Na visăo da startup, quais seriam as desvantagens potenciais de se manter uma parceria ou relacionamento com uma grande empresa?

\section{1 = Discordo totalmente da afirmaçăo e $5=$ Concordo totalmente com a afirmação*}

Só responder essa pergunta sob as seguintes condiçő́es:

A resposta foi 'Não' na questão '7 [RI7]' (A startup mantém parceria ou relacionamento com alguma grande empresa? Considere a situaçăo atual ou relacionamentos e parcerias já realizadas.)

Por favor, escolha a resposta adequada para cada item:

\begin{tabular}{|c|c|c|c|c|c|}
\hline & 1 & 2 & 3 & 4 & 5 \\
\hline Perda de informaçōes relacionadas a propriedade intelectual* & 0 & $\mathrm{O}$ & 0 & $\mathrm{O}$ & 0 \\
\hline Complexidade de gestăo & 0 & $\mathrm{Q}$ & $\mathrm{O}$ & $Q$ & o \\
\hline $\begin{array}{c}\text { Riscos financeiros e organizacionais, pelo comportamento oportunista do } \\
\text { parceiro }\end{array}$ & $Q$ & $Q$ & $Q$ & $Q$ & 0 \\
\hline Risco de tornar-se dependente de um parceiro & 0 & $Q$ & $\mathrm{O}$ & $Q$ & o \\
\hline Perda parcial da autonomia de decisăo & 0 & $\mathrm{O}$ & 0 & 0 & 0 \\
\hline $\begin{array}{l}\text { A cultura organizacional** do parceiro pode entrar em conflito com a cultura } \\
\text { da startup }\end{array}$ & 0 & 0 & 0 & 0 & $\circ$ \\
\hline Perda de flexibilidade organizacional*** & 0 & $\mathrm{O}$ & 0 & 0 & 0 \\
\hline Implicaçőes antitruste & 0 & 0 & 0 & $\mathrm{O}$ & O \\
\hline
\end{tabular}

*Segundo definiçăo da Organizaçăo Mundial de Propriedade Intelectual (OMPI), a propriedade intelectual refere-se às criaçס̋es da mente: invençס̋es, obras literárias e artisticas, e símbolos, nomes, imagens, desenhos e modelos utilizados no comércio. A propriedade intelectual abrange duas grandes áreas: Propriedade Industrial (patentes, marcas, desenho industrial, indicaçőes geográficas e proteçăo de cultivares) e Direito Autoral (obras literárias e artísticas, programas de computador, domínios na Internet e cultura imaterial).

**A cultura organizacional pode ser entendida como um conjunto de valores, normas e princípios năo escritos, que estabelecem o tom e o estilo de comportamento das pessoas que na empresa trabalham. Valores 
representam a importåncia que as organizaçб̋es dăo a determinadas coisas, como por exemplo, certos comportamentos ou posicionamentos: ética, trabalho em equipe, justiça, transparência, inovaçăo, etc.

***Flexibilidade organizacional está relacionada à capacidade da empresa de implementar ou de se adaptar a mudanças que ocorrem em ambientes complexos e muito competitivos.

****A finalidade da legislaçăo antitruste é a defesa da concorrência e a estimulaçăo de ambientes onde sejam garantidos uma competiçăo justa, livre de vícios, preservando a iniciativa privada $\mathbf{e}$ a eficiência dos meios de produçăo.

12 [

Na visăo da startup, quais seriam as desvantagens potenciais de se manter uma parceria ou relacionamento com uma grande empresa?

\section{1 = Discordo totalmente da afirmaçăo e 5 = Concordo totalmente com a afirmação*}

Só responder essa pergunta sob as seguintes condiçő́es:

A resposta foi 'Sim' na questăo '7 [RI7]' (A startup mantém parceria ou relacionamento com alguma grande empresa? Considere a situaçăo atual ou relacionamentos e parcerias já realizadas.)

Por favor, escolha a resposta adequada para cada item:

$\begin{array}{lllll}1 & 2 & 3 & 4 & 5\end{array}$

\begin{tabular}{|c|c|c|c|c|}
\hline Perda de informaçōes relacionadas a propriedade intelectual* & $0 Q$ & $\mathrm{O}$ & $Q$ & o \\
\hline Complexidade de gestăo & 00 & 0 & 0 & 0 \\
\hline $\begin{array}{c}\text { Riscos financeiros e organizacionais, pelo comportamento oportunista do } \\
\text { parceiro }\end{array}$ & 00 & 0 & 0 & 0 \\
\hline Risco de tornar-se dependente de um parceiro & 0 & 0 & 0 & 0 \\
\hline Perda parcial da autonomia de decisăo & 00 & 0 & 0 & $\circ$ \\
\hline $\begin{array}{l}\text { A cultura organizacional** do parceiro pode entrar em conflito com a cultura } \\
\text { da startup }\end{array}$ & 00 & 0 & 0 & 0 \\
\hline Perda de flexibilidade organizacional ${ }^{* * *}$ & 00 & 0 & 0 & $\odot$ \\
\hline Implicaçőes antitruste & 00 & 0 & $\mathrm{O}$ & 0 \\
\hline
\end{tabular}

*Segundo definiçăo da Organizaçăo Mundial de Propriedade Intelectual (OMPI), a propriedade intelectual refere-se às criaçס̋es da mente: invençס̋es, obras literárias e artísticas, e símbolos, nomes, imagens, desenhos e modelos utilizados no comércio. A propriedade intelectual abrange duas grandes áreas: Propriedade Industrial (patentes, marcas, desenho industrial, indicaçőes geográficas e proteçăo de cultivares) e Direito Autoral (obras literárias e artísticas, programas de computador, domínios na Internet e cultura imaterial).

**A cultura organizacional pode ser entendida como um conjunto de valores, normas e princípios năo escritos, que estabelecem o tom e o estilo de comportamento das pessoas que na empresa trabalham. Valores 
representam a importância que as organizaçర్es dẫo a determinadas coisas, como por exemplo, certos comportamentos ou posicionamentos: ética, trabalho em equipe, justiça, transparência, inovaçăo, etc.

**Flexibilidade organizacional está relacionada à capacidade da empresa de implementar ou de se adaptar a mudanças que ocorrem em ambientes complexos e muito competitivos.

****A finalidade da legislaçăo antitruste é a defesa da concorrência e a estimulaçăo de ambientes onde sejam garantidos uma competiçăo justa, livre de vícios, preservando a iniciativa privada $e$ a eficiência dos meios de produçẵo.

Obrigado por sua participaçăo e valiosa contribuiçăo para a pesquisa cientifica! Se tiver alguma dúvida com relaçăo ao questionário ou interesse no estudo, sinta-se à vontade para entrar em contato: alexandrecajuela@usp.br

Esclarecemos que após a conclusăo da pesquisa, tanto a grande empresa quanto a startup poderăo, se desejarem, ter acesso às informaçס̃es sobre a metodologia e os resultados obtidos.

Enviar questionário

Obrigado por ter preenchido o questionário. 